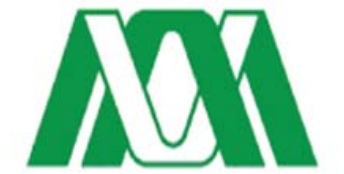

UNIVERSIDAD AUTÓNOMA METROPOLITANA

UNIDAD IZTAPALAPA

Casa abierta al tiempo

\title{
FOTODEGRADACION DE NAPROXENO SODICO \\ Y OXITETRACICLINA EN MEDIO ACUOSO \\ EMPLEANDO COMO FOTOCATALIZADORES \\ ÓXIDOS MIXTOS DERIVADOS DE HIDROXIDOS \\ DOBLES LAMINARES MgAl
}

Tesis que presenta

Gabriela Jácome Acatitla

para obtener el grado de

Doctor en Ciencias (Química)

Asesor: Francisco Tzompantzi Morales

Jurado calificador

Presidente: Dra. Gloria Alicia del Ángel Montes

Secretario: Dr. Miguel Angel García Sánchez

Vocales: Dra. Mayra Angélica Álvarez Lemus

Dra. Elsa Miriam Arce Estrada

Dr. Rubén Arroyo Murillo 
FOTODEGRADACION DE NAPROXENO SODICO Y OXITETRACICLINA EN MEDIO ACUOSO EMPLEANDO COMO FOTOCATALIZADORES OXIDOS MIXTOS DERIVADOS DE

HIDROXIDOS DOBLES LAMINARES MgAl

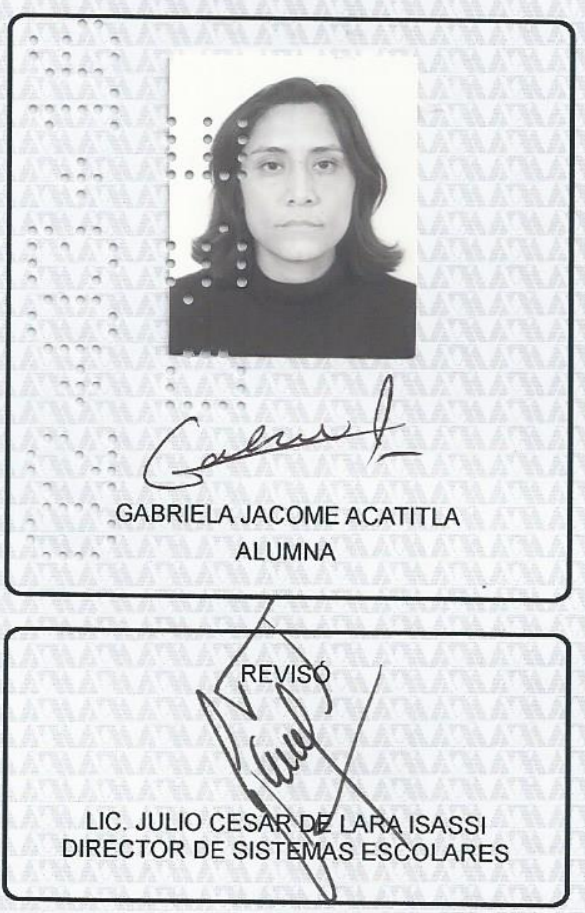

Bajo la Presidencia del primero y con carácter de Secretario el último, se reunieron a la presentación de la Disertación Pública cuya denominación aparece al margen, para la obtención del grado de:

DOCTORA EN CIENCIAS (QUIMICA)

DE: GABRIELA JACOME ACATITLA

y de acuerdo con el artículo 78 fracción IV del Reglamento de Estudios Superiores de la Universidad Autónoma Metropolitana, los miembros del jurado resolvieron:

\section{APROBAR}

Acto continuo, el presidente del jurado comunicó a la interesada el resultado de la evaluación $y$, en caso aprobatorio, le fue tomada la protesta.
DIRECTOR DE LA DIVISIÓN DE CBI

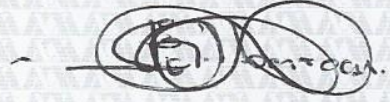

DR. JOSE GILBERTO CORDOBA HERRERA
PRESIDENTE

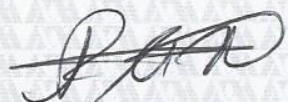

DR. RUBEN ARROYO MURILLO

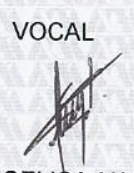

DRA. MAYRA ANGELICA ALVAREZ IEMUS

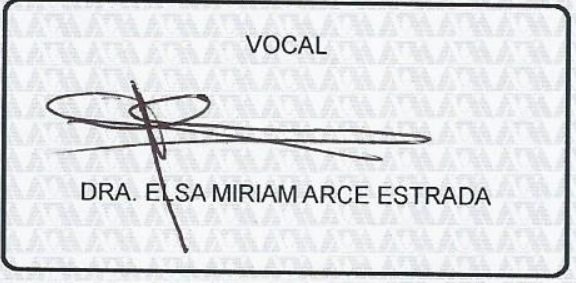

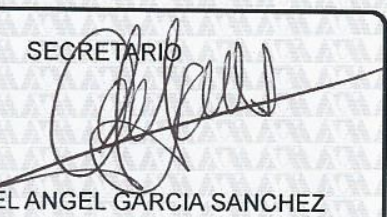




\section{AGRADECIMIENTOS}

A mi mamá Paz $(\dagger)$ y a mi abuela Lupita $(\dagger)$ por enseñarme el valor del trabajo, la humildad y la independencia. Las amo.

A mi padre Vicente y mis hermanos, Isra y Pepe por su cariño, comprensión y palabras de aliento para seguir adelante y cumplir una meta más en mi vida.

A José Arvizu Montaño por su incondicional amistad. Gracias por hacerme una mejor persona.

A Lucky, Lilly, Solovino, Chirguita y Nelly, por todo su amor y hacerme reír en momentos difíciles.

A mis amigos Jacobo Ismael, Juan Manuel, Pilar, Armando, Hugo Apolo, Erika, Jonathan, Francisco, Cinthia, Rodrigo. Amistades que son ciertas nadie las puede turbar (Miguel de Cervantes)

Al Dr. Rosendo López González por su amistad y orientación durante mi estancia en el laboratorio de catálisis.

Al Dr. Francisco Tzompantzi por permitirme desarrollar mis ideas y llevarlas a cabo durante mis estudios de posgrado.

Al Dr. Ricardo Gómez Romero por su apoyo, asesoría y por compartirme su inmenso conocimiento.

A mis compañeros de laboratorio Gaby, Luis Angel, Lupita, Yanet, Octavio, Getsemani, Miroslava, Abraham, Jesús, Jacob, Karla, Saúl, Alejandro, Cenit, Coco, Yazuri, Sandra, Sandra Lucia, Claudia, Sonia y Diana.

A mis sinodales por el tiempo brindado para la revisión de la tesis

Al pueblo mexicano por otórgame una beca para mis estudios de posgrado. 
INDICE GENERAL

RESUMEN

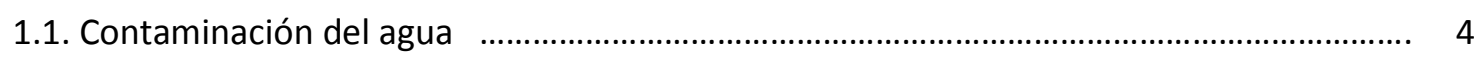

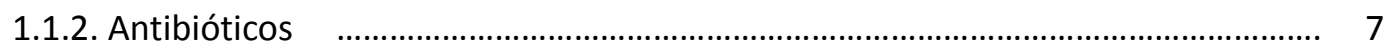

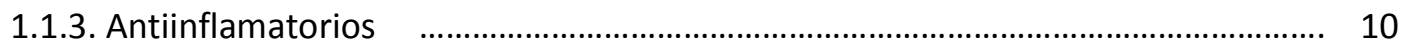

1.1.4. Técnicas de remoción y eliminación de fármacos $\quad$............................................... 12

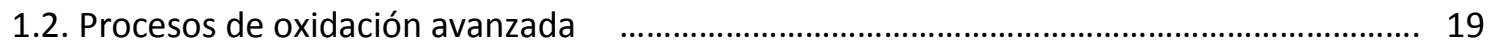

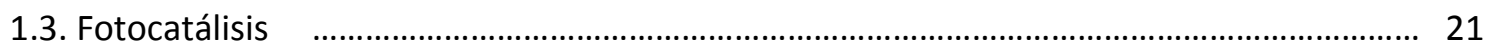

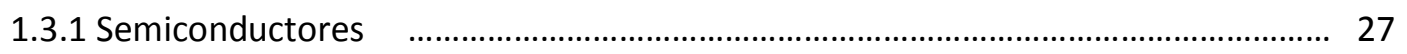

1.3.1.1. Tipos de semiconductores $\quad$....................................................................... 29

1.3.2. Mecanismo del procesos fotocatalítico ........................................................... 30

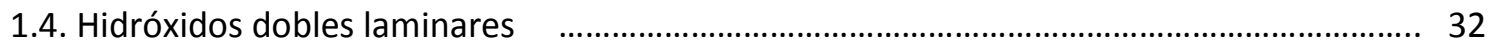

1.4.1. Propiedades estructurales $\quad$............................................................................... 32

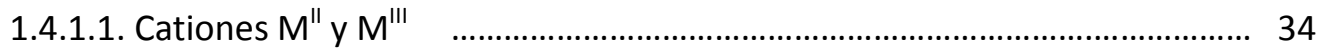

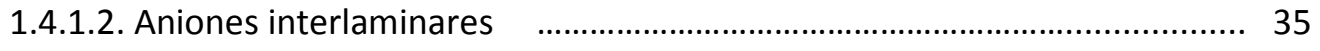

1.4.1.3 Apilamiento $\quad$..................................................................................... 36

1.4.2. Métodos de síntesis $\quad$........................................................................................ 39

1.4.3. Usos de los hidróxidos dobles laminares $\quad$............................................................. 40

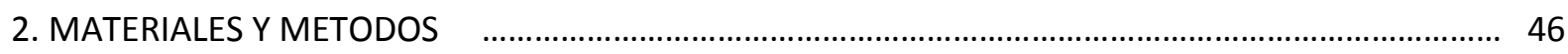

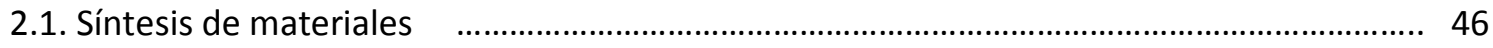

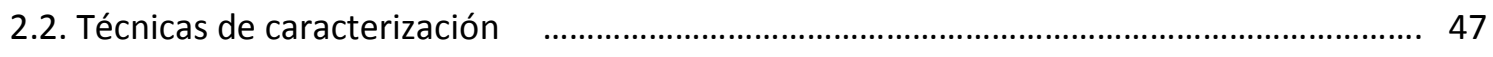

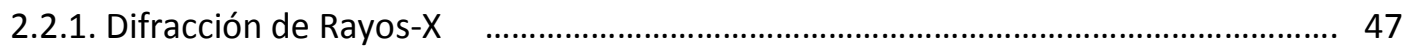

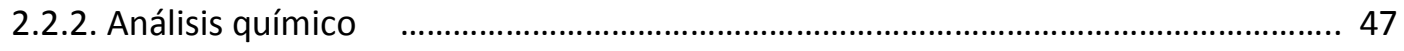

2.2.3. Análisis termogravimétrico $\quad$................................................................................. 47

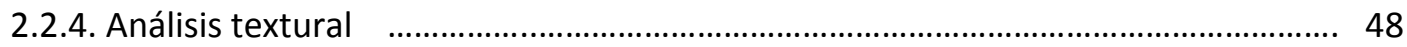




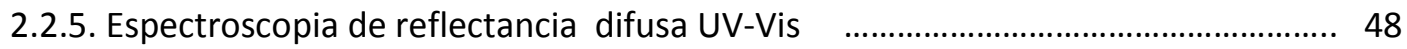

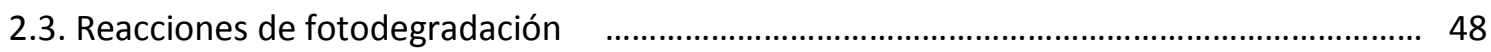

2.3.1 Cinética de las reacciones fotocatalíticas $\quad$.............................................................. 49

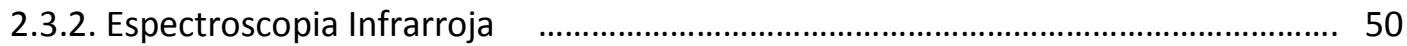

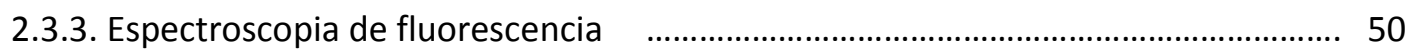

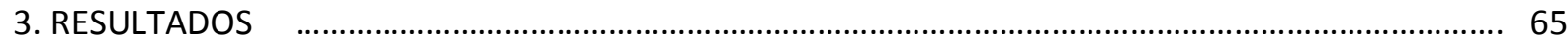

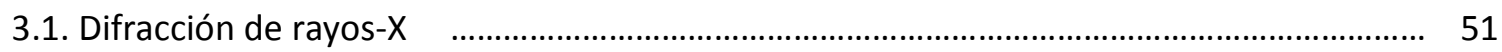

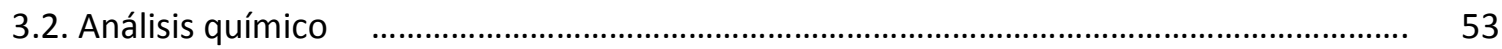

3.3. Análisis termogravimétrico ........................................................................................... 54

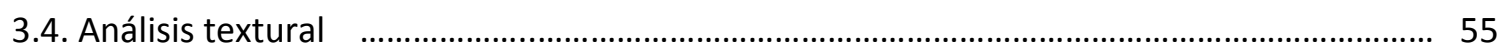

3.5. Energía de banda prohibida $\quad$............................................................................................ 57

3.6. Reacciones de fotodegradación $\quad$.......................................................................................... 59

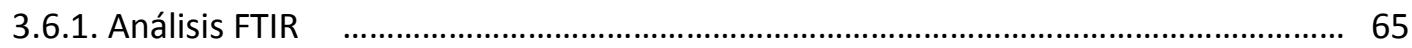

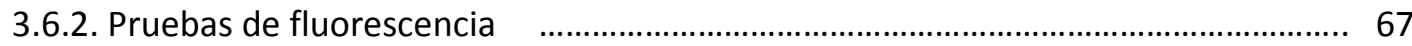

3.6.3. Elucidación del comportamiento fotocatalítico $\quad$.................................................... 70

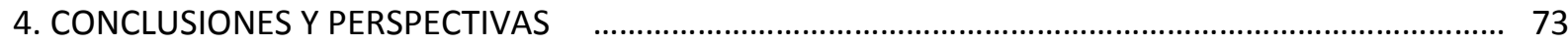

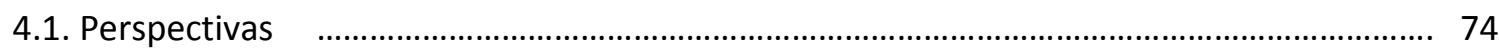

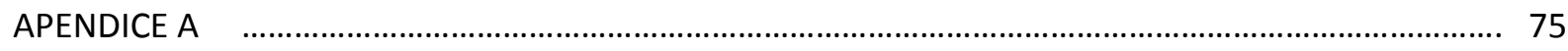

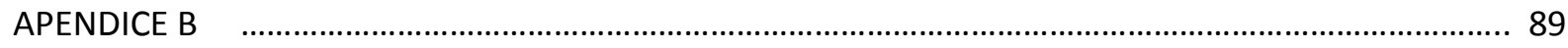

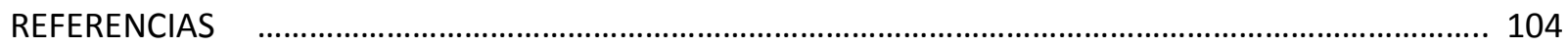




\section{INDICE DE TABLAS}

Tabla 1.1. Fármacos más comunmente detectados en agua residual.

Tabla 1.2. Degradación de algunos fármacos mediante procesos de oxidación avanzada a base de ozono.

Tabla 1.3. Degradación de algunos fármacos mediante procesos fotocatalíticos.

Tabla 1.4. Radio iónico de los cationes metálicos más comunes empleados en las síntesis de LDH’s .. 34

Tabla 1.5. Valores de pH para la precipitación de algunos hidróxidos $M(I I)$ y $M(I I I)$

Tabla 3.1. Parámetros de celda y tamaño de cristalito de los LDH's MgAl sintetizados y secados a $373 \mathrm{~K}$ por $12 \mathrm{~h}$.

Tabla 3.2. Composición química y área superficial específica LDH’s MgAl sintetizados

Tabla 3.3. Área superficial específica y tamaño de poro de los óxidos mixtos MgAl

Tabla 3.4. Energía de banda prohibida para los LDH's MgAl calcinados considerando transiciones indirectas y directas.

Tabla 3.5. Constantes aparentes de velocidad, tiempo de vida media y porcentaje de fotodegradación para naproxeno sódico.

Tabla 3.6. Constantes aparentes de velocidad, tiempo de vida media y porcentaje de fotodegradación para oxitetraciclina. 


\section{INDICE DE FIGURAS}

Figura 1.1. Distribución del agua en la Tierra.

Figura 1.2. Incidencia de fármacos en el agua superficial de diversos países. El color indica el ingreso económico de las naciones analizadas. Los grupos de antibióticos están designados por $\mathrm{ML}=$ macrolidos, $\mathrm{QL}=$ quinolonas, $\mathrm{SA}=$ sulfonamidas, $\mathrm{TC}=$ tetraciclinas y $\mathrm{TRI}=$ trimetroprima. La línea horizontal dentro de los rectángulos de los gráficos es la concentración promedio.

Figura 1.3. Estructura química de la oxitetraciclina y algunos medicamentos comerciales que la contienen

Figura 1.4. Estructura química del naproxeno y algunos medicamentos comerciales que contienen esta sustancia.

Figura 1.5. Distribución de AOP's empleados en la degradación de productos fármaceuticos.

Figura 1.6. Algunas aplicaciones de los procesos fotocatalíticos

Figura 1.7. Influencia de diversos parámetros físicos en la velocidad de reacción $r$ de un proceso fotocatalítico, a) masa del catalizador, b) longitud de onda, c) concentración de la molécula diana, d) temperatura y e) flujo radiante.

Figura 1.8. Representación idealizada de la estructura de bandas de metales, semiconductores y aislantes

Figura 1.9. Donación de electrones de un nivel donador para la formación de semiconductor tipo n. Aceptación de electrones de la BV por un nivel aceptor para la formación de semiconductor tipo $\mathrm{p}$.... 29

Figura 1.10. Mecanismo fotocatalítico en partículas semiconductoras.

Figura 1.11. Posición relativa de las bandas de valencia y conducción de algunos semiconductores respecto al electrodo normal de hidrógeno 
Figura 1.12. Representación esquemática de la estructura de los hidróxidos dobles laminares.

Figura 1.13. Esquema para la derivación de todos los politipos de dos laminas hidróxiladas.

Figura 1.14. Algunas aplicaciones de los hidróxidos dobles laminares.

Figura 2.1. Diagrama de flujo para la síntesis de los catalizadores MgAl.

Figura 2.2. Diagrama de flujo del proceso fotocatalítico.

Figura 3.1. Patrones DRX de los LDH's MgAl sintetizados con diferente razón molar M"'/M"I'

Figura 3.2. Termogramas de los LDH's MgAl sintetizados 54

Figura 3.3. Isotermas de adsorción-desorción de $N_{2}$ de los materiales calcinados

Figura 3.4. Distribución de tamaño de poro de los LDH's MgAl.

56

Figura 3.5. Espectro de reflectancia difusa para los LDH's MgAl calcinados considerando: a) transiciones indirectas y b) directas.

Figura 3.6. Espectros UV - Vis de a) naproxeno sódico y b) oxitetraciclina remanentes en solución a diferentes tiempos de la reacción de fotodegradacion empleando el material MgAl3. 60

Figura 3.7. Adsorción y fotodegradación de naproxeno sódico en solución acuosa por hidrotalcitas MgAl calcinadas con diferente razón molar $\mathrm{M}^{\mathrm{II}} / \mathrm{M}^{\mathrm{III}}$; fotolisis y fotodegradación empleando $\mathrm{TiO}_{2}$.

Figura 3.8. Adsorción y fotodegradación de oxitetraciclina en solución acuosa por hidrotalcitas MgAl calcinadas con diferente razón molar $\mathrm{M}^{\prime \prime} / \mathrm{M}^{\mathrm{III}}$; fotolisis y fotodegradación empleando $\mathrm{TiO}_{2}$. 
Figura 3.9. Cinética de pseudo primer orden para la fotodegradación de naproxeno sódico empleando LDH's MgAl calcinados con diferente razón molar M"1"M"'I

Figura 3.10. Cinética de pseudo primer orden para la fotodegradación de oxitetraciclina empleando LDH's MgAl calcinados con diferente razón molar $\mathrm{M}^{\prime \prime} / \mathrm{M}^{\prime \prime \prime}$

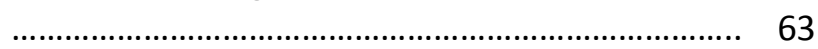

Figura 3.11. Espectro FTIR de los LDH's MgAl calcinados después de la fotodegradación de (a) naproxeno sódico y (b) oxitetraciclina

Figura 3.12. Formación de un producto hidroxilado fluorescente a partir de la reacción entre la coumarina y radicales $\mathrm{OH}$.

Figura 3.13. Espectro de fluorescencia usando una longitud de onda de excitación de $332 \mathrm{~nm}$ para los sistemas: (a) coumarina irradiada con luz UV y (b) coumarina-MgAl3-luz UV

Fig. 3.14. Intensidad de fluorescencia de 7-hidroxicoumarina en función del tiempo para los sistemas Coumarina-luz UV y Coumarina-MgAl3-luz UV

Figura 3.15. Representación esquemática del comportamiento fotocatalítico de los materiales calcinados en las fotodegradación de naproxeno sódico y oxitetraciclina 


\section{RESUMEN}

Tres hidróxidos dobles laminares MgAl con diferente razón molar $\mathrm{M}^{\prime \prime} / \mathrm{M}^{\prime \prime \prime}$, fueron sintetizados mediante el método de cooprecipitación, utilizando como agentes precursores nitratos de los cationes metálicos y soluciones de $\mathrm{K}_{2} \mathrm{CO}_{3} / \mathrm{KOH}$ para ajustar el pH de los sistemas de reacción a un valor de $9 \pm 0.5$.

Los sólidos sintetizados fueron caracterizados por difracción de rayos- $\mathrm{X}$, espectroscopia de energía dispersiva (EDS), adsorción-desorción de $\mathrm{N}_{2}$, análisis termogravimétrico y espectroscopia de reflectancia difusa UV-Vis. La actividad catalítica de los materiales, previamente calcinados a $723 \mathrm{~K}$, fue evaluada mediante la degradación de dos fármacos solubles en agua, naproxeno sódico, antinflamatorio no esteroideo, y oxitetraciclina, antibiótico de amplio espectro perteneciente a la familia de las tetraciclinas.

Los materiales MgAl calcinados mostraron una alta eficiencia en la fotodegradación de las moléculas de prueba; después de 5 horas de reacción, cerca del 90\% de naproxeno sódico y 70\% de oxitetraciclina, fueron mineralizadas por el material con mayor actividad fotocatalítica. Con fines comparativos, se realizaron estudios de fotolisis y fotodegradación empleando $\mathrm{TiO}_{2}$ P25. Los fotocatalizadores sintetizados exhibieron una mayor actividad en la eliminación de las moléculas de prueba que el $\mathrm{TiO}_{2}$.

Los análisis de espectroscopia FTIR realizados a los sólidos recuperados después del proceso de fotodegradación, indicaron que ningún intermediario de reacción o los fármacos en su forma nativa, se adhirieron a la superficie de los catalizadores. Estudios de fluorescencia apuntan hacia la generación de radicales $\mathrm{OH} \cdot$ como especies oxidativas de las moléculas objetivo, utilizando los materiales calcinados e irradiados con luz ultravioleta. 


\section{OBJETIVOS}

\section{Objetivo general}

Sintetizar hidróxidos dobles laminares MgAl con diferente razón molar $\mathrm{M}^{\prime \prime} / \mathrm{M}^{\text {III }}$ por el método de cooprecipitación, para ser empleados en la fotodegradación en medio acuoso de naproxeno sódico y oxitetraciclina.

\section{Objetivos específicos}

a) Sintetizar tres hidróxidos dobles laminares con razones molares $M^{\prime \prime} / M^{\prime \prime \prime}$ de 2, 3 y 4, por el método de coprecipitación a partir de los nitratos de los cationes metálicos y soluciones de $\mathrm{K}_{2} \mathrm{CO}_{3} / \mathrm{KOH}$ para el ajuste del $\mathrm{pH}$ a un valor de $9 \pm 0.5$ y como fuente de aniones interlaminares.

b) Determinar las propiedades fisicoquímicas de los materiales sintetizados por medio de:

- Difracción de rayos-X

- Espectroscopia dispersiva

- Adsorción-desorción de $\mathrm{N}_{2}$

- Análisis termogravimétrico

- Espectroscopia UV-Vis de reflectancia difusa

c) Estudiar la actividad fotocatalítica de los materiales sintetizados vía la degradación de naproxeno sódico y oxitetraciclina, como moléculas de prueba. La evolución de la concentración de los fármacos en función del tiempo, será monitoreada por espectroscopia UV-Vis y análisis de carbono orgánico total. Se realizarán dos pruebas alternas al proceso fotocatalítico, las cuales son:

- Análisis FTIR de los sólidos secos después del proceso fotocatalítico para una posible detección del fármaco en forma nativa o intermediarios de reacción

- Pruebas de fluorescencia para la detección de radicales $\mathrm{OH}$. 


\section{INTRODUCCION}

Los productos farmacéuticos son un grupo diverso de compuestos químicos empleados en medicina humana y veterinaria para la cura y control de enfermedades, combate al dolor y control natal. En años recientes y con el desarrollo de técnicas analíticas más sofisticadas, una gran variedad de ellos, han sido detectados en efluentes de agua residual, superficial y mantos acuíferos en concentraciones que van de los $\mathrm{ng} / \mathrm{L}$ a los $\mu \mathrm{g} / \mathrm{L}[1,2]$.

A diferencia de otros contaminantes, tales como dioxinas y PCBs (policlorobifenilos), los fármacos son sustancias caracterizadas por su alta estabilidad química y su capacidad para producir respuestas biológicas específicas [3]. Debido a ello, los métodos convencionales aplicados en plantas de tratamiento, no son lo suficientemente eficaces para su remoción, por lo que muchos de estos productos terminan en cuerpos de agua superficial. Asimismo, el uso de agua residual sin tratamiento previo para el riego de cosechas, ha ocasionado la contaminación directa del suelo y la filtración de diversos fármacos a mantos acuíferos poco profundos. Una de las principales preocupaciones sobre la presencia de productos farmacéuticos en ecosistemas acuáticos, es su posible efecto fisiológico sobre organismos no objetivo. Diversas investigaciones han sugerido un vínculo entre la existencia de fármacos en efluentes naturales y alteraciones en el sistema endocrino de ciertas especies de animales [4-5].

Aunque los fármacos detectados en agua contaminada y efluentes naturales incluyen una gran variedad de compuestos [6, 7], es frecuente que se reporte la presencia de naproxeno sódico y oxitetraciclina en las muestras analizadas. El naproxeno sódico es uno de los anti-inflamatorios no esteroideos más comúnmente empleados para reducir la inflamación y la percepción de dolor. En diversos países, este producto es de libre venta, por lo cual su incidencia en agua residual es alta. Por otra parte, la oxitetraciclina es un antibiótico de amplio espectro, que además de ser utilizado en medicina humana, es una de las sustancias de mayor consumo en el sector agropecuario, por lo que su presencia en cuerpos de agua y ecosistemas del suelo es constante.

Algunas de las técnicas fisicoquímicas, aplicadas para la remoción de fármacos en medio acuoso, han sido los procesos de oxidación avanzada, AOP's por sus siglas en inglés, la adsorción y la filtración por membranas [1, 4-12]. De todas ellas, los AOP's son hasta ahora, los únicos métodos que han permitido la mineralización del fármaco y sus posible metabolitos. 
Los procesos de oxidación avanzada son un conjunto de técnicas caracterizadas por la oxidación de compuestos orgánicos mediante la generación de especies reactivas de oxígeno, principalmente radicales $\mathrm{OH} \cdot$. Aunque los AOP's comprenden reacciones tan diversas como la ozonización, los procesos Fenton, foto-Fenton, la electrólisis y fotólisis, la fotocatálisis heterogénea es uno de los procesos más eficientes en la transformación de contaminantes orgánicos a $\mathrm{CO}_{2}, \mathrm{H}_{2} \mathrm{O}$ y ácidos minerales; asimismo los materiales empleados como catalizadores suelen ser sólidos inorgánicos inocuos, con alta actividad catalítica y poca selectividad.

Pese a su eficacia, pocos han sido los materiales probados en la fotodegradación de fármacos; además del dióxido de titanio, el $\mathrm{ZnO}, \mathrm{CdS}$ y $\mathrm{SnO}_{2}$ han sido empleados como fotocatalizadores en este proceso [10]. Estos sólidos no han mostrado un incremento significativo respecto a la alta actividad fotocatalítica del $\mathrm{TiO}_{2}$, además de que la síntesis de algunos de ellos es perjudicial para el medio ambiente. La búsqueda de nuevos materiales de bajo costo, amigables con el ambiente y eficientes en la degradación y mineralización de contaminantes orgánicos, ha atraído considerable atención hacia los hidróxidos dobles laminares, LDH's por sus siglas en inglés.

Los hidróxidos dobles laminares son arcillas aniónicas cuya estructura cristalina consiste en láminas tipo brucita cargadas positivamente, debido a la sustitución isomórfica de cationes divalentes por iones metálicos trivalentes. En la zona interlaminar se localizan moléculas de agua y aniones, los cuales compensan la carga positiva del sólido. Estos compuestos han sido utilizados en una gran variedad de aplicaciones tecnológicas e industriales, entre las cuales se incluyen: aditivos para PVC, retardantes de flama, adsorbentes y en la formulación de antiácidos [13]. Los óxidos mixtos derivados de la descomposición térmica de los $\mathrm{LDH}^{\prime}$ s, se han empleado frecuentemente como catalizadores y soportes para catalizador debido a su estabilidad térmica, basicidad, alta área superficial y a la capacidad de regenerar su estructura laminar al ser colocados en medio acuoso (efecto memoria). No obstante, pocos estudios han explorado el comportamiento de estos óxidos en procesos fotoquímicos. Un número limitado de investigaciones, ha reportado el comportamiento fisicoquímico de estos materiales en la fotodegradación de colorantes [14, 15] y compuestos fenólicos [16, 17].

En el presente trabajo de investigación tres hidróxidos dobles laminares con diferente razón molar $\mathrm{M}^{\prime \prime} / \mathrm{M}^{\prime \prime \prime}$ (donde $\mathrm{M}^{\prime \prime}$ y $\mathrm{M}^{\text {III }}$ son los cationes di y trivalentes respectivamente), sintetizados por el método de coprecipitación y caracterizados por diversas técnicas analíticas, fueron empleados en la fotodegradación en medio acuoso, de dos fármacos comúnmente empleados en medicina, naproxeno 
sódico y oxitetraciclina. La eficiencia de los materiales sintetizados fue cotejada con la fotólisis de las moléculas orgánicas y su fotodegradación por medio de $\mathrm{TiO}_{2}$ P25.

\section{ANTECEDENTES}

\subsection{Contaminación del agua}

Aunque más de tres cuartas partes del planeta Tierra se encuentran cubiertas por agua, menos del 3\% corresponde a agua dulce; de esta cantidad, cerca del $70 \%$ se encuentra congelada en polos y glaciares, $30 \%$ se localiza en mantos acuíferos, y solo un $1 \%$, localizado en ríos, lagos, arroyos y humedales, es accesible para los seres humano [18].

Pese a que la cantidad de agua dulce disponible es mínima, con objeto de abastecer actividades industriales, agropecuarias y el consumo de comunidades humanas cada vez más numerosas, la extracción de agua dulce se ha incrementado significativamente a nivel mundial y, en tan solo 30 años, 1970-2000, se registró un aumento de aproximadamente 50\% [19]. Sin bien las precipitaciones anuales permiten el reabastecimiento de las fuentes de extracción y pueden proporcionar hasta $7000 \mathrm{~m}^{3}$ de agua por habitante [20], su distribución no uniforme en tiempo y espacio, la tala inmoderada de bosques y la impermeabilización del suelo como consecuencia de la urbanización, han provocado la carencia del vital líquido en diversas regiones del planeta.

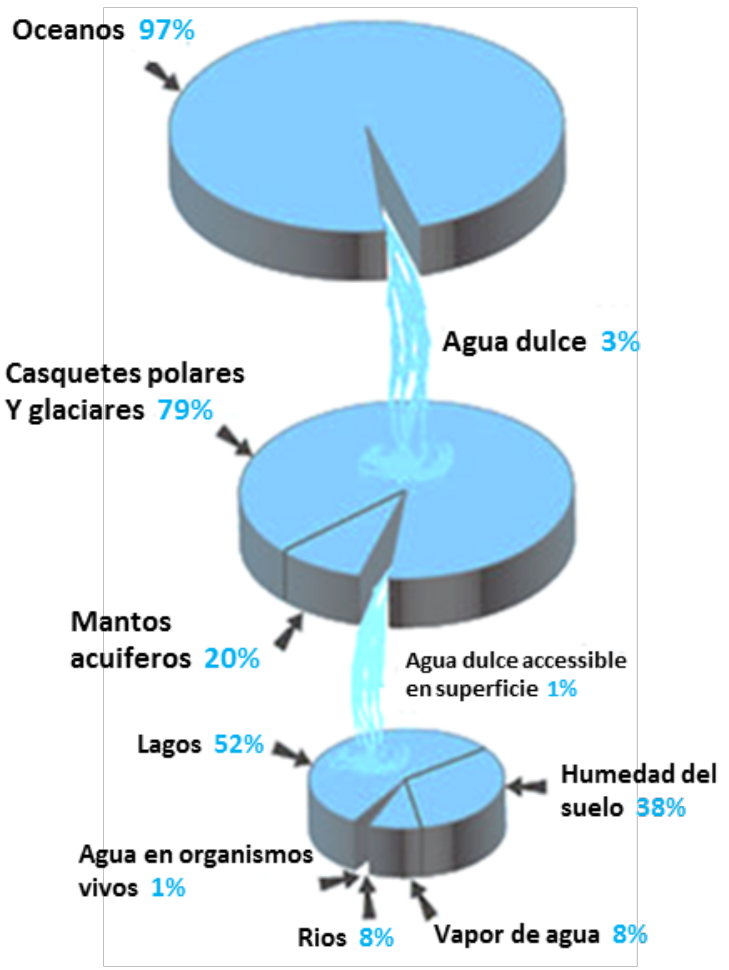

Figura 1.1. Distribución del agua en la Tierra. Imagen modificada del sitio Pinterest:

https://www.pinterest.com/pin/533817362053688160/

Actualmente más de la cuarta parte de los países del mundo sufre de escasez. La intensa demanda de agua, también ha suscitado la sobreexplotación de un gran número de depósitos subterráneos poco 
profundos. Sólo en México, el número de acuíferos en esta categoría se elevó de 32 en 1975 a 102 en $2011[19]$.

La disponibilidad de agua dulce, no es la única problemática a la cual se deben enfrentan las actuales sociedades humanas; la calidad del líquido es quizá un asunto de mayor importancia, dado que influye de manera directa en la salud de la población y en la integridad de los ecosistemas acuáticos. Una consecuencia de la utilización del agua en actividades humanas, es su continua contaminación con diversas sustancias de origen biológico y químico. Sin un tratamiento adecuado, el agua residual que se reintegra al ciclo hidrológico, contamina severamente cuerpos subterráneos y superficiales, así como también, imposibilita su reutilización en diversas aplicaciones. Pese a lo anterior, se estima que menos del $2 \%$ de las ciudades del mundo cuentan con plantas de tratamiento, por lo que entre 85 y $90 \%$ del agua residual no es depurada antes de su reincorporación a los efluentes naturales. Así, el uso sustentable del agua, además de incluir la concientización sobre el uso racionalizado del líquido y la construcción de infraestructura eficiente para su captación, almacenamiento y distribución, requiere de un tratamiento adecuado del agua residual producto de las actividades humanas.

El agua residual proveniente de la industria, el sector agropecuario, edificios públicos y viviendas, contiene una gran cantidad de materia orgánica, organismos patógenos, metales pesados y sustancias de origen químico, tales como fertilizantes, pesticidas, detergentes y productos farmacéuticos. Para la remoción de estos contaminantes, las plantas de tratamiento emplean, principalmente, procedimientos primarios, es decir métodos biofísicos, que incluyen lodos activados, lagunas de estabilización, lagunas aireadas y filtros biológicos; en el caso del agua residual severamente contaminada, el proceso biológico es acompañado por la aplicación de técnicas fisicoquímicas. Sin embargo, con frecuencia el tratamiento de agua residual es a nivel primario, por lo que los compuestos químicos no biodegradables pasan a los efluentes naturales, poniendo en riesgo la salud de la población y el equilibrio de los ecosistemas acuáticos. Tal es el caso de fármacos y hormonas [2, 21, 22].

Los fármacos y hormonas son compuestos de origen químico, empleados en medicina humana y veterinaria para la cura y control de enfermedades, combate al dolor y control natal. Al entrar a un organismo, estas sustancias atraviesan por una serie de pasos que incluyen su metabolización, es decir modificaciones químicas por la acción de diferentes enzimas, y su excreción mediante la orina y las heces. En este último paso, no solo se evacua al fármaco en su forma nativa, también son expulsados los subproductos de su metabolización. Aunque son considerados micro-contaminantes, concentración en el intervalo de $\mathrm{ng} / \mathrm{L}-\mu \mathrm{g} / \mathrm{L}$, el incremento en su consumo a nivel mundial y la aparición constante de 
nuevos medicamentos, ha ocasionado su alta incidencia en aguas residuales. Se calcula que la demanda per cápita

de fármacos, se multiplico entre 20 y 30\% en diversos países para el periodo 2000-2008 [23]; asimismo alrededor de 4000 medicamentos son producidos año con año para su comercialización global [24]. Si bien, el agua residual doméstica y de la industria farmacéutica es depurada en plantas de tratamiento, se ha reportado que, debido a su actividad biológica y a su alta estabilidad química, la remoción y/o degradación de los fármacos y sus metabolitos solo es parcial, por lo que una gran parte de estas sustancias, pasan a los efluentes naturales [7, 25].

Al igual que otros contaminantes de origen químico, diversos fármacos y hormonas son compuesto persistentes y bio-acumulables, lo cual puede poner en riesgo el equilibrio de los ecosistemas acuáticos. Pese a que no se conocen con exactitud los efectos eco-toxicológicos de los fármacos y sus metabolitos, ya sea puros o como componentes de mezclas complejas de contaminantes, diversas investigaciones realizados a partir de la década de los años 90, han encontrado una estrecha relación entre la presencia de productos farmacéuticos y problemas de salud en la flora y fauna acuática, tales como el decremento en la fertilidad de peces, pájaros y ostras, la feminización de poblaciones de peces y pájaros, alteración en funciones inmunes de pájaros y mamíferos y la disminución en el éxito de la ruptura de cascarón en peces, pájaros y tortugas [4, 5, 26].

En años recientes y gracias al desarrollo de técnicas analíticas más sofisticadas, ha sido posible la detección e identificación de una gran diversidad de fármacos que se encuentran en agua residual. La tabla 1.1 contiene algunos de estos medicamentos; destacan por su uso extendido y variedad los antibióticos y analgésicos. 
Tabla 1.1 Fármacos más comunmente detectados en agua residual. Datos tomados de [5], [10] y [27]

\begin{tabular}{|c|l|}
\hline \hline Uso terapeutico & \multicolumn{1}{c|}{ Tipo y nombre de fármaco } \\
\hline \hline Antibióticos & $\begin{array}{l}\text { Sulfametazol, ciprofloxacin, trimetroprim } \\
\text { penicilina, oxitetraciclina, tetraciclina }\end{array}$ \\
Analgésicos & $\begin{array}{l}\text { Diclofenaco, naproxeno, ibuprofeno } \\
\text { ketoprofeno, carbazepina }\end{array}$ \\
Fármacos cardiovasculares & $\begin{array}{l}\text { Propanolol, atenolol, metropolol } \\
\text { ácido clofibrico, gemifibrozil,fezafibrato }\end{array}$ \\
Hormonas & $\begin{array}{l}17 \text { - } \alpha \text {-etinilestradiol, estrona, } 17 \beta \text {-estradiol } \\
\text { estriol }\end{array}$ \\
\hline \hline
\end{tabular}

\subsubsection{Antibióticos.}

Los antibióticos son sustancias que incluso en pequeñas concentraciones, pueden inhibir el crecimiento o la multiplicación de bacterias y hongos. La mayor parte de estos compuestos son producidos por ciertos microrganismos, aunque algunos de ellos son obtenidos mediante síntesis química. Debido a la frecuencia de enfermedades de origen infeccioso, los antibióticos se encuentran entre los fármacos con mayor producción a nivel mundial; se calcula que el sector farmacéutico fabrica aproximadamente 200, 000 toneladas anualmente [25].

La incidencia de los antibióticos en agua residual y efluentes naturales, depende directamente de las condiciones socio-económicas de la región analizada. Debido a diferentes factores tales como los brotes frecuentes de enfermedades infecciosas, poco control en la automedicación de los individuos y menor acceso a la recolección y tratamiento de agua residual, los países con menores ingresos per cápita presentan una mayor concentración de antibióticos en efluentes superficiales y mantos acuíferos poco profundos. Al estudiar la presencia de tetraciclinas, macrólidos, sulfonamidas, quinolonas y trimetoprima en agua superficial contaminada, P. A. Segura et al [28], encontraron que en los países con ingresos bajo-medio y bajo, la concentración promedio de estas sustancias químicas era de 3.2 a 
39.2 veces más alta que aquella registrada en naciones con altos ingresos económicos; en el caso de los estados con ingreso medio-alto la diferencia es de 1.0 a 14.9 veces mayor respecto a países ricos [28]. La figura 1.2 muestra la ocurrencia de los 5 tipos de antibióticos mencionados anteriormente en el agua superficial de diversos países. El ingreso per cápita de cada uno de los territorios analizados se indica mediante el uso de color.

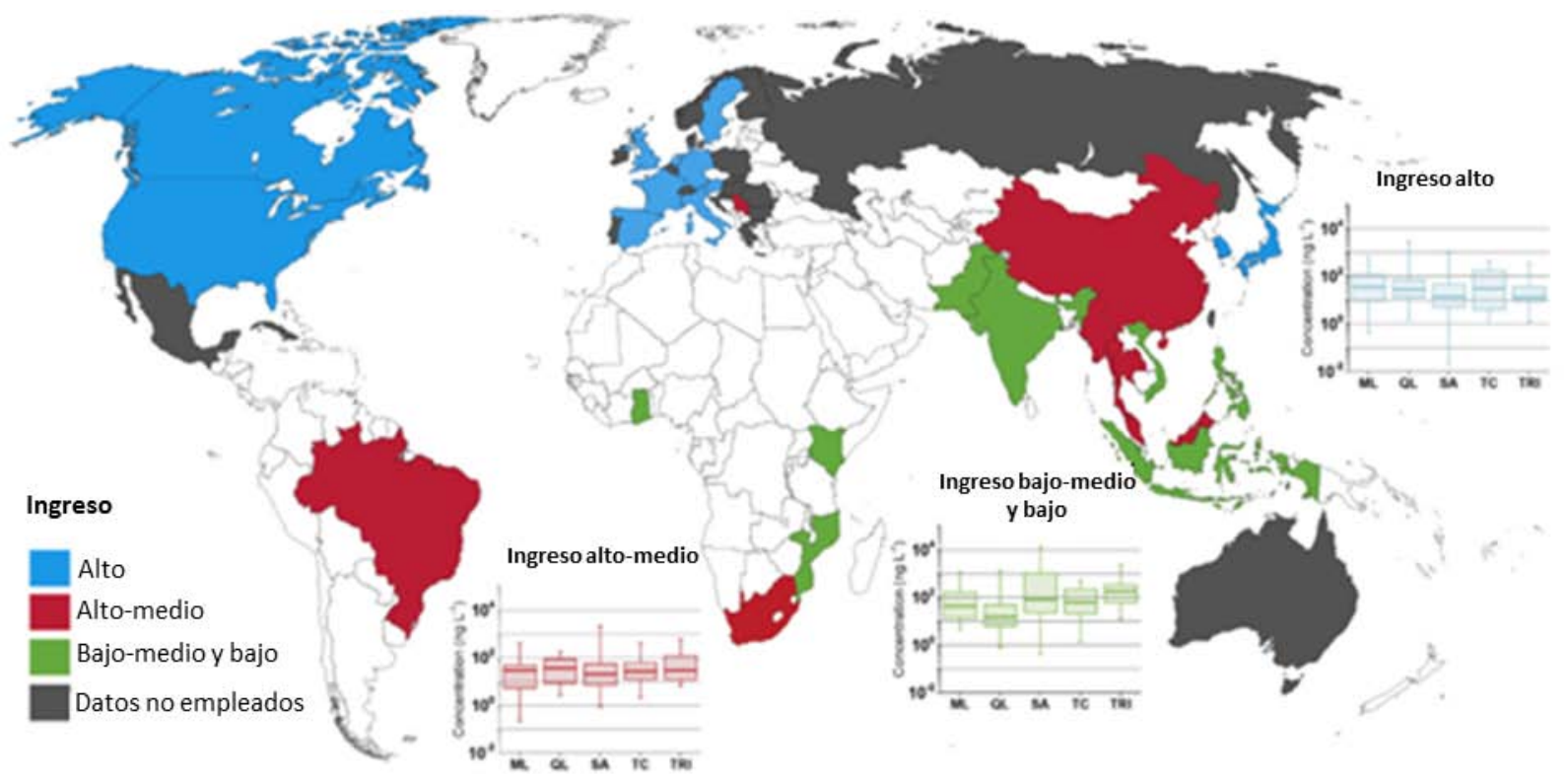

Figura 1.2. Incidencia de fármacos en el agua superficial de diversos países. El color indica el ingreso económico de las naciones analizadas. Los grupos de antibióticos están designados por $\mathrm{ML}=$ macrolidos, $\mathrm{QL}=$ quinolonas, $\mathrm{SA}=$ sulfonamidas, $\mathrm{TC}=$ tetraciclinas y TRI = trimetroprima. La línea horizontal dentro de los rectángulos de los gráficos es la concentración promedio. Tomado de [16]

Aunque, en general, la concentración de antibióticos en efluentes naturales y mantos acuíferos no excede los $2000 \mathrm{ng} / \mathrm{L}$, numerosas investigaciones han mostrado que la presencia de algunas de estas sustancias incluso en pequeñas cantidades, puede ser altamente perjudicial para la biota acuática. Por ejemplo, se ha reportado que la ciprofloxacina en concentraciones de 12 a $120 \mathrm{ng} / \mathrm{L}$, puede modificar el material genético de ciertas algas marinas [28, 29]; algunos antibióticos, tales como oxitetraciclina, eritromicina, sulfametoxazol y trimetroprima, son inmunotóxicos para el mejillón Elliptio complanata cuando se encuentran en el intervalo de concentración de 20-1100 ng/L [30]. Asimismo, se ha sugerido 
que la frecuente descarga de mezclas de antibióticos en cuerpos de agua naturales, más que ocasionar daños agudos inmediatos, provoca afecciones sutiles y crónicas en la flora y fauna de los ecosistemas acuáticos.

Otro de los graves problemas que ha suscitado la presencia de antibióticos en agua residual y efluentes superficiales, es la creciente resistencia que exhiben ciertos patógenos a la acción de diferentes fármacos $[25,31,32]$. Los microorganismos que se encuentran en el agua de desecho, suelen exponerse a una mezcla de altas concentraciones de fármacos y sus respectivos metabolitos. En este entorno tan complejo, los especímenes patógenos pueden cambiar su material genético o adquirir uno nuevo mediante transferencias genéticas horizontales, lo cual incrementa sus mecanismos de defensa contra diversos fármacos. Más aun, el uso de agua residual doméstica para el riego de cosechas, práctica muy extendida en países con ingresos medios y bajos, puede esparcir esta combinación de antibióticos y metabolitos en el suelo, ocasionando desequilibrios y la mutación genética de las comunidades de microrganismos que se habitan este ecosistema. Asimismo, se ha encontrado que la presencia de estas sustancias modifica las condiciones ambientales del suelo, causa la intoxicación de la flora y fauna, perturba el ciclo natural de los nutrientes $y$, debido a sus propiedades fisicoquímicas algunos antibióticos, tales como la oxitetraciclina, pueden ser filtrados a mantos acuíferos poco profundos.

Debido a que exhibe una actividad antimicrobial de amplio espectro contra diversas enfermedades producidas por bacterias, la oxitetraciclina es uno de los antibióticos más prescritos en medicina humana y veterinaria. Perteneciente al grupo de las tetraciclinas, este fármaco de origen natural consta de una estructura anular de 4 anillos con diversos sustituyentes, entre los que destacan un grupo carboxiamida, una amina terciaria y un hidróxilo fenólico en la posición 10, los cuales, junto con el conjunto policiclico básico del compuesto, determinan su acción antibacterial (Figura 1.3). Este antibiótico es predominantemente bacteriostático, es decir inhibe el crecimiento de las bacterias, pero en altas dosis puede ser bactericida [33, 34]. 
Al igual que otros productos farmacéuticos, un alto porcentaje de la oxitetraciclina es evacuada por el organismo huésped y permanece activa en el medio ambiente. Por ejemplo, se ha reportado que los residuos de este antibiótico excretados por animales de granja, conservan su acción antibacterial por más de 20 días; además, al ser fácilmente adsorbida por suelos de tipo arcilloso, puede quedar protegida de una posible biodegradación [35]. Su alto consumo a nivel mundial y su ineficiente remoción en plantas de tratamiento, ocasiona su frecuente aparición en agua residual y cuerpos de agua naturales. En Estados Unidos se ha reportado la presencia de este antibiótico en agua residual doméstica en una concentración promedio de $4.2 \pm 0.4 \mu \mathrm{g} / \mathrm{L}$ [5],

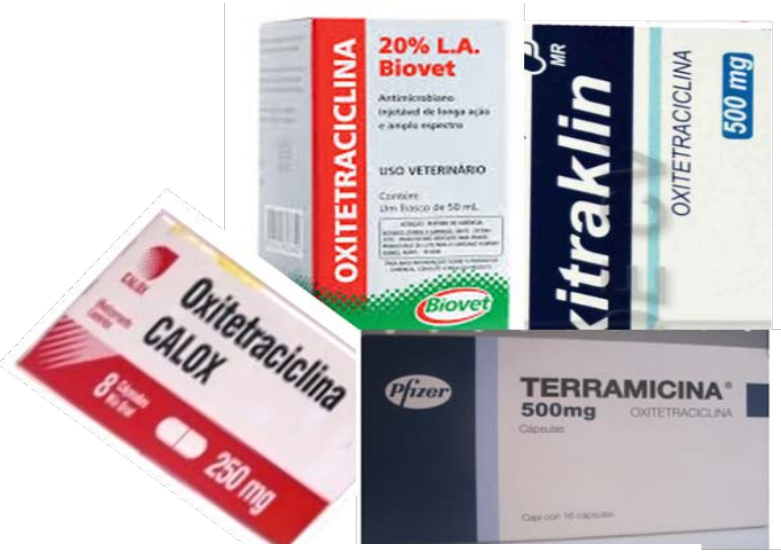<smiles>CN(C)C1C(O)=C(C(N)=O)C(=O)C2(O)C(O)=C3C(=O)c4c(O)cccc4C(C)(O)C3C(O)C12</smiles>

Figura 1.3. Estructura química de la oxitetraciclina y algunos medicamentos comerciales que la contienen mientras que en Pakistán, ha sido detectada a niveles de $3.2 \mu \mathrm{g} / \mathrm{L}[25]$.

Pese a que la polución por antibióticos representa un grave problema para la salud de la población humana y los ecosistemas, los fármacos conocidos como analgésicos no esteroideos son quizá un grupo de contaminantes emergentes más perjudiciales para el medio ambiente. Debido a que en diversos países su venta no requiere receta médica, el consumo global y anual de estas sustancias es muy elevado; asimismo la información que se tiene sobre sus posibles daños a organismos no objetivo, es aún muy limitada.

\subsubsection{Antiinflamatorios}

Los analgésicos son compuestos químicos administrados para disminuir la percepción del dolor sin provocar en el individuo la pérdida de conciencia ni la alteración de la actividad refleja [36]. De acuerdo a su origen, pueden ser clasificados como esteroideos y no esteroideos. Los primeros, son corticoides naturales o semi-sintéticos de uso muy limitado ya que producen una gran variedad de efectos 
secundarios en el individuo, tales como el Síndrome de Cushing. Los antinflamatorios no esteroideos (AINE) son un grupo de fármacos que además de emplearse como analgésicos, tienen una potente acción antiinflamatoria y antipirética. El uso de estos medicamentos tiene pocos efectos adversos en el individuo por lo que son medicamentos muy populares. Los ácidos orgánicos, entre los que se encuentran el ácido acetilsalicílico, ibuprofeno, idometacian y naproxeno, representan la mayor parte de los AINE que actualmente se comercializan.

Aunque pueden ser prescritos, los AINE son fármacos de libre venta, por lo que su consumo a nivel mundial es muy alto. Se estima que sólo en Alemania 87.5 millones de recetas para la adquisición de estas sustancias fueron dadas en 2001 [37]. Debido a su uso extendido, diversos AINE han sido identificados en efluentes de agua residual y en algunos ecosistemas acuáticos. Entre las sustancias identificadas, es frecuente la presencia de naproxeno en concentraciones que van de los $25 \mathrm{ng} / \mathrm{L}$ a 33.9 $\mu \mathrm{g} / \mathrm{L}[8]$.

El naproxeno es un derivado del ácido propiónico, cuyo nombre químico es ácido (+)-6-metoxi- $\alpha$-metil-2naftalenacético. Estructuralmente cuenta con dos anillos bencénicos sustituidos con un grupo metoxi y un ácido carboxílico (Figura 1.4). Al igual que otros AINE, actúa sobre el sistema nervioso central o nivel periférico inhibiendo la actividad de las enzimas ciclooxigenasas, lo cual impide la síntesis de prostaglandinas y tromboxanos, sustancias responsables de la regulación del dolor. Se comercializa como ácido o como su sal sódica, la cual se absorbe más rápidamente en el tracto gastrointestinal. Aunque existe poca información sobre sus efectos ecotoxicológicos, algunas investigaciones han mostrado que el naproxeno y algunos de los productos que forma al interaccionar con la luz ultravioleta, pueden tener efectos agudos y crónicos en comunidades de bacterias, algas, anfibios y algunos

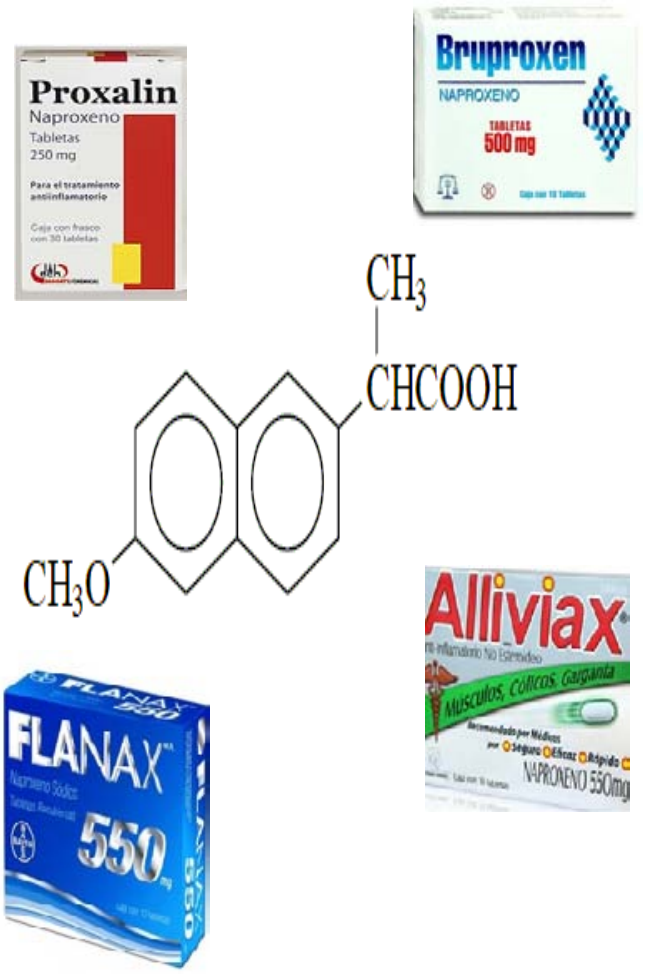

Figura 1.4. Estructura química del naproxeno y algunos medicamentos comerciales que contienen esta sustancia.

microcrustáceos [8, 37]. 
También se ha encontrado que esta sustancia y sus metabolitos pueden acumularse en organismos acuáticos que habitan áreas cercanas al punto de descarga del agua residual tratada con métodos primarios [38]. Debido a que las prostaglandinas desempeñan funciones biológicas específicas en diversas especies de agua fresca, como peces, pájaros, moluscos, corales, entre otras, el continuo depósito de sustancias que inhiban su formación, puede ocasionar graves deficiencias en la salud de estos especímenes, y a largo plazo generar un desequilibrio de los ecosistemas.

Por su alta ocurrencia en la naturaleza y sus posibles daños a la biota acuática y terrestre, se ha hecho cada vez más indispensable, el desarrollo y la implementación de técnicas que permitan la eliminación eficaz de fármacos recalcitrantes, como lo son los antibióticos y los antiinflamatorios no esteroideos.

\subsubsection{Técnicas de remoción y eliminación de fármacos}

Diversos métodos han sido probados en la remoción y eliminación de productos farmacéuticos. La adsorción y la fotodegradación por medio de procesos de oxidación avanzada han sido algunas de las técnicas más significativas hasta ahora implementadas.

La adsorción es un fenómeno por el cual un soluto (adsorbato), que puede estar en fase liquida o gaseosa, se adhiere a la superficie de un sólido (adsorbente) debido a la insaturación del campo de fuerzas del material. Esta técnica ha sido comúnmente empleada en la remoción de diferentes grupos de fármacos que van desde los antibióticos, los antiinflamatorios, antiepilépticos y hormonas. Aunque los adsorbentes empleados han sido muy diversos, destacan por su uso frecuente las montmorillonitas, naturales o modificadas con iones orgánicos, y el carbón activado. Por ejemplo, Kulshrestha et al. reportaron la adsorción de oxitetraciclina en montmorillonita con cationes interlaminares $\mathrm{Na}$ y la arcilla modificada con hexadeciltrimetilamonio [35]; los resultados mostraron que el proceso de adsorción depende del $\mathrm{pH}$ y de la cantidad de materia orgánica presente en el medio. En este mineral también se han intercalado bencildimetilhexadecilamonio para la adsorción de tetraciclina y sulfonamida, y tetrabutilamonio para la remoción de flurbiprofen [39]. El carbón, potencial adsorbente de bajo costo, se ha empleado para la remoción de antiinflamatorios. Cuerda-Correa et al. estudiaron la adsorción de naproxeno y ketoprofeno en carbón negro; aunque el proceso depende de diversos factores, tales como el $\mathrm{pH}$, la temperatura y la fuerza iónica, en condiciones óptimas, el material puede adsorber $517 \mathrm{mg} / \mathrm{g}$ de naproxeno y 400 mg/g de ketoprofeno [40]. En una línea de investigación similar, Yu Zirui et al. reportaron 
la remoción de poco más del 90\% de naproxeno en dos tipos de carbón activado [11]. Las membranas de filtración (nanofiltración u osmosis inversa) también han sido empleadas para la remoción de antibióticos y hormonas $[2,4]$. Pese a la eficiencia de ésta técnica, la capacidad de retención de la molécula objetivo, se ve reducida por la presencia de materia orgánica natural o compuestos químicos.

Pese a que las técnicas de adsorción se han aplicado con éxito en la remoción de diversos fármacos, los compuestos quedan almacenados en el adsorbente sin ser degradados y pueden ser desorbidos paulatinamente hacia el medio ambiente. Por su parte, los procesos de oxidación avanzada (AOP por sus siglas en inglés), no sólo transforman al contaminante en sustancias menos tóxicas y más biodegradables, si no también pueden lograr su mineralización a $\mathrm{CO}_{2}$, agua y ácidos inorgánicos.

Los $\mathrm{AOP}^{\prime}$ son métodos de oxidación basados en la generación de especies altamente reactivas, principalmente $\mathrm{OH} \cdot$, para la destrucción de moléculas objetivo. Aunque desde hace algunos años, estas técnicas se han aplicado en la degradación de diferentes contaminantes orgánicos tales como pesticidas, herbicidas, surfactantes y compuestos fenólicos, recientemente se ha reportado su aplicación en la eliminación de fármacos, con resultados promisorios. De los diversos métodos clasificados como AOP's, cuatro han sido lo más aplicados para el estudio de la remoción de productos farmacéuticos en agua residual y superficial: fotolisis, reacciones Fenton y foto-Fenton, ozonización y fotocatálisis heterogénea (Figura 1.5)

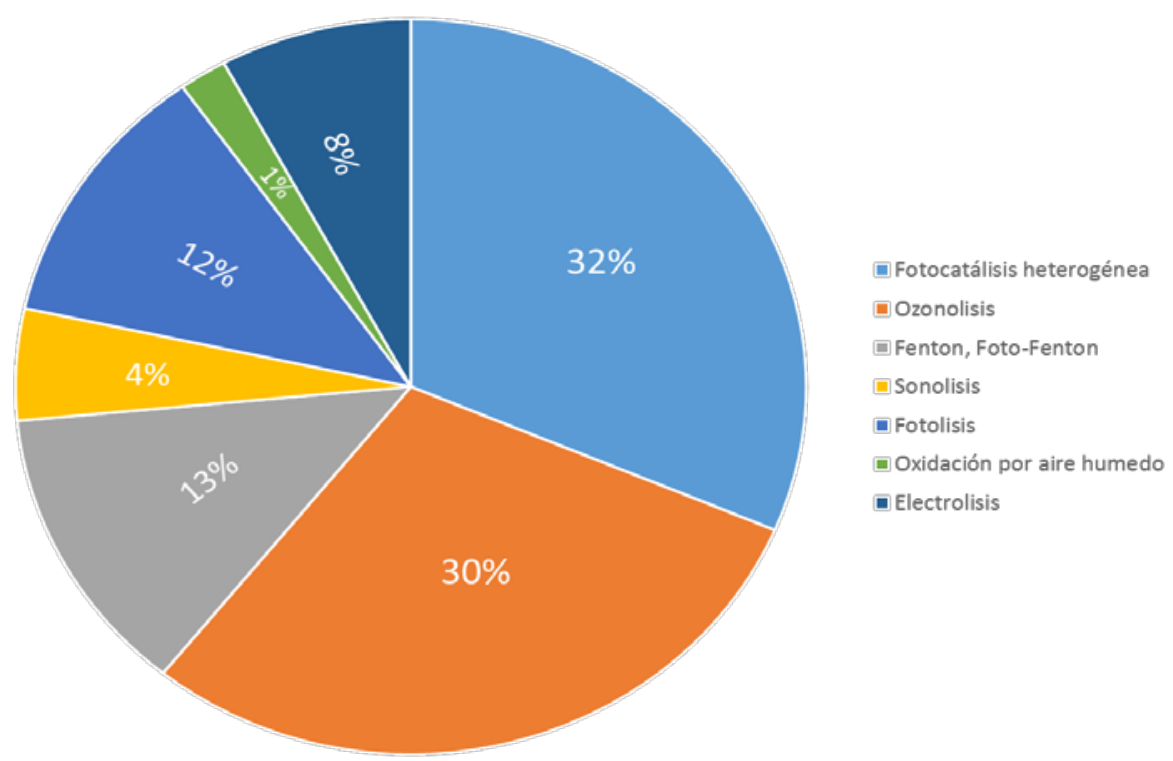

Fig. 1.5. Distribución de AOP's empleados en la degradación de productos fármaceuticos. Imagen modificada de [10] 


\section{Fotólisis}

Las reacciones de fotólisis conllevan la interacción de radiación ultravioleta o visible con moléculas orgánicas, para inducir reacciones fotoquímicas que permitan su degradación. En este sentido, la eficiencia del proceso depende en gran medida de las propiedades ópticas del compuesto. Numerosos fármacos son fotoactivos, es decir absorben radiación luminosa. Este hecho, ha sido aprovechado para la realización de diversas investigaciones enfocadas en la destrucción de estas sustancias mediante fotólisis. Los resultados han mostrado que la degradación de los productos farmacéuticos es rápida y eficiente, especialmente cuando se emplean otros oxidantes (fotolisis indirecta). Por ejemplo, I. Kim et al. investigaron la degradación de 30 productos farmacéuticos incluidos antibióticos, antiinflamatorios y anti-convulsionantes, depositados en una misma matriz, mediante fotólisis directa e indirecta. Se encontró que sólo 3 fármacos pueden ser degradados, >90\%; mediante fotólisis directa en tanto que al agregar $\mathrm{H}_{2} \mathrm{O}_{2}$, se logra un porcentaje de degradación similar para 23 de ellos [1]. Por otra parte, Shaojun J. et al. estudiaron la oxidación de oxitetraciclina (10-40 ppm) por fotólisis directa. Después de 4 horas de reacción, poco más del $73 \%$ del antibiótico fue degradado [41]. Otro factor determinante en la fotólisis de contaminantes orgánicos, es la radiación que incide en el sistema. Pereira et al. analizaron la fotólisis directa de 3 antinflamatorios, naproxeno, ketoprofeno y carbamazepina, variando la cantidad de irradiación electromagnética en los sistemas de reacción. A altas intensidades, lograron la degradación del 99\% de cada uno de los fármacos [42]. Otras fármacos degradados por fotolisis han sido: metronidazol, penicilina, paracetamol, sulfamidas y algunas hormonas [10].

La eliminación de fármacos mediante fotólisis, presenta ciertas desventajas, entre las que se incluyen:

* El fármaco debe absorber radiación a la longitud de onda que emite la lámpara utilizada

* Se ha reportado una baja mineralización de los productos farmacéuticos por fotólisis directa

* Algunos de los subproductos de reacción pueden ser más tóxicos que el compuesto original

DellaGreca et al. encontraron que la interacción de la molécula de naproxeno con luz ultravioleta podía generar fotoproductos con estructura cíclica, más tóxicos que el fármaco nativo [43]; resultados similares fueron obtenidos por Isodori et al. [44]. La presencia de subproductos nocivos, también se ha reportado en los procesos de fotodegradación de triclosan y triclocarban [45]. 
Las reacciones Fenton son procesos homogéneos de oxidación, que emplean Fe (II) o Fe (III) en presencia de $\mathrm{H}_{2} \mathrm{O}_{2}$ para la producción de radicales $\mathrm{OH}$. El uso de luz UV puede incrementar la eficiencia de la reacción (proceso foto-Fenton). Distintos fármacos han sido eficientemente degradados por este método de oxidación. Méndez-Arriaga F. et al. estudiaron la degradación de ibuprofeno, antiinflamatorio no esteroideo de uso muy extendido. A 2 horas de reacción, se logró la transformación total del fármaco original y $40 \%$ de su mineralización [46]. González P. et al. reportaron la degradación de sulfametoxazol por medio de un proceso foto-Fenton; encontraron que la degradación y mineralización del fármaco aumenta al incrementarse la concentración de $\mathrm{H}_{2} \mathrm{O}_{2}$, y que los subproductos de reacción no presentan una alta toxicidad [47]. El precursor de Fe empleado es un factor determinante en la eficiencia del proceso. Pereira J.H. O. S. et al. investigaron la degradación de oxitetraciclina por medio de un proceso foto-Fenton, empleando como fuente de iones $\mathrm{Fe}$, nitratos y carboxilatos. Los resultados muestran que el proceso de degradación es más eficiente cuando se emplean carboxilatos, debido a que se evita la formación de complejos entre el antibiótico y los iones Fe; aunado a ello, los subproductos de reacción pierden su efecto antibacterial e incrementan su biodegradabilidad [48]. Similarmente, Trovó A. G. et al. reportaron la degradación de amoxicilina mediante reacciones foto-Fenton, utilizando diferentes sales de Fe. Después de 4 horas de reacción, se pudo degradar más del $70 \%$ del antibiótico empleando oxalatos del metal y se la toxicidad de los productos de reacción decrece paulatinamente [49].

Algunos aspectos desfavorables de los procesos Fenton y foto-Fenton son: i) la producción de gran cantidad de lodos ricos en Fe, 2) control estricto del pH de la reacción y 3) uso de oxidantes de alto costo como $\mathrm{H}_{2} \mathrm{O}_{2}$.

\section{$>$ Ozonización}

El ozono es un potente oxidante que puede atacar moléculas orgánicas de manera indirecta, generación de radicales $\mathrm{OH} \cdot$ mediante su descomposición en agua, o por ataque eléctrofilico directo a ciertos grupos del compuesto orgánico. La eficiencia del proceso se incrementa si se emplea luz UV u otros agentes oxidantes tal como el $\mathrm{H}_{2} \mathrm{O}_{2}$. La tabla 1.2 muestra algunos de los fármacos degradados por ozonización. 
Tabla 1.2. Degradación de algunos fármacos mediante procesos de oxidación avanzada a base de ozono.

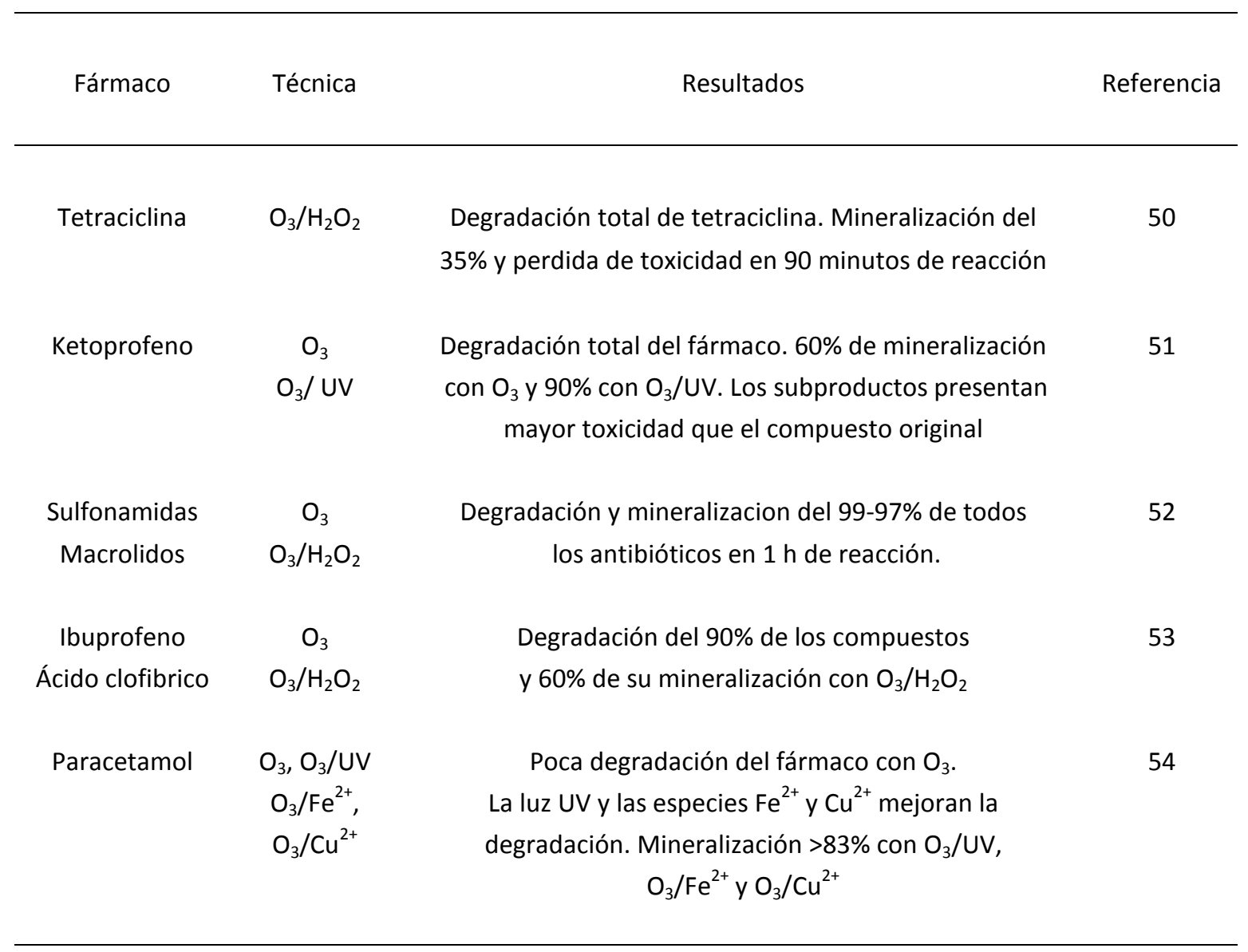

Por esta técnica también han sido degradadas hormonas esteroideas, diclofenaco, metronidazol, penicilina y sulfametoxazol $[10,45]$.

Aunque la ozonización permite la rápida y eficiente degradación de diversos productos farmacéuticos, su aplicación al tratamiento de agua residual, requiere del uso de agentes oxidantes de alto costo $\left(\mathrm{O}_{3}\right.$, $\mathrm{H}_{2} \mathrm{O}_{2}$ ) y del control de pH durante el transcurso de la fotodegradación.

\section{Fotocatálisis}

En los procesos fotocatalíticos, un óxido metálico, por lo regular semiconductor, es irradiado con luz ultravioleta o visible para generar especies reactivas de oxígeno que consecuentemente logren oxidar a los contaminantes orgánicos. Factores tales como la longitud de onda e intensidad de la radiación, pH y 
presencia de materia orgánica u otros agentes oxidantes, pueden mejorar la eficiencia de la degradación. Diversos grupos de fármacos, entre los que se encuentran antinflamatorios, antibióticos, hormonas, y medicamentos cardiovasculares, han sido fotodegradados mediante esta técnica (tabla 1.3) 
Tabla 1.3. Degradación de algunos fármacos mediante procesos fotocatalíticos

$\begin{array}{lll}\text { Fármaco Técnica } & \text { Resultados } & \text { Refencia }\end{array}$

\begin{tabular}{|c|c|c|c|}
\hline $\begin{array}{l}\text { Ibuprofeno, } \\
\text { naproxeno, } \\
\text { diclofenaco }\end{array}$ & $\begin{array}{c}\mathrm{TiO}_{2} / \text { luz solar } \\
\text { artificial }\end{array}$ & $\begin{array}{l}\text { Mineralización del } 80 \% \text { de ibuprofeno y } \\
\text { alrededor de } 26 \% \text { de naproxeno y diclofenaco } \\
\text { en condiciones óptimas de } \mathrm{O}_{2} \text { y carga de } \\
\text { catalizador. Sólo los subproductos de } \\
\text { ibuprofeno tienen un tratamiento postbiologico }\end{array}$ & 55 \\
\hline $\begin{array}{l}\text { Sulfapiridina } \\
\text { sulfacloropiridazina } \\
\text { sulfisoxasol }\end{array}$ & $\mathrm{TiO}_{2} / \mathrm{UV}$ & $\begin{array}{c}\text { Mineralización }>80 \% \text { de los tres fármacos } \\
\text { en } 4 \text { h de reacción. Degradación } \\
\text { via radicales } \mathrm{OH} \text {. }\end{array}$ & 56 \\
\hline Oxitetraciclina & $\begin{array}{l}\mathrm{TiO}_{2} / \text { luz solar artificial } \\
\mathrm{TiO}_{2} / \text { luz solar } \\
\text { Planta piloto }\end{array}$ & $\begin{array}{c}\text { Remoción del } 100 \% \text { y mineralización > 90\% } \\
\text { sistemaTiO2/luz solar artificial y } 80 \% \text { para } \\
\text { planta piloto. Los productos de reacción son } \\
\text { biodegradables y de menor toxicidad }\end{array}$ & 32 \\
\hline Carbamazepina & $\mathrm{TiO}_{2} /$ luz UV & $\begin{array}{c}90 \% \text { de remoción y } 74 \% \text { de mineralización } \\
\text { del fármaco después de } 90 \text { minutos de reacción } \\
\text { bajo condiciones óptimas de pH y carga } \\
\text { de catalizador }\end{array}$ & 57 \\
\hline Tetraciclina & $\mathrm{Sr}-\mathrm{Bi}_{2} \mathrm{O}_{3} /$ luz visible & $\begin{array}{c}\text { Remoción del } 91.2 \% \text { del fármaco en } 2 \mathrm{~h} \\
\text { de irradiación. Subproductos menos tóxicos } \\
\text { que la molécula objetivo }\end{array}$ & 58 \\
\hline Atenolol & $\mathrm{TiO}_{2} / \mathrm{UV}$ & $\begin{array}{l}\text { Remoción total del fármaco en } 60 \text { minutos de } \\
\text { reacción. Probable formación de intermediarios } \\
\text { más estables. Mineralización del 70\% después } \\
\text { de } 6 \text { h de irradiación }\end{array}$ & 59 \\
\hline $\begin{array}{c}\text { Estrona } \\
\beta \text {-estradiol }\end{array}$ & $\mathrm{TiO}_{2} / \mathrm{UV}$ & $\begin{array}{l}\text { Remoción del } 97 \% \text { de las hormonas en } 4 \text { horas } \\
\text { de reacción con lámpara de } 150 \text { W y 98\% con } \\
\text { lámpara de } 15 \mathrm{~W} \text { en } 1 \mathrm{~h} \text {. } \mathrm{pH} \text {, cantidad de } \\
\text { materia orgánica y carga de catalizador } \\
\text { facilitan la fotodegradación de la molécula }\end{array}$ & 60 \\
\hline
\end{tabular}


De acuerdo a los resultados reportados, la fotocatálisis de fármacos es altamente eficiente no solo en la degradación de estas sustancias sino también en su transformación en $\mathrm{CO}_{2}, \mathrm{H}_{2} \mathrm{O}$ y ácidos inorgánicos; diversas investigaciones han mostrado que los productos farmacéuticos, pueden removerse del agua hasta un $100 \%$ y, en un número considerable de casos, se ha logrado poco más del $70 \%$ de su mineralización.

Esta técnica de oxidación avanzada, también ofrece amplias ventajas respecto a otros AOP's. Por ejemplo, su aplicación es en condiciones ambientales y los materiales empleados como catalizadores suelen ser sustancias inocuas. Aunado a lo anterior, la búsqueda de la optimización del proceso ha llevado al uso de fuentes de energía renovables tal como la luz solar. Pese a que el uso de esta técnica a nivel industrial implicaría un tratamiento adicional para la remoción del sólido, se han propuesto algunas soluciones, tal como el uso simultaneo de membranas de separación o la inmovilización del catalizador en determinadas matrices.

No obstante que, materiales distintos al $\mathrm{TiO}_{2}$ han sido probados en reacciones de fotodegradación, los resultados obtenidos han exhibido sólo un ligero incremento en la eficiencia del proceso [10]; por ello, se continúan explorando nuevas rutas para la síntesis de nuevos catalizadores altamente eficaces, amigables con el ambiente y cuya preparación sea preferentemente de bajo costo.

\subsection{Procesos de oxidación avanzada}

Los procesos de oxidación avanzada son un tipo especial de técnicas de oxidación, generalmente realizadas a temperatura y presión ambiente, caracterizadas por la formación de radicales $\mathrm{OH} \cdot$, los cuales sucesivamente, interaccionan con las moléculas orgánicas del medio [61-64]. El objetivo principal de los proceso de oxidación avanzada, es la completa mineralización de los compuestos orgánicos, es decir su transformación a $\mathrm{CO}_{2}, \mathrm{H}_{2} \mathrm{O}$ y ácidos minerales, empleando radicales $\mathrm{OH}$. Aunque su tiempo de vida media es muy corto, estas especies son extraordinariamente reactivas (potencial de oxidación 2.80 V) y poco selectivas al ataque, lo cual permite la oxidación de una gran variedad de contaminantes, incluidos aquellos que presentan una alta estabilidad química.

Los procesos de oxidación avanzada engloban diversas técnicas cuya diferencia radica en la forma de producción de los radicales $\mathrm{OH}$. De acuerdo a las condiciones de los sistemas de reacción empleados para la generación de estas especies, los AOP se clasifican en [65]: 
Procesos homogéneos con aporte de energía

a) Radiación ultravioleta

$>$ Ozono-UV $\left(\mathrm{O}_{3} / \mathrm{UV}\right)$

$>$ Peróxido de hidrógeno-UV $\left(\mathrm{H}_{2} \mathrm{O}_{2} / \mathrm{UV}\right)$

$>$ Ozono-peróxido de hidrógeno-UV $\left(\mathrm{O}_{3} / \mathrm{H}_{2} \mathrm{O}_{2} / \mathrm{UV}\right)$

$>$ Foto-Fenton $\left(\mathrm{Fe}^{2+} / \mathrm{H}_{2} \mathrm{O}_{2} / \mathrm{UV}\right)$

b) Radiación ultrasónica

$>$ Ozono-US $\left(\mathrm{O}_{3} / \mathrm{US}\right)$

$>$ Peróxido de hidrógeno-US $\left(\mathrm{H}_{2} \mathrm{O}_{2} /\right.$ US $)$

Procesos homogéneos sin aporte de energía

$>$ Ozonización en medio alcalino $\left(\mathrm{O}_{3} / \mathrm{OH}^{-}\right)$

$>$ Ozonización con peróxido de hidrógeno $\left(\mathrm{O}_{3} / \mathrm{H}_{2} \mathrm{O}_{2}\right)$ y $\left(\mathrm{O}_{3} / \mathrm{H}_{2} \mathrm{O}_{2} / \mathrm{OH}^{-}\right)$

$>$ Proceso Fenton $\left(\mathrm{H}_{2} \mathrm{O}_{2} / \mathrm{Fe}^{2+}\right)$

Procesos heterogéneos con aporte de energía

$>$ Ozonización fotocatalítica $\left(\mathrm{O}_{3} /\right.$ fotocatalizador/UV)

$>$ Fotocatálisis heterogénea (fotocatalizador/UV), (fotocatalizador $/ \mathrm{H}_{2} \mathrm{O}_{2} / \mathrm{UV}$ )

Procesos heterogéneos sin aporte de energía

$>$ Ozonización catalítica $\left(\mathrm{O}_{3} /\right.$ catalizador $)$

Cada una de estas técnicas oxidativas requiere de condiciones específicas para la formación de radicales $\mathrm{OH} \cdot \mathrm{y}$, aunque son muy eficaces en la eliminación de contaminantes orgánicos recalcitrantes, su alta demanda de energía y el uso de reactivos costosos suscita que estas técnicas de oxidación se apliquen previa o posteriormente a los tratamientos biológicos tradicionales.

Entre la variedad de procesos de oxidación avanzada que se conocen hasta ahora, la fotocatálisis heterogénea es probablemente uno de los campos en el cual, se han logrado diversos avances sustanciales en los últimos 40 años. A diferencia de otros procesos AOP's, la fotocatálisis heterogénea no es una técnica selectiva por lo cual puede aplicarse en el tratamiento de agua residual con mezclas de contaminantes; los materiales empleados como catalizadores, generalmente semiconductores, no son tóxicos y su síntesis puede ser de bajo costo; la operación de los sistemas fotocatalíticos es simple y la posibilidad del uso de radiación solar como fuente de energía, le otorga un valor como tecnología 
sustentable. A pesar de todos los adelantos conseguidos en el estudio de los procesos fotocatalíticos, su aplicación industrial no ha sido posible, debido al elevado costo energético que representa el uso de lámparas UV-Vis.

\subsection{Fotocatálisis}

El termino fotocatálisis apareció por vez primera en 1911; Eibner, en Alemania incorporo el concepto en su investigación sobre el efecto de la iluminación de ZnO en la decoloración del azul de Prusia. Más recientemente, este nuevo concepto se utilizó en algunos estudios que exploraban la oxidación de compuestos orgánicos por medio de sólidos inorgánicos radiados con luz [66]. Pese a lo novedoso de aquellas publicaciones, el interés en este tipo de procesos decayó por más de dos décadas. A mediados de los años 30's, se realizaron nuevos estudios sobre reacciones fotocatalíticas, entre las cuales se encontraba una investigación sobre el uso del $\mathrm{TiO}_{2}$ en el blanqueamiento de algunos colorantes en presencia de $\mathrm{O}_{2}$. Debido a la falta de aplicaciones prácticas, la inclinación hacia esta ciencia emergente disminuyó considerablemente. En la década de los años 60's, los procesos fotocatalíticos nuevamente cobraron importancia y los materiales $\mathrm{TiO}_{2}$ y $\mathrm{ZnO}$ fueron estudiados con mayor profundidad en la fotooxidación de ciertas moléculas orgánicas.

En 1970, el aumento en los precios del crudo desato una "crisis petrolera" a nivel mundial, que llevo a diversos países a la búsqueda de fuentes de energía alternas. En ese contexto, dos investigadores japoneses, Fujishima y Honda, publicaron en 1972 la fotólisis electroquímica de agua, utilizando un electrodo de rutilo expuesto a radiación ultravioleta cercana [67]. Esta investigación abrió nuevas vías

para la producción de $\mathrm{H}_{2}$ a partir de recursos abundantes y económicos como lo son el agua y la luz solar y represento el evento inicial que globalizó el estudio de la fotocatálisis. Actualmente más de 1000 artículos sobre procesos fotocatalíticos son publicados anualmente [68].

De acuerdo a la Unión Internacional de Química Pura y Aplicada (IUPAC) la fotocatálisis es definida como [69] "el cambio en la velocidad de una reacción química o su iniciación bajo la acción de radiación ultravioleta, visible o infrarroja en la presencia de una sustancia - el fotocatalizador-que absorbe luz y participa en la transformación química de los participantes de la reacción". Por su parte un fotocatalizador es "un catalizador capaz de producir, bajo la absorción de luz, transformaciones químicas en los participantes de una reacción. El estado excitado de un fotocatalizador, interacciona 
repetidamente con los participantes de la reacción formando intermediarios de reacción y regenerándose después de cada ciclo de tales interacciones".

La reacciones fotocatalíticas pueden realizarse en diversos medios: fases líquidas orgánicas, fase gas y en medios acuosos. Al igual que en la catálisis heterogénea convencional, el proceso global puede dividirse en 5 pasos, siendo la activación del catalizador, paso 3, la principal diferencia entre estas dos disciplinas $[68,70]$ :

1.- Transferencia de los reactantes del fluido (líquido o gas)

2.- Absorción de los reactantes sobre la superficie del catalizador

3.- Reacción fotocatalítica:

a) absorción de fotones por parte del fotocatalizador

b) generación de pares electrón-hueco

c) reacciones de transferencia electrónica (neutralización de carga, formación de especies reactivas de oxígeno, reacciones de superficie)

4.- Desorción de los productos finales

5.- Transferencia de los productos de reacción al fluido.

En la interfase fluido-sólido, la reacción de transferencia de electrón puede realizarse de 4 formas diferentes: I) el radical y el sustrato pueden estar adsorbidos, II) un sustrato adsorbido reacciona con un radical en solución, III) el radical adsorbido reacciona con el sustrato en solución y IV) la reacción ocurre con ambas especies en solución [71]. 
Aunque, debido a su versatilidad, la fotocatálisis se ha aplicado en una gran variedad de reacciones que incluyen transferencia de hidrógeno, deposición de metales, remoción de contaminantes gaseosos, síntesis orgánica fina y producción de $\mathrm{H}_{2}$ por water splitting, uno de sus mayores usos ha sido en el campo de la oxidación de contaminantes orgánicos en medio acuoso. En estos procesos oxidativos, radicales $\mathrm{OH} \cdot$, generados mediante el uso de semiconductores y radiación ultravioleta o visible, fragmentan la molécula orgánica en compuestos de menor peso molecular hasta su completa transformación a $\mathrm{CO}_{2}, \mathrm{H}_{2} \mathrm{O}$ y ácidos

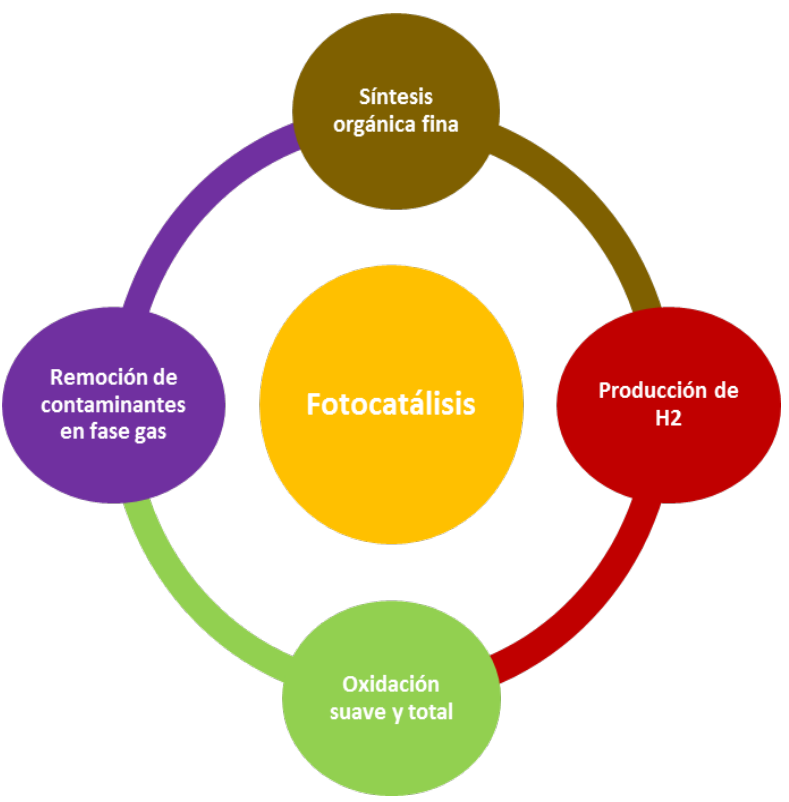

Fig. 1.6. Algunas aplicaciones de los procesos fotocatalíticos

minerales

La reacción de fotodegradación comienza con la absorción de radiación electromagnética por parte del catalizador y la consecuente formación de pares electrón-hueco. Los electrones generados reducen al oxígeno molecular disuelto en el medio, mientras que los huecos pueden oxidar moléculas de agua o iones $\mathrm{OH}^{-}$a radicales $\mathrm{OH} \cdot$. La alta reactividad de este radical permitirá la degradación del contaminante orgánico y de los subproductos de reacción que se formen a lo largo de la reacción. Las moléculas del compuesto orgánico que estén adsorbidas en el catalizador pueden ser directamente oxidadas por una transferencia de electrón. Este mecanismo de oxidación ha sido propuesto mediante el estudio a profundidad de sistemas fotocatalíticos con $\mathrm{TiO}_{2}$, el cual es hasta ahora uno de los materiales más comúnmente empleados debido a su bajo costo, estabilidad y eficacia. El proceso de fotodegradación catalítica con óxido de titanio puede representarse por medio de las siguientes ecuaciones: 


$$
\begin{aligned}
& \mathrm{TiO}_{2} \stackrel{h v}{\rightarrow} e^{-}+h^{+} \\
& \mathrm{TiO}_{2}\left(h^{+}\right)+\mathrm{H}_{2} \mathrm{O} \rightarrow \mathrm{TiO}_{2}+\mathrm{OH} \bullet+H^{+} \\
& \mathrm{TiO}_{2}\left(h^{+}\right)+\mathrm{OH}^{-} \rightarrow \mathrm{TiO}_{2}+\mathrm{OH} \bullet \\
& \mathrm{TiO}_{2}\left(h^{+}\right)+X_{a d} \rightarrow \mathrm{TiO}_{2}+\mathrm{X} \bullet
\end{aligned}
$$

donde $X$ representa aquellas moléculas del contaminante que están adsorbidas. Algunos factores físicos tales como la masa del catalizador, la longitud de onda de excitación, temperatura, flujo radiante y concentración y naturaleza del contaminante, afectan de manera directa el proceso de fotodegradación, por lo que la optimización de estos parámetros es clave para la eficiencia global del proceso.

\section{Masa de catalizador}

Independientemente de la configuración del reactor, la velocidad inicial de los procesos fotocatalíticos es directamente proporcional a la masa, $m$, del catalizador (fig. 2.7-A). Sin embargo, después de un determinado valor de $\mathrm{m}$, la reacción deja de ser dependiente de éste parámetro. Un exceso de catalizador provoca un efecto pantalla, en el cual se impide la absorción efectiva de fotones.

\section{$>$ Longitud de onda}

La longitud de onda de la radiación incidente, es otro parámetro que afecta la velocidad de una reacción fotocatalítica. La variación de $r$ en función de la longitud de onda, $\lambda$, es coincidente con el espectro de absorción del fotocatalizador (fig. 1.7-B), el cual presenta un umbral correspondiente a su energía de banda prohibida.

\section{Temperatura}

Uno de los aspectos más atractivos de los procesos fotocatalíticos, especialmente de aquellos dirigidos a la degradación de contaminantes orgánicos, es que, en el intervalo de temperatura de $20^{\circ} \mathrm{C} \leq \theta \leq$ $80^{\circ} \mathrm{C}$, su energía de activación es muy pequeña por lo que no requieren energía adicional (calentamiento) a la activación fotónica y pueden ser realizados a temperatura ambiente. Por debajo 
de los $20^{\circ} \mathrm{C}$, los productos generados pueden ser adsorbidos con facilidad e inhibir sitios activos del catalizador, lo cual genera un decremento en la velocidad de reacción. Temperaturas superiores a los $80^{\circ} \mathrm{C}$ incrementan la recombinación electrón-hueco, provocando una disminución en la actividad fotocatalítica (fig. 1.7-D).

\section{Flujo radiante.}

Uno de los factores determinantes en la velocidad $r$ de un proceso fotocatalítico es la formación de pares electrón-hueco, los cuales se generan a partir de la interacción entre flujo radiante, representado por $\phi$, y el fotocatalizador. Se ha encontrado que la velocidad de una reacción fotocatalítica es directamente proporcional a $\phi$, hasta un determinado valor en el cual se vuelve proporcional a $\phi^{1 / 2}$ (fig. 1.7-E) La disminución de la actividad fotocatalítica a flujos radiantes altos se debe a que la recombinación hueco-electrón se vuelve significativa, por lo cual la formación de especies reactivas de oxigeno disminuye [72].

Naturaleza y Concentración del reactante.

Tradicionalmente se ha reportado que la mineralización fotocatalítica de moléculas orgánicas se ajusta al modelo cinético de Langmuir-Hinshelwood $(L-H)$, el cual establece que la velocidad $\boldsymbol{r}$ de una reacción en régimen heterogéneo, depende de la fracción de superficie catalítica que se encuentra cubierta por el compuesto orgánico. Su expresión matemática es:

$$
r=k \theta=k\left(\frac{K C}{1+K C}\right)
$$

donde $k$ es la constante de velocidad de la reacción, $\theta$ es el grado de recubrimiento, $K$ la constante de adsorción del adsorbato y $C$ la concentración del sustrato. El grado de recubrimiento del catalizador dependerá de la concentración del compuesto orgánico así como de su capacidad para adherirse a la superficie catalítica. En general, se ha encontrado que la velocidad de reacción es linealmente dependiente a la concentración del sustrato, hasta un determinado valor en el cual la eficiencia de la reacción fotocatalítica comienza a decaer, debido a que la cantidad de especies reactivas de oxígeno, permanece constante a un determinado valor de longitud de onda y masa de catalizador, por lo que a concentraciones altas de una molécula objetivo, la cantidad de especies reactivas de oxigeno se vuelve inadecuada para interaccionar con la molécula objetivo. Aunado a lo anterior, el incremento en la 
concentración del sustrato puede ocasionar la formación de intermediarios que se adhieren a la superficie catalítica. Si la difusión de éstos es lenta, sitios activos del sólido se desactivarán y la eficiencia en la fotodegradación decrecerá (fig. 1.7-C).

La naturaleza de las moléculas orgánicas también influye en la eficiencia de un proceso fotocatalítico; investigaciones realizadas sobre la influencia de grupos sustituyentes en la fotodegradación de compuestos orgánicos aromáticos empleando $\mathrm{TiO}_{2}$, mostraron que las moléculas con sustituyentes electro-atractores se adsorben con mayor facilidad sobre la superficie de catalizador que aquellas que poseen grupos electro-donadores. Este fenómeno se ve reflejado en una mayor eficiencia en la fotodegradación de los compuestos con grupos electro-atractores [71].
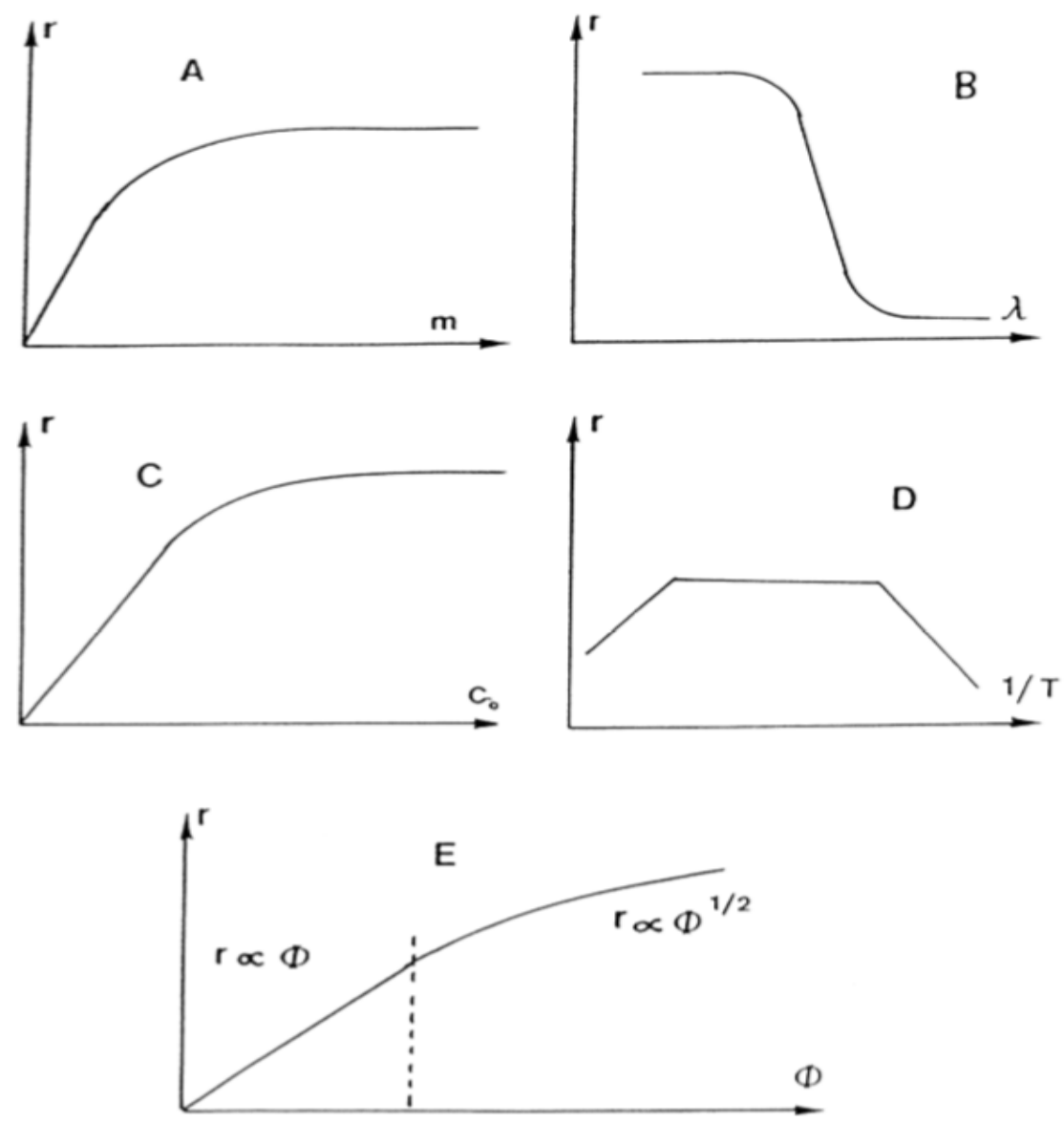

Figura 1.7. Influencia de diversos parámetros físicos en la velocidad de reacción $r$ de un proceso fotocatalítico, a) masa del catalizador, b) longitud de onda, c) concentración de la molécula diana, d) temperatura y e) flujo radiante. Imagen tomada de [70] 
Uno de los aspectos más importantes en los procesos fotocatalíticos, es la eficiente absorción de fotones por parte del material y las subsecuentes reacciones que ocurren en la interfase solido-líquido; debido a lo anterior, existe un gran número de investigaciones enfocadas en el diseño y/o mejoramiento de los fotocatalizadores. Los sólidos semiconductores, generalmente óxidos metálicos y calcogenuros, han sido hasta ahora los materiales más comúnmente empleados, a razón de su estructura electrónica, la cual les confiere potenciales adecuados para su participación en reacciones redox y la posibilidad de ser activados rápidamente mediante radiación electromagnética.

\subsubsection{Semiconductores}

Desde la aparición de los primeros estudios sobre procesos fotocatalíticos hasta la actualidad, los sólidos semiconductores han sido los materiales más empleados como fotocatalizadores, ya que además de poseer un amplio espectro de absorción con coeficientes de extinción altos, sus propiedades ópticas pueden ser fácilmente alteradas mediante diversas técnicas tales como el uso de sensibilizadores, el dopaje con metales y no metales, la dispersión del semiconductor en soportes y la formación de materiales compuestos.

Los sólidos semiconductores están constituidos por una amplia gama de materiales que van desde los

elementos ( $\mathrm{Si}, \mathrm{Ga}, \mathrm{Ge}, \mathrm{C}$ ) hasta óxidos y calcogenuros. Estos sólidos inorgánicos presentan una conductividad eléctrica menor que la de los conductores metálicos pero superior a la de los aislantes. Esta propiedad en particular puede ser explicada cualitativamente mediante la estructura de bandas. 
Cuando los átomos están muy próximos entre sí, como ocurre en un cristal, sus orbitales se traslapan y forman una serie de estados deslocalizados cuya separación es muy pequeña dando como resultado la formación de bandas que contienen estados energéticos que los electrones pueden ocupar. Entre estas bandas existen estados energéticos "no permitidos" que en su conjunto forman una banda de energía prohibida (band gap $\circ E_{g}$ ). La banda que se encuentra limitando la parte inferior del gap recibe el nombre de banda de valencia mientras que aquella que se encuentra en la parte superior es conocida como banda de conducción (fig 1.8).

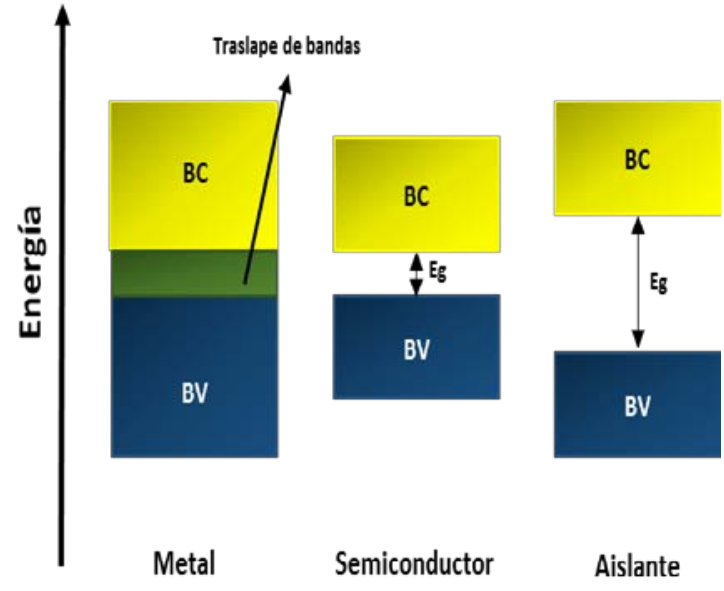

Fig. 1.8. Representación idealizada de la estructura de bandas de metales, semiconductores y aislantes (BC es la banda de conducción mientras que BV es la banda de valencia.

En el estado fundamental y a $\mathrm{O} \mathrm{K}$, los electrones ocupan estados electrónicos hasta un determinado valor de energía $\mathrm{E}_{\mathrm{f}}$ (Energía de Fermi). La posición de $\mathrm{E}_{\mathrm{f}}$ con respecto a la banda de valencia y la banda de conducción distingue a los conductores de los semiconductores y aislantes: para los primeros la energía de Fermi se encuentra dentro de la banda de conducción, mientras que para los semiconductores y aislantes $E_{f}$ se localiza en la banda de energía prohibida. El ancho de la banda de energía prohibida, es la característica fundamental que diferencia a los semiconductores de los aislantes: para los semiconductores, el valor de $\mathrm{Eg}$ es lo suficientemente pequeño para promover electrones, térmica o fotónicamente, de la banda de valencia a la banda de conducción. Los valores superiores de Eg en los materiales aislantes, impiden que ocurra este fenómeno.

A diferencia de los sólidos conductores, la capacidad de transporte de carga eléctrica en un material semiconductor es producto de dos fenómenos que ocurren conjuntamente: por una parte, los electrones promovidos que se encuentran en la banda de conducción pueden moverse con facilidad a estados energéticos vacíos; por otro lado, las vacancias o "huecos" generados en la banda de valencia por el salto de electrones a la banda de conducción, pueden ser ocupados por otros electrones que se ubican en dicha banda [66, 73, 74]. A $0 \mathrm{~K}$ la densidad de portadores de carga es nula y el material es prácticamente un aislante. Un aumento en la temperatura ocasiona la promoción de electrones de la 
banda de valencia a la banda de conducción, produciéndose un aumento en la concentración de electrones en BC y de huecos en BV.

\subsubsection{Tipos de semiconductores}

La adición de una pequeña cantidad de impurezas a la red cristalina de un semiconductor, puede cambiar de manera sustancial sus propiedades electrónicas. El material "contaminado" o "dopado" es descrito como extrínseco, denominación que permite su distinción de aquellos semiconductores puros o intrínsecos.

El dopaje de un material semiconductor, crea niveles energéticos adicionales que caen dentro de la banda de energía prohibida. La localización de estos niveles depende de la naturaleza de los átomos sustituyentes: si se introducen especies donadoras, es decir átomos con una valencia mayor que aquella que poseen las partículas en el material intrínseco, se forman niveles energéticos próximos a la banda de conducción. A temperaturas mayores de $0 \mathrm{~K}$, los electrones que se encuentran en éstos estados son excitados y pasan a la banda de conducción, produciéndose un aumento en la conductividad debido al incremento de electrones o portadores de carga negativa, por lo cual estos materiales reciben el nombre de

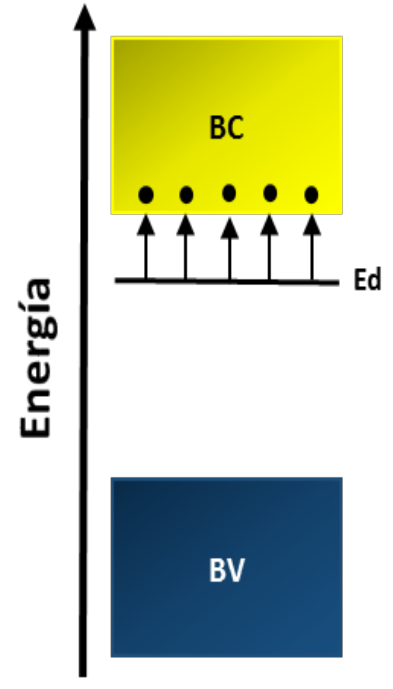

Semiconductor tipo $n$
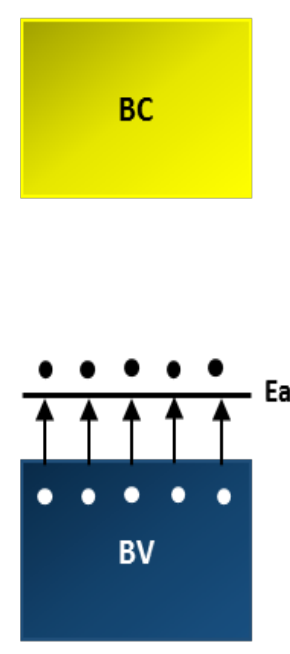

Semiconductor tipo $p$

Fig. 1.9. Donación de electrones de un nivel donador para la formación de semiconductor tipo n. Aceptación de electrones de la BV por un nivel aceptor para la formación de semiconductor tipo $p$. semiconductores tipo $n$ (Fig. 1.9).

Por otra parte, si el sólido es modificado con especies aceptoras, átomos con valencias menores, se introducen niveles energéticos localizados en la parte superior de la banda de valencia. Con un pequeño incremento en la energía térmica, los electrones de BV son excitados a estos estados energéticos, aumentando la densidad de huecos o portadores de carga positiva. El material resultante recibe el nombre de semiconductor tipo $p$ (fig. 1.9). 


\subsubsection{Mecanismo del proceso fotocatalítico}

La construcción de un sistema fotocatalítico bien definido, requiere de la identificación y clarificación de los mecanismos por los cuales se generan los pares electrón-hueco y el proceso que tiene lugar, hasta que estos portadores de carga son transferidos a moléculas aceptoras o donadoras para desencadenar reacciones químicas.

Como se mencionó anteriormente, las reacciones fotocatalíticas comienzan cuando fotones de igual o mayor energía que la Eg son absorbidos por el material. Esta radiación promueve electrones de la banda de valencia a la banda de conducción, fenómeno que genera huecos en BV. Las cargas fotoinducidas pueden recombinarse en el interior o en la superficie del fotocatalizador liberando energía como calor o pueden migrar para reaccionar con las especies adsorbidas. La recombinación disminuye abruptamente las cargas activas disponibles para las reacciones fotocatalíticas; este proceso puede ser limitado mediante la variación de algunas propiedades del material, tales como la estructura cristalina, el tamaño de partícula y la cristalinidad. Las cargas que lleguen a la superficie serán transferidas a las sustancias químicas adsorbidas: los electrones reducirán a especies aceptoras, mientras que los huecos se combinan con un electrón proveniente de una especie donadora (fig. 1.10). Estos eventos constituyen la base de los procesos fotocatalíticos, ya que a partir de ellos se desencadenan reacciones de rompimiento y/o formación de enlaces químicos [75-77].

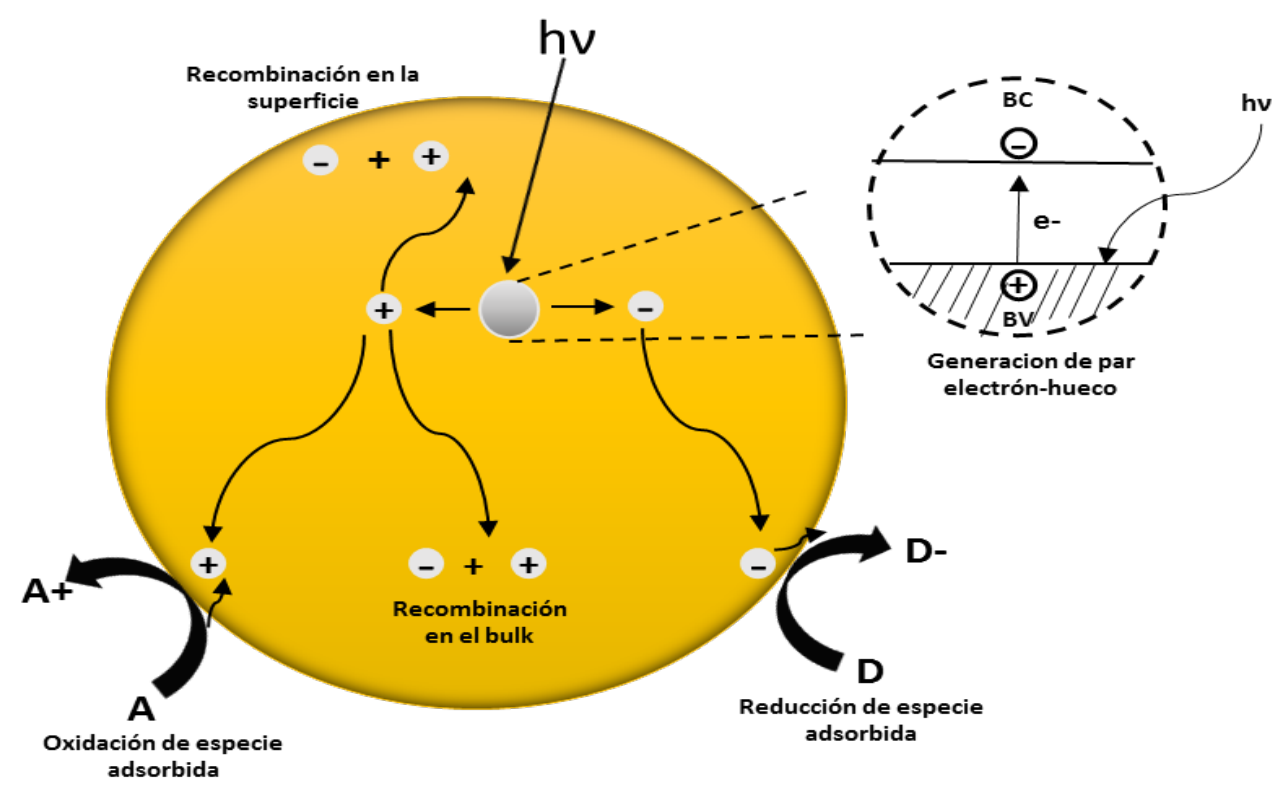

Fig. 1.10. Mecanismo fotocatalítico en partículas semiconductoras. Imagen adaptada de [66] 
Las reacciones de transferencia de carga, requieren de la interacción entre las bandas de valencia y conducción del material y los potenciales de reducción de las especies adsorbidas. Así una sustancia puede ser reducida por un electrón del sólido si su potencial redox es más positivo que el de la banda de conducción, en tanto que la banda de valencia debe ser más negativa para que un hueco oxide a la especie adsorbida [75, 78]. La figura 1.11 muestra la energía de banda prohibida con respecto al electrodo normal de hidrógeno para algunos semiconductores.

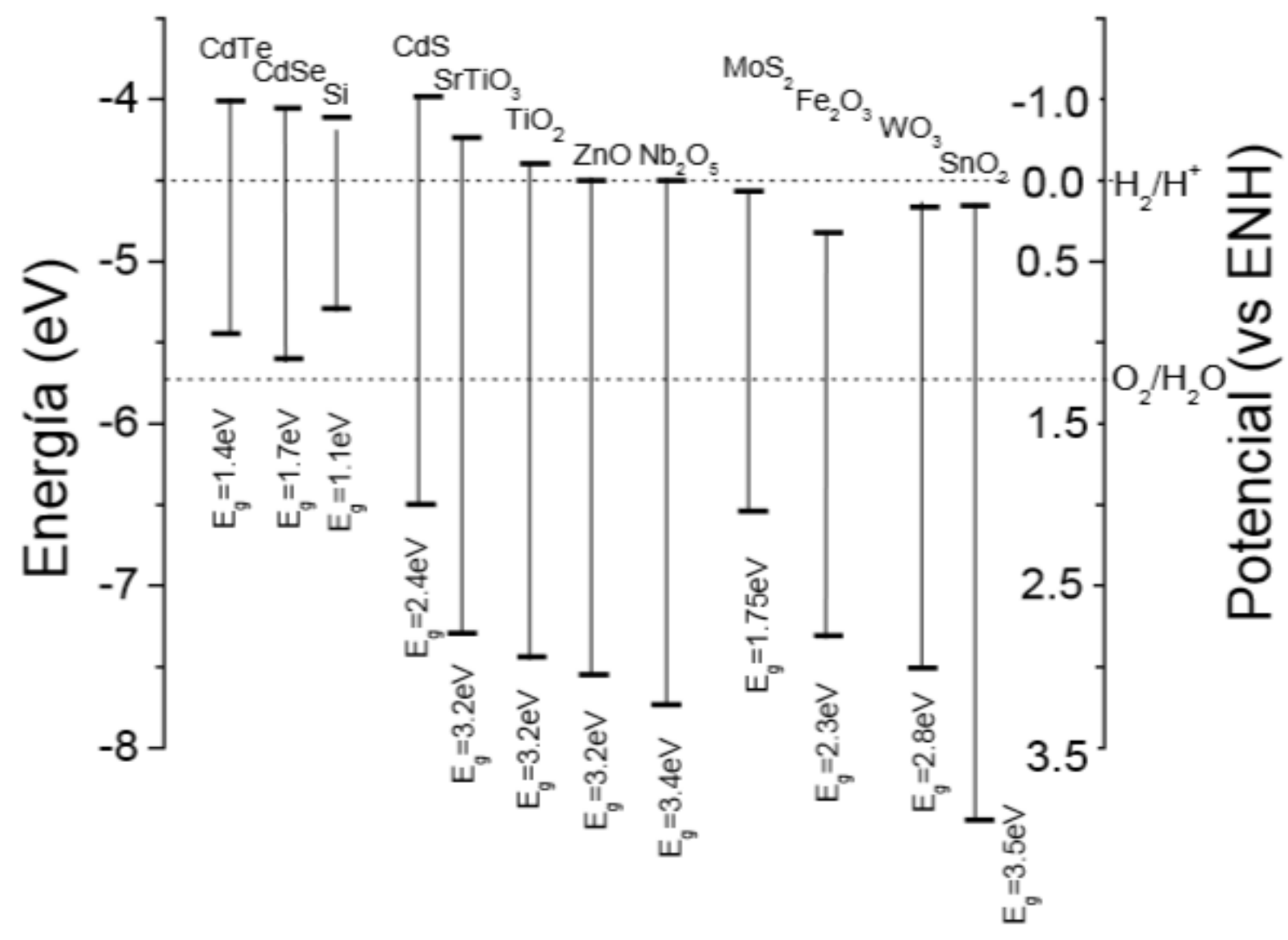

Fig. 1.11. Posición relativa de las bandas de valencia y conducción de algunos semiconductores respecto al electrodo normal de hidrogeno. Imagen tomada de [78].

De acuerdo a la posición de sus bandas de valencia y conducción, los óxidos con métales de transición pueden ser eficientes en reacciones de fotooxidación, no obstante su actividad catalítica es muy limitada en procesos de reducción. En contraste, algunos sulfuros tienen un poder de reducción alto, lo que les permite ser empleados con éxito en reacciones de reducción del agua. Por último, ciertos 
semiconductores poseen un poder de reducción y oxidación lo suficientemente fuerte que los hace adecuados para participar en ambos tipos de reacciones.

Aunque el $\mathrm{TiO}_{2}$ ha sido el semiconductor más comúnmente empleado en procesos fotocatalíticos, en años recientes se han diseñado un gran número de nuevos fotocatalizadores, entre los que se encuentran los hidróxidos dobles laminares. Debido a sus propiedades físicas, tales como área superficial grande, alta capacidad de intercambio aniónico y basicidad, estas arcillas aniónicas se han utilizado en diversas reacciones catalíticas convencionales. Pese a que su uso como fotocatalizadores es aún incipiente, han mostrado una alta eficiencia en la fotodegradación de algunos contaminantes orgánicos, por lo que pueden ser materiales promisorios para aplicaciones fotoquímicas.

\subsection{Hidróxidos dobles laminares}

El término hidróxidos dobles laminares (LDH’s por sus siglas en inglés), arcillas aniónicas o materiales tipo hidrotalcita, es aplicado a una serie de sólidos naturales o sintéticos caracterizados por contener laminas hidróxiladas con dos o más tipos de cationes metálicos y en cuyo dominio interlaminar se encuentran especies anionicas. Aunque el hallazgo de estos materiales tiene más de 150 años (descubrimiento de la hidrotalcita en Suecia, 1842), no fue sino hasta la década de los años 60's que, con base a estudios de difracción de rayos $\mathrm{X}$, sus principales características estructurales fueron conocidas. A partir de entonces, se han realizado diversas investigaciones teóricas y experimentales que han evidenciado detalles más precisos sobre la estructura de estos materiales, tal como los posibles intervalos de composición y estequiometria, la simetría del apilamiento de las láminas hidróxiladas y el arreglo de aniones y moléculas de agua en el espacio interlaminar.

\subsubsection{Propiedades estructurales}

La estructura básica de los hidróxidos dobles laminares, cuya fórmula general es $\left[\mathrm{M}^{\prime \prime}{ }_{1-x} \mathrm{M}^{\prime \prime \prime}{ }_{x}(\mathrm{OH})_{2}\right]^{x+}\left[\mathrm{A}^{\mathrm{n}-}\right.$ ]$_{x / n} \cdot y \mathrm{H}_{2} \mathrm{O}$, es similar a aquella que presenta la brucita, $\mathrm{Mg}(\mathrm{OH})_{2}$; en ella, los cationes divalentes $\mathrm{Mg}^{2+}$ se encuentran octaédricamente coordinados por iones $\mathrm{OH}^{-}$. Las unidades octaédricas comparten aristas dando paso a la formación de hojas infinitas, las cuales a su vez, se apilan una sobre otra y se mantienen unidas mediante enlaces de puente de hidrógeno. Los hidróxidos dobles laminares se forman a partir de la sustitución isomórfica de algunas especies $\mathrm{M}^{2+}$ por cationes de valencia superior pero de radio iónico 
similar. Esta sustitución genera una carga positiva en las láminas hidróxiladas, y es compensada por aniones que se localizan en la zona interlaminar, donde también se encuentran moléculas de agua (fig. 1.12).
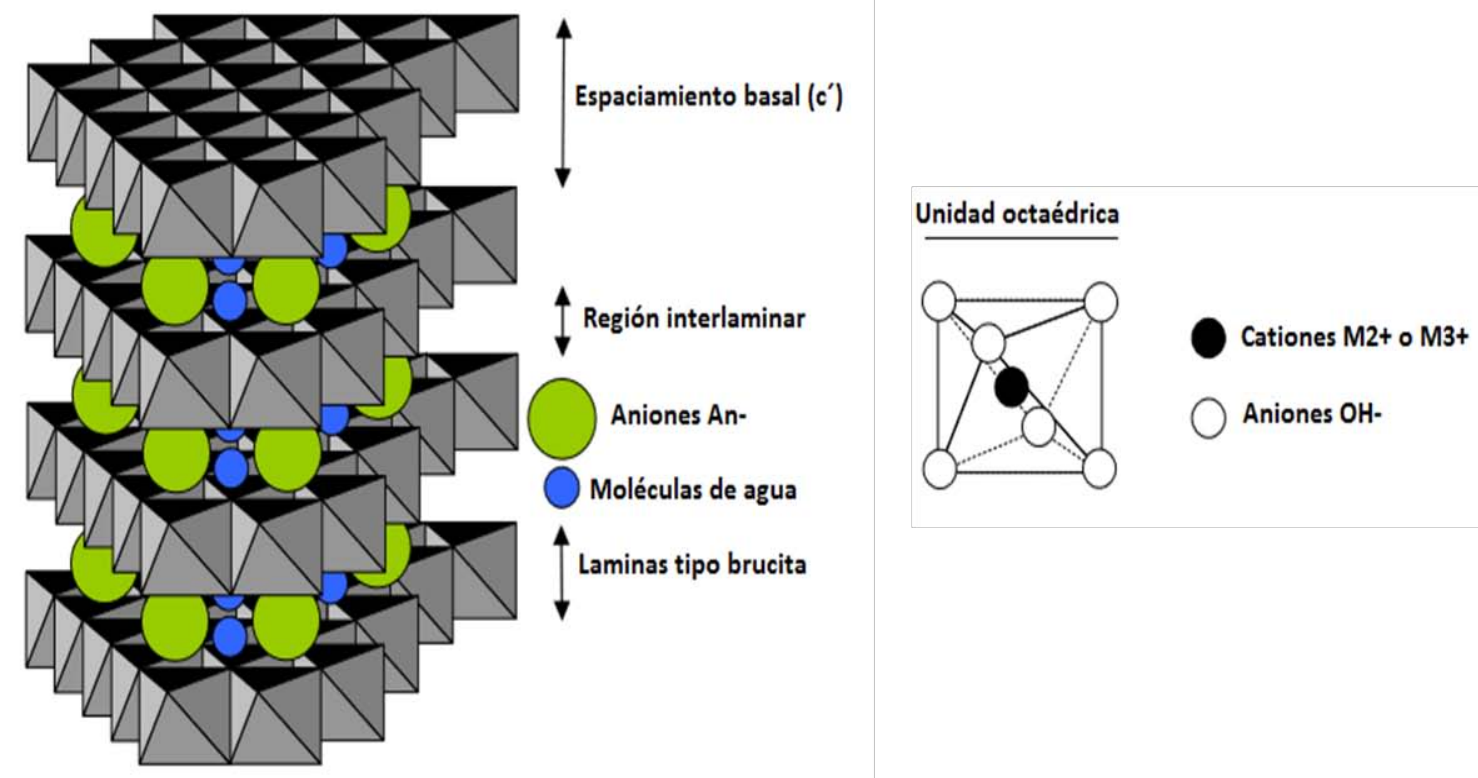

Fig. 1.12. Representación esquemática de la estructura de los hidróxidos dobles laminares. Imagen tomada de [14]

La posibilidad de modificar diversos parámetros estructurales, ha facilitado la síntesis de un gran número de LDH's, cuyas principales características quedan determinadas por la naturaleza de los cationes divalentes y trivalentes, la razón molar $\mathrm{M}^{\prime \prime} / \mathrm{M}^{\prime \prime \prime}$, los aniones en la región interlaminar y el tipo de apilamiento de las láminas hidroxiladas. 


\subsubsection{Naturaleza de los cationes $M^{\prime \prime}$ y $M^{\prime \prime \prime}$}

Los cationes metálicos $M^{\prime \prime}$ y $M^{\prime \prime \prime}$ que pueden formar estructuras tipo hidrotalcita, poseen un radio iónico similar al de la especie $\mathrm{Mg}^{2+}$. Aunque existe una gran variedad de especies que pueden colocarse en los espacios octaédricos de las láminas tipo brucita, el intervalo de radio iónico para cationes divalentes es de 0.65-0.80 ̊̊, mientras que, con excepción del $\mathrm{Al}^{3+}$, el intervalo para iones trivalentes es de 0.62-0.69 (Tabla 1.4)
Tabla 1.4. Radio iónico de los cationes metálicos más comunes empleados en las síntesis de LDH's [13].

\begin{tabular}{cc|cc}
\hline \multicolumn{2}{c|}{$M^{\prime \prime}(\AA ̊)$} & \multicolumn{2}{|c}{$M^{\prime \prime \prime}(\AA ̊)$} \\
\hline
\end{tabular}

No siempre los valores absolutos del radio iónico garantizan la sustitución isomórfica de especies M"; tal es el caso del $\mathrm{Cu}^{2+}$, el cual sufre distorsiones Jahn- Teller, que generan estructuras con octaedros distorsionados. El empleo de otro catión divalente, permite la separación de los iones $\mathrm{Cu}^{2+}$ y la consiguiente formación de la fase cristalina LDH.

La inserción de cationes con una marcada diferencia en tamaño respecto a la especie $M^{\prime \prime}$, representa otra situación particular en el cual, la formación de la fase hidrotalcita no se rige por el radio iónico. Así, aunque el $\mathrm{Ca}^{2+}$ es un catión muy grande para coordinarse octaédricamente en los huecos generados por el empaquetamiento compacto de iones $\mathrm{OH}^{-}$, se ha reportado la formación de sólidos tipo hidrotalcita que contienen pequeñas cantidades de $\mathrm{Ca}^{2+}$. Más aun, se ha reportado la síntesis de LDH con cationes monovalentes muy pequeños tales como $\mathrm{Li}^{+}[13]$.

El intervalo de estequiometrias para el cual es posible la formación de una fase pura LDH es muy estrecho. Pese a que se ha reportado la síntesis de materiales tipo hidrotalcita con valores inusuales de $x$, diversos estudios han mostrado que la fase LDH sólo puede obtenerse para estequiometrias en el intervalo de $0.20<x<0.33$ (razón molar $M^{\prime \prime} / M^{\prime \prime \prime}$ de 2-4). Para valores distintos de $x$, se presenta la formación de hidróxidos puros y compuestos con otras fases cristalinas; en el caso de que $x>0.33$, aumenta el número de enlaces tipo $\mathrm{M}^{\prime \prime \prime}-\mathrm{O}-\mathrm{M}^{\prime \prime \prime}$, generándose la formación de $\mathrm{M}(\mathrm{OH})_{3}$. Similarmente, a 
valores de $\mathrm{x}$ menores a 0.20 , el incremento en la cantidad de octaedros con cationes $\mathrm{M}^{\prime \prime}$, ocasiona la segregación de $\mathrm{M}(\mathrm{OH})_{2}$.

\subsubsection{Aniones interlaminares}

Hasta ahora no se conoce alguna variable limitante respecto a la naturaleza de los aniones que pueden ser insertados en un hidróxido doble laminar, excepto que no deben formar complejos con los cationes metálicos presentes y requieren ser estables en el rango de $\mathrm{pH}$ al cual se lleva a cabo la síntesis. Debido a la gran afinidad de estos materiales por el $\mathrm{CO}_{3}{ }^{2-}$, el factor más difícil de evitar al emplear aniones distintos, es la contaminación por $\mathrm{CO}_{2}$ disuelto en agua. Distintos sustancias de origen orgánico e inorgánico se han logrado intercalar en los dominios interlaminares de estos sólidos; algunos de estas especies son:

I) Inorgánicos, tales como halogenuros, $\mathrm{NO}_{3}{ }^{-}, \mathrm{ClO}_{4}{ }^{-}, \mathrm{SO}_{4}{ }^{2-}, \mathrm{WO}_{4}{ }^{2-}, \mathrm{OH}^{-}, \mathrm{CrO}_{4}{ }^{2-}$ y $\left[\mathrm{Fe}(\mathrm{CN})_{6}\right]^{3-}$.

II) Ácidos orgánicos entre los que se encuentran el ácido oxálico, succínico, malónico, sebacico, dodecanicarboxílico y acílico.

III) Heteropoliácidos, entre los que se pueden mencionar a $\left(\mathrm{PMo}_{12} \mathrm{O}_{40}\right)^{3-}$ y $\left(\mathrm{PW}_{12} \mathrm{O}_{40}\right)^{3-}$.

IV) Fármacos, como diclofenaco, naproxeno, ibuprofeno, gemfibrozil, amplicilina y ácido nalidixico.

La naturaleza del anión empleado para compensar la carga positiva del hidróxido doble laminar, determina el parámetro de red c', el cual indica el grosor de una lámina consistente de una hoja tipo brucita y un espacio interlaminar [79]. Aunque se ha observado que el valor de c', aumenta al incrementarse el radio iónico del anión huésped, en algunos casos, esta variable no puede ser empleada para explicar el grosor del espacio interlaminar. Por ejemplo, los valores de c' para LDH's ZnAl que contienen $\mathrm{SO}_{4}{ }^{2-}$ y $\mathrm{ClO}_{4}{ }^{-}$(aniones de tamaño similar) son 8.58 y 9.20 respectivamente. Esta diferencia se debe a que el anión $\mathrm{SO}_{4}{ }^{2-}$ forma enlaces más fuertes con los grupos $\mathrm{OH}$ de las laminas tipo brucita, reduciendo el espacio interlaminar. Un caso similar se observa en $\mathrm{LDH}^{\prime}$ s que contienen aniones $\mathrm{CO}_{3}{ }^{2-}$. Debido a los fuertes enlaces de puente de hidrogeno que se originan al emplear esta especie como anión huésped, el grosor del dominio interlaminar es similar a los valores obtenidos en arcillas aniónicas que contienen halógenos monovalentes. La orientación del anión huésped, es otro de los factores que influye en el valor del parámetro c'; tal es el caso de $\mathrm{LDH}^{\prime}$ 's que contienen aniones $\mathrm{NO}_{3}{ }^{-}$. Se ha reportado que el parámetro c' en LDH's ZnAl que contienen este anión, es de aproximadamente $8.79 \AA ̊$. Este valor 
tan alto es originado no sólo por la monovalencia del anión sino también porque es forzado a adquirir un arreglo que favorezca el empaquetamiento más compacto posible, generando una fuerte repulsión en la zona interlaminar cuando la concentración de aniones aumenta. En conclusión, el tamaño del anión, su orientación y la fuerza de enlace entre éste y los grupos $\mathrm{OH}$ de las láminas hidroxiladas, determinarán el grosor del espacio interlaminar.

\subsubsection{Apilamiento}

Al igual que con otras estructuras laminares, en los materiales tipo hidrotalcita, el número de placas hidróxiladas y la secuencia de apilamiento entre ellas origina una gran variedad de estructuras cristalinas, llamadas politipos. Las investigaciones enfocadas en los aspectos cristalográficos de los LDH's, han permitido la elucidación de estas estructuras basándose principalmente en el análisis de intensidades, posiciones y ausencias sistemáticas de reflexiones en patrones de difracción de rayos-X.

El arreglo de los iones hidróxido en los materiales tipo hidrotalcita, genera un empaquetamiento compacto en el cual los cationes divalentes y trivalentes ocupan aleatoriamente los huecos octaédricos. Si los sitios cristalográficos no equivalentes que pueden ocupar los iones $\mathrm{OH}^{-}$se denotan como A, B y C, y las posiciones de los cationes metálicos se designan por las letras $\mathbf{a}, \mathbf{b}$ y $\mathbf{c}$, una lámina tipo brucita puede representarse simbólicamente como AbC. Los grupos hidróxido de la parte inferior de una segunda lamina hidroxilada, apilada sobre la placa $A b C$, pueden residir sobre los sitios $C$, en cuyo caso se formaran prismas en la espacio interlaminar (interlamina tipo P), u ocupar los sitios A o B dando paso a la generación de estructuras octaédricas (interlamina tipo O). Más aun, la secuencia de apilamiento de las láminas hidróxiladas puede seguir simetrías hexagonales $(H) \circ$ romboédricas $(R)$. El siguiente esquema propuesto por Bookin y Drifts [80], permite la derivación de estructuras cristalinas que poseen dos tipos de láminas hidroxiladas. 


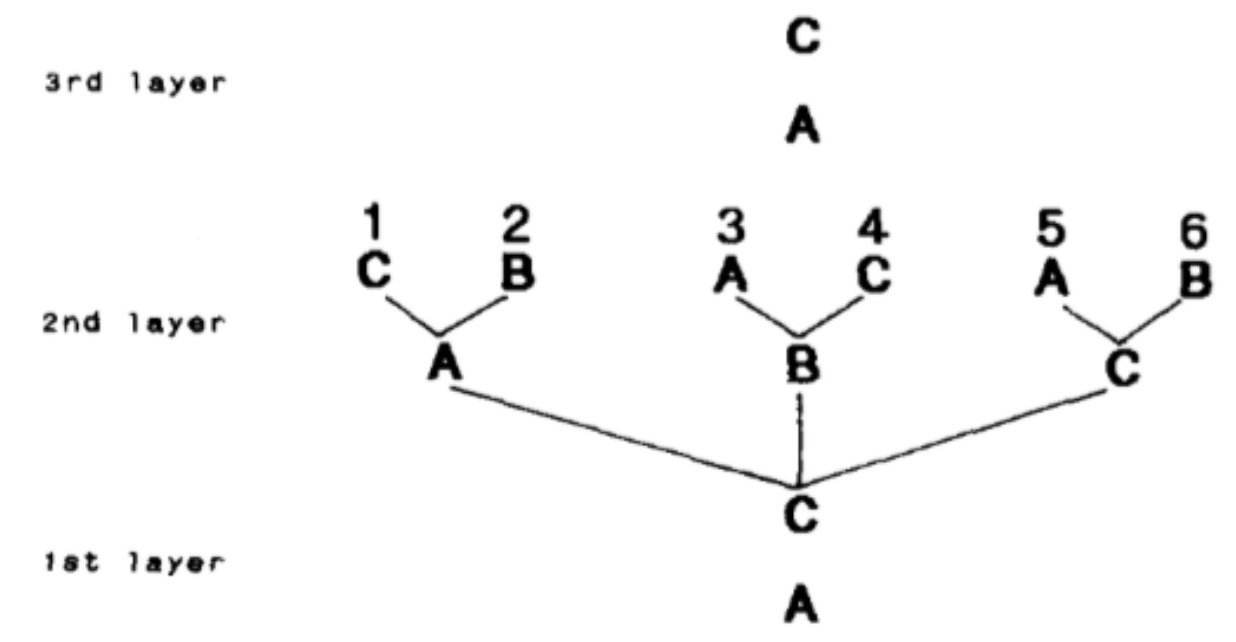

Fig. 1.13. Esquema para la derivación de todos los politipos de dos laminas hidróxiladas

Si los espacios interlaminares tipo $\mathrm{P}$ se representan por el signo $=\mathrm{y}$ los tipo $\mathrm{O}$ quedan denotados por el signo , entonces se encuentra que hay 3 politipos de estructuras con dos láminas hidróxiladas, las estructuras 2 y 4 , y 3 y 6 son equivalentes, los cuales quedan representadas como:

$\begin{array}{ll}\ldots . . A b C=C b A=A b C \ldots . & 2 \mathrm{H}_{1} \\ \ldots . A b C \sim A c B \sim A b C \ldots . & 2 \mathrm{H}_{2} \\ \ldots . A b C \sim B c A=A b C \ldots . & 2 \mathrm{H}_{3}\end{array}$

donde el número 2 indica el número de láminas tipo brucita que contiene la celda, $\mathrm{H}$ la simetría de apilamiento y el subíndice el politipo formado. En el politipo $2 \mathrm{H}_{1}$, todos los cationes ocupan las posiciones b; en el caso de las estructuras $2 \mathrm{H}_{2}$ y $2 \mathrm{H}_{3}$ estas especies se distribuyen en los sitios cristalograficos b y c. Mientras que los politipos $2 \mathrm{H}_{1}$ y $2 \mathrm{H}_{2}$ presentan sólo un tipo de arreglo interlaminar, P y $\mathrm{O}$ respectivamente, la estructura $2 \mathrm{H}_{3}$ presenta ambos tipos de interlaminas situadas alternativamente.

Empleando un esquema similar, se encuentra que hay 9 estructuras cristalinas formadas con 3 láminas tipo brucita, en las cuales 2 tienen una simetría de apilamiento romboédrica y el resto hexagonal: 


$\begin{array}{ll}\ldots . . A b C=C a B=B c A=A b C \ldots & 3 R_{1} \\ \ldots . A b C \sim B c A \sim C a B \sim A b C \ldots . & 3 R_{2} \\ \ldots . A b C \sim A c B \sim A c B \sim A b C \ldots . & 3 H_{1} \\ \ldots . A b C \sim A c B \sim C a B \sim A b C \ldots . & 3 H_{2} \\ \ldots . A b C \sim A c B=B c A \sim A b C \ldots . & 3 H_{3} \\ \ldots . A b C \sim A b C=C b A=A b C . . . & 3 H_{4} \\ \ldots . A b C \sim A c B=B a C \sim A b C \ldots . & 3 H_{5} \\ \ldots . . A b C \sim A c B \sim C b A=A b C \ldots . & 3 H_{6} \\ \ldots . A b C \sim A b A \sim B c A=A b C . . . & 3 H_{7}\end{array}$

En los politipos $3 R_{1}, 3 R_{2}$ y $3 H_{2}$, los cationes metálicos se distribuyen uniformemente en los sitios $\mathbf{a}$, b y $\mathbf{c}$. Aunque la mayor parte de estas estructuras presenta interlaminas de ambos tipos, la estructura $3 \mathrm{R}_{1}$ solo contiene arreglos prismáticos, en tanto que, en los politipos $3 \mathrm{R}_{2}, 3 \mathrm{H}_{1}$ y $3 \mathrm{H}_{2}$ las interlaminas son de tipo octaédrico.

La descripción de un gran número de politipos, con simetrías hexagonales o romboédricas, formados a partir del apilamiento de seis laminas hidroxiladas, también ha sido reportada en la literatura [80, 81].

El politipo que presenta un hidróxido doble laminar puede ser identificado, en principio, mediante la difracción de rayos-X. En la práctica, la especificación de la estructura politipo de muchos se estos materiales es muy complicada, debido a que los sólidos con el mismo número de láminas hidróxiladas por celda unitaria y la misma simetría de apilamiento presentan reflexiones similares. Pese a lo anterior, la simetría de apilamiento puede ser fácilmente determinada por medio del análisis de las reflexiones (01l) y (10l) que ocurren en ángulos intermedios: en simetrías romboédricas estas reflexiones se encuentran ausentes, al menos que se cumpla la condición $-h+k+l=3 n$, donde $n$ es un entero y $h, k$ y I son índices de Miller, mientras que en estructuras hexagonales se observan fuertes reflexiones en posiciones $-h+k+I \neq 3 n[81]$. 


\subsubsection{Métodos de síntesis}

Diversas técnicas de síntesis han sido empleadas exitosamente en la preparación de hidróxidos dobles laminares. Algunas de ellas son:

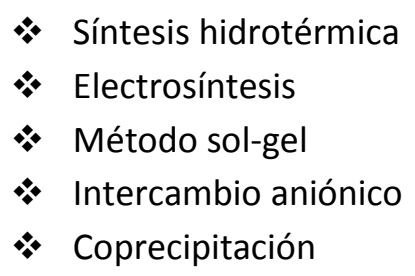

De los métodos anteriores, la cooprecipitación ha sido la técnica más frecuentemente usada en la preparación de estos sólidos, debido a que, además de permitir la modificación de diferentes parámetros estructurales, tales como la razón molar $\mathrm{M}^{\prime \prime} / \mathrm{M}^{\prime \prime \prime}$, la identidad de los cationes metálicos y del anión interlaminar, grandes cantidades de material pueden ser obtenidas a costos viables.

El mecanismo de ésta técnica de síntesis, consiste en la formación de láminas tipo brucita con distribuciones uniformes de cationes metálicos y aniones interlaminares solvatados, mediante la condensación de complejos metálicos hexa-acuosos que se encuentran en solución [81, 82]. La precipitación simultanea de los cationes metálicos requiere condiciones de supersaturación; esto se logra mediante el control del $\mathrm{pH}$ del sistema de reacción y en particular, se precisa que su valor sea igual o mayor que el pH de precipitación del catión metálico más soluble. Todos los hidróxidos de los cationes que se emplean para la síntesis de LDH's, Tabla 1.5. Valores de pH para la precipitación de algunos hidróxidos $\mathrm{M}$ (II) y $\mathrm{M}$ (III) [81]

\begin{tabular}{|ccc|}
\hline Catión & $\mathrm{pH} 10^{-2} \mathrm{M}$ & $\mathrm{pH} 10^{-4} \mathrm{M}$ \\
& & \\
\hline & & \\
$\mathrm{Al}^{3+}$ & 3.9 & 9 \\
$\mathrm{Cr}^{3+}$ & 5 & 9.5 \\
$\mathrm{Cu}^{2+}$ & 5 & 6.5 \\
$\mathrm{Zn}^{2+}$ & 6.5 & 8 \\
$\mathrm{Ni}^{2+}$ & 7 & 8.5 \\
$\mathrm{Fe}^{2+}$ & 7.5 & 9 \\
$\mathrm{Co}^{2+}$ & 7.5 & 9 \\
$\mathrm{Mn}^{2+}$ & 8.5 & 10 \\
& & \\
\hline
\end{tabular}
precipitan en un intervalo de pH de 8-10 (Tabla 1.5). Valores de pH más básicos ocasionan la redisolución de algunos iones metálicos. 
Un tratamiento térmico posterior a la síntesis es necesario para aumentar la cristalinidad del material. Dos variantes del método de cooprecipitación son los más comúnmente empleados en la preparación de LDH's: la cooprecipitación a baja supersaturación y la cooprecipitación a alta supersaturación.

La cooprecipitación a baja supersaturación, se realiza mediante la adición lenta de una mezcla de soluciones de los cationes divalentes y trivalentes, en la razón molar $\mathrm{M}^{\text {II }} / \mathrm{M}^{\text {III }}$ seleccionada, a un reactor que contiene una solución acuosa del anión interlaminar. Una segunda solución alcalina es adicionada simultáneamente a una velocidad que permita mantener el $\mathrm{pH}$ en un valor adecuado para la cooprecipitación de los iones metálicos. Los materiales sintetizados por éste método presentan una cristalinidad mayor que aquellos que son preparados a alta supersaturación, debido a que en el último caso la velocidad de nucleación es mayor que la rapidez con la cual crece el cristal. Una gran diversidad de aniones orgánicos e inorgánicos, biomoléculas, farmacéuticos y especies activas catalíticamente, han sido intercalados con éxito mediante la aplicación de esta técnica de síntesis.

Por otra parte, en la cooprecipitación a alta supersaturación, la mezcla de cationes metálicos es adicionada a una solución alcalina que contiene el anión interlaminar deseado. Debido a las variaciones de $\mathrm{pH}$ durante la síntesis, es frecuente la formación de impurezas, tales como $\mathrm{M}(\mathrm{OH})_{2}$ y/o $\mathrm{M}(\mathrm{OH})_{3}$, y la consecuente obtención de materiales con razones molares $\mathrm{M}^{\prime \prime} / \mathrm{M}^{\prime \prime \prime}$ no deseadas. Una gran variedad de hidróxidos dobles laminares bimetálicos y multimetálicos han sido preparados mediante cooprecipitacion a alta supersaturación; asimismo ciertos iones de origen orgánico, glutamato, aspartato, teleftalato, dicarboxílatos, ácido L- aspártico, se han podido intercalar en los espacios interlaminares.

\subsubsection{Usos de hidróxidos dobles laminares}

Aunado a la posibilidad de modificar diversas variables estructurales y a los bajos costos de síntesis, los hidróxidos dobles laminares poseen ciertas propiedades físicas que permiten su aplicación práctica, ya sea de manera directa o después de un tratamiento térmico, en catálisis, medicina, adsorción y procesos industriales. (fig. 2.15) 


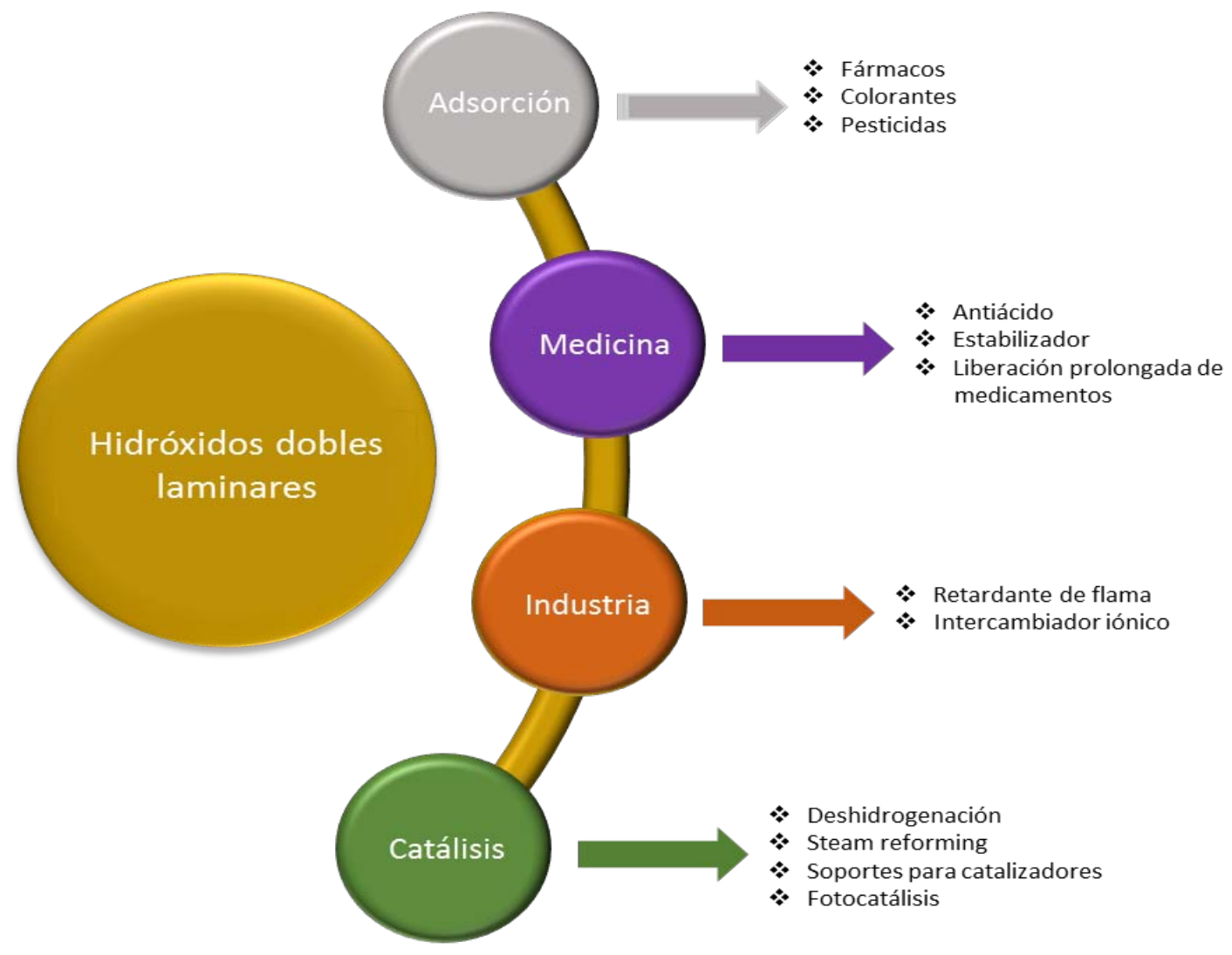

Fig. 1.14. Algunas aplicaciones de los hidróxidos dobles laminares

Aplicaciones en adsorción e intercambio iónico.

Debido a su estructura laminar, área superficial y alta capacidad de intercambio iónico, los hidróxidos dobles laminares han sido empleados en la remoción de una gran cantidad de aniones orgánicos e inorgánicos en solución, y aunque en menor medida, también se ha reportado la incorporación de algunas moléculas polares en las zonas interlaminares.

En general, los hidróxidos dobles laminares pueden retiran especies aniónicas en solución, por tres diferentes mecanismos: adsorción, intercambio aniónico y reconstrucción del material calcinado por medio del "efecto memoria", el cual consiste en la reconstrucción de la estructura laminar original cuando el LDH calcinado entra en contacto con soluciones de aniones.

Aunque la capacidad de intercambio aniónico (AEC, por sus siglas en inglés) de los hidróxidos dobles laminares es similar a la de algunas resinas poliméricas (2-3 meq/g), su estabilidad térmica ha permitido la aplicación de estos materiales en procesos que se llevan a cabo a altas temperaturas, tal como el tratamiento al agua proveniente de reactores nucleares [79]. La AEC de los sólidos tipo hidrotalcita, es 
afectada por la naturaleza del anión inicialmente presente en los dominios interlaminares [81, 83-85]; los materiales que contienen nitratos y cloruros son los mejores precursores para las reacciones de intercambio iónico [79]. La densidad de carga de los aniones en solución influye en la selectividad del intercambio: los LDH's mostrarán una mayor afinidad hacia los aniones multivalentes que hacia aquellos monovalentes $[79,81]$.

Los hidróxidos dobles laminares han sido empleados, tanto calcinados como sin previo tratamiento térmico, en la adsorción en medio acuoso de oxoaniones [84], pesticidas [86], ácidos orgánicos [13] y fármacos $[81,85]$. Acorde con numerosas investigaciones, la capacidad de adsorción de estos materiales se incrementa al ser calcinados. Esta diferencia de comportamiento puede estar ligada a diversas razones pero, en general, se infiere que la mayor capacidad de adsorción se debe a: I) la calcinación incrementa el área superficial del sólido, II) aumenta la porosidad del LDH y III) existe una menor cantidad de iones $\mathrm{CO}_{3}{ }^{2-}$, los cuales son difíciles de desplazar.

La temperatura de calcinación es un factor importante que afecta los procesos de adsorción de los LDH's. La descomposición térmica de estos sólidos a una temperatura de $400-500^{\circ} \mathrm{C}$ permite la formación de óxidos mixtos estables y muy activos que pueden reconstruir con facilidad su estructura laminar por medio de rehidratación y sorción de diversos aniones [84, 87].

\section{Medicina}

Las primeras aplicaciones de los hidróxidos dobles laminares en medicina fueron principalmente como antiácido y antipepsinico $[13,79,81]$. Más recientemente, la biocompatibilidad de estos materiales ha permitido su uso en otras áreas de la medicina, especialmente en la formulación de fármacos. Aunque en la industria farmacéutica se ha empleado el LDH MgAl como excipiente y estabilizador de algunos medicamentos, la posibilidad de intercalar diversos fármacos de carácter aniónico en su dominio interlaminar, ha cobrado especial interés. Debido a que las tendencias actuales en tecnología farmacéutica requieren que la dosificación de cualquier medicamento, provea niveles terapéuticos por largos periodos y evite los efectos tóxicos de la administración repetitiva, numerosas investigaciones se han enfocado al diseño de nuevos sistemas que permitan la liberación prolongada de los fármacos. En este sentido, se ha encontrado que la región interlaminar de los LDH's puede intercalar, almacenar y proteger del medio ambiente y liberar de manera prolongada diferentes fármacos de naturaleza aniónica. La liberación de estas sustancias en el organismo puede ocurrir por medio de un intercambio iónico; la velocidad de difusión del medicamento estará determinada por la interacción entre el material y el fármaco huésped, la rigidez de las láminas y la trayectoria de difusión [81]. Algunos de los fármacos 
intercalados en LDH's, son: diclofenaco, naproxeno, ibuprofeno [81, 83], ácido ferúlico, salicilato, glutamato [83], ampicilina gramidicina y ácido nalidixico [85].

El uso de los LDH's como sistemas para la liberación prolongada de fármacos, se ha visto limitado por el carácter básico de estos materiales: la administración oral de un medicamento intercalado en estos sólidos no es posible, debido a que la arcilla aniónica sería destruida por el pH del estómago.

$>$ Industria

En el área de la industria, los hidróxidos dobles laminares han encontrado su principal aplicación como retardantes de flama $[13,79]$.

Algunos materiales, tales como los polímeros y los textiles, combustionan rápidamente o sufren reacciones autocatalíticas al incrementarse la temperatura o bajo la influencia de radiación UV. Para evitar estos procesos se emplean ciertos compuestos, conocidos como retardantes de flama, que incrementan significativamente el punto de ignición de los materiales y/o evitan que éstos esparzan el fuego rápidamente. Pese a que existen diferentes sustancias que pueden ser usadas como retardantes de flama,

algunas de ellas contienen metales pesados tóxicos para el medio ambiente mientras que la aplicación de otras incrementa significativamente los costos de producción. Una alternativa de bajo costo y amigable con el ambiente, ha sido el uso de hidróxidos dobles laminares, los cuales retardan el proceso de combustión mediante la generación de gases no combustibles y por dilución, es decir la formación de productos de reacción no inflamables.

Los hidróxidos dobles laminares también se han utilizado como inhibidores de corrosión en pinturas y revestimientos e intercambiadores aniónicos en la industria del concreto.

\section{$>$ Catálisis}

La descomposición térmica de los hidróxidos dobles laminares produce óxidos mixtos homogéneos con áreas superficiales altas y propiedades básicas. Estas características y la posibilidad de modificar diversos parámetros estructurales, hacen de los LDH's excelentes precursores para la generación de sólidos con diferentes aplicaciones catalíticas que van desde reacciones de polimerización hasta procesos fotocatalíticos. 
El carácter básico de los óxidos mixtos derivados de LDH's, ha hecho posible su aplicación en diversas reacciones orgánicas, tales como la polimerización de óxidos de alquenos y la condensación aldólica de aldehídos a cetonas $[79,88]$.

Los hidróxidos dobles laminares que contienen iones metálicos de transición, se han utilizado como precursores para catalizadores redox. Se ha encontrado que los materiales sintetizados mediante este método presentan mayor estabilidad y una actividad catalítica más prolongada que aquellos que son preparadores por alguna otra técnica convencional. Algunas de las reacciones redox que incluyen el uso de catalizadores derivados de LDH son el reformado de hidrocarburos, la reducción de nitrobenceno y la síntesis de alcoholes $[13,88]$.

Óxidos metálicos de transición se han sido soportados en el LDH MgAl calcinado para la remoción de $\mathrm{SO}_{x}$ y para reacciones de deshidrogenación catalítica. Tanto los LDH's calcinados como aquellos sin previo tratamiento térmico han sido empleados como soportes para metales nobles, observándose una mayor actividad y selectividad de estos catalizadores en reacciones de síntesis orgánica. Más recientemente, se ha reportado el uso de estos materiales como soportes para la inmovilización de enzimas. Se encontró que las enzimas soportadas presenta una mayor resistencia a cambios en las condiciones de reacción y que su actividad catalítica puede mantenerse por periodos más largos [81].

Debido a la posibilidad de intercalar diversos aniones, los hidróxidos dobles laminares han sido empleados para inmovilizar complejos catalíticos, tales como oxometalatos, polioxometalatos y porfirinas de $\mathrm{Mn}[81,88]$.

Pese a que los sólidos derivados de LDH's, han tenido múltiples aplicaciones catalíticas, su uso en reacciones fotoquímicas ha sido escasamente investigado. Un número limitado de estudios ha reportado el comportamiento fisicoquímico de estos materiales en la fotodegradación de contaminantes orgánicos, tales como ácido 2,4-diclorofenoxiacetico [86], colorantes [14, 15] y compuestos fenólicos [16, 17], empleando luz ultravioleta. La alta eficiencia de estos materiales en reacciones fotocatalíticas, ha ocasionado el desarrollo de nuevos catalizadores derivados de LDH's capaces de absorber radiación visible. Recientemente Fan et al. [89] intercalaron $\alpha-\mathrm{Ag}_{2} \mathrm{WO}_{4}$ en un hidróxido doble laminar $\mathrm{ZnCr}$, obteniendo un catalizador capaz de degradar Rodamina B empleando luz visible. S.-J. et al. [90] mostraron que los catalizadores derivados de LDH's Zn/M (M = Al, Fe, Ti y Fe/Ti) irradiados con luz visible, pueden degradar hasta $72 \%$ de este colorante después de 120 min. 
Debido a su bajo costo de síntesis, fácil preparación e inocuidad con el medio ambiente, los LDH's son un grupo de materiales tecnológicamente promisorios. Aunque, en la actualidad, cuentan con diversas aplicaciones científicas e industriales, poco se ha explorado su uso como fotocatalizadores. Las futuras investigaciones que se realicen en esta área, serán claves para lograr un mayor aprovechamiento de estos versátiles materiales.

Ya que los hidróxidos dobles laminares se han empleado con éxito en la adsorción de diversos fármacos, previo a las reacciones de fotodegradación, se realizaron estudios de adsorción para determinar posibles interferencias con el proceso fotocatalítico. Los resultados se muestran en el apéndice A. 


\section{MATERIALES Y METODOS}

\subsection{Síntesis de materiales}

Tres hidróxidos dobles laminares $\mathrm{Mg}$-Al con diferentes razones molares fueron sintetizados por el método de cooprecipitación. Para ello, soluciones acuosas de las sales $\mathrm{Mg}\left(\mathrm{NO}_{3}\right)_{2} \cdot 6 \mathrm{H}_{2} \mathrm{O}$ (Reasol, $98 \%$ ) y $\mathrm{Al}\left(\mathrm{NO}_{3}\right)_{3} \cdot 9 \mathrm{H}_{2} \mathrm{O}$ (Reasol, 98\%) fueron agregadas a un reactor de vidrio en cantidades adecuadas para obtener razones molares $\mathrm{M}^{\prime \prime} / \mathrm{M}^{\prime \prime \prime}$ de 2, 3 y 4 . El pH de la mezcla de sales fue ajustado a un valor de $9 \pm$ 0.5 mediante la adición de una solución de $\mathrm{NaOH}$ y $\mathrm{Na}_{2} \mathrm{CO}_{3}(1 \mathrm{M})$. Los sistemas de reacción se mantuvieron bajo agitación vigorosa a una temperatura de $373 \mathrm{~K}$ por 24 horas. Los precipitados obtenidos fueron filtrados, lavados exhaustivamente con agua desionizada y secados a $353 \mathrm{~K}$ por 18 horas. Finalmente los materiales sintetizados se calcinaron a $723 \mathrm{~K}$ por 12 horas, empleando una rampa de calentamiento con una velocidad de $274 \mathrm{~K} / \mathrm{min}$ (fig. 2.1). Las materiales a examinar fueron denoninados MgAl2, MgAl3 y MgAl4, donde el número denota la razón molar M"1/M"'.
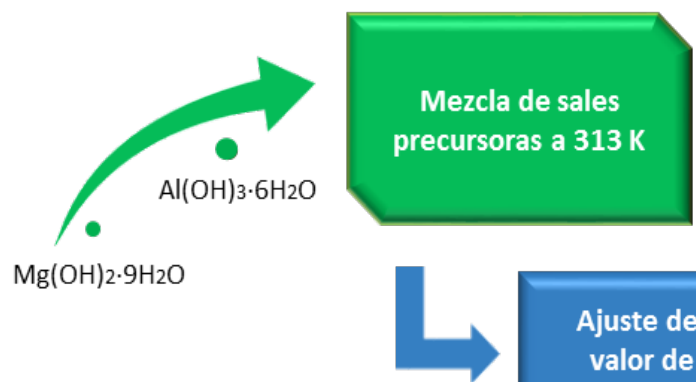

Ajuste de $\mathrm{pH}$ a un

valor de $9 \pm 0.5$

mediante la adición

de $\mathrm{NaOH}$ y $\mathrm{Na}_{2} \mathrm{CO}_{3}$

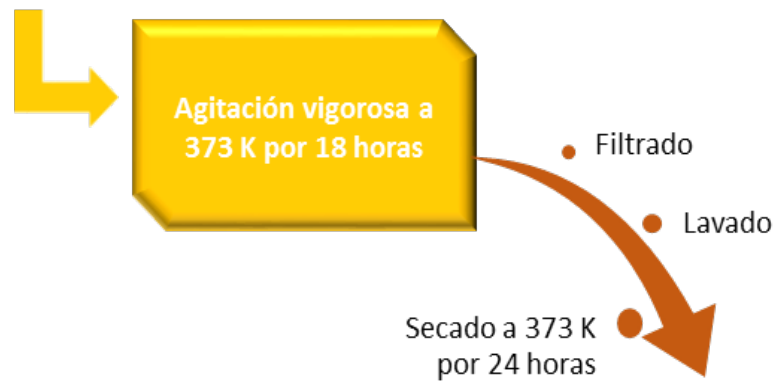

Calcinación de

muestras a $723 \mathrm{~K}$

por 12 horas

Fig. 2.1. Diagrama de flujo para la síntesis de los catalizadores MgAl. 


\subsection{Técnicas de caracterización}

Los materiales obtenidos fueron caracterizados mediante las siguientes técnicas:

\subsubsection{Difracción de rayos $-\mathrm{X}$}

El análisis de difracción de rayos $\mathrm{X}$ de los LDH's MgAl sin calcinar, se realizó en un difractometro de rayos $X$ Siemens $\mathrm{D} 500$, empleando un cristal de grafito como monocromador para seleccionar radiación $\mathrm{Cu}-K \alpha$ con un paso de $0.02^{\circ} \mathrm{s}^{-1}$. Los parámetros de celda de los materiales, fueron calculados con las siguientes ecuaciones:

$$
\begin{aligned}
& c=3 d_{003} \\
& a=2 d_{110} \quad \ldots . . .(2.1)
\end{aligned}
$$

El tamaño de cristalito fue obtenido mediante la ecuación de Scherrer, cuya expresión matemática es

$$
D=\frac{K \lambda}{\beta \cos \theta}
$$

donde $K$ es una constante relacionada a la forma del cristal y tiene un valor de $0.891, \lambda$ es la longitud de onda de los rayos $X$ incidentes (en $\mathrm{nm}$ ), $\beta$ es en ancho del pico de difracción a la altura máxima media y $\theta$ es el ángulo de Bragg.

\subsubsection{Análisis químico}

La composición química de los sólidos sintetizados fue obtenida mediante espectroscopia de energía dispersiva, empleando un microscopio TEM Zeiss EM-910, con una resolución de $0.34 \mathrm{~nm}$, un voltaje de $120 \mathrm{kV}$ y un detector Noran.

\subsubsection{Análisis termogravimetrico}

El análisis termogravimétrico de los hidróxidos dobles laminares MgAl se realizó en un analizador térmico Diamond TGA/DTA usando un flujo de $\mathrm{N}_{2}$ de $10 \mathrm{~mL} / \mathrm{min}$ y una rampa de calentamiento de 283 $\mathrm{K} / \mathrm{min}$, desde una temperatura ambiente hasta los $1073 \mathrm{~K}$. 


\subsubsection{Análisis textural}

Las propiedades texturales de los sólidos calcinados fueron analizadas por medio de la construcción de isotermas de adsorción-desorción de $\mathrm{N}_{2}$ usando un equipo Quantrachrome Autosorb-3B. Las muestras fueron previamente desgasificadas ( $10^{-5}$ Torr) en vacío a $673 \mathrm{~K}$ por 12 horas. El área superficial específica y la distribución de tamaño de poro fueron determinados mediante los métodos BET y BJH respectivamente.

\subsubsection{Espectroscopia de reflectancia difusa UV-Vis}

Las energías de banda prohibida (Eg) de los materiales sintetizados fueron obtenidas mediante medidas de reflectancia difusa, usando un espectrofotómetro Cary 100 UV-Vis Scan Varian con esfera de integración. El intervalo de longitud de onda medido fue de 200-800 nm. La ecuación de Kubelka-Munk:

$$
F(R)=\frac{(1-R)^{2}}{2 R}
$$

donde $\mathrm{R}$ es la reflectancia, fue utilizada para calcular el valor de la energía de banda prohibida, considerando transiciones directas e indirectas. El fundamento de este método se explica en el apéndice B.

\subsection{Reacciones de fotodegradación}

La actividad fotocatalítica de los LDH's MgAl calcinados (723 k por 12 horas) se evaluó siguiendo la fotodegradación de dos fármacos, naproxeno sódico (Sigma 98\%) y clorohidrato de oxitetraciclina (Sigma, 95\%). Para ello, se prepararon soluciones conteniendo $50 \mathrm{ppm}$ del compuesto en agua destilada. $200 \mathrm{~mL}$ de estas soluciones fueron puestos en contacto con $0.1 \mathrm{~g}$ de los catalizadores en la obscuridad y a temperatura ambiente por 1 hora. Transcurrido este lapso, los sistemas de reacción se irradiaron con luz UV, empleando una lámpara Pen Ray Supply (2.16 W, 18 mA y $\lambda=254 \mathrm{~nm})$, por 6 horas bajo agitación vigorosa. Durante diferentes periodos de la reacción, fueron tomadas alícuotas de aproximadamente 3 $\mathrm{mL}$ usando filtros de nylon. El pH del medio no fue ajustado en ningún momento del proceso fotocatalítico.

Con fines comparativos, estudios de fotólisis y fotodegradación empleado $\mathrm{TiO}_{2}$, fueron realizados bajo las mismas condiciones que aquellas impuestas a los fotocatalizadores sintetizados. El siguiente 
esquema describe brevemente el proceso desarrollado para determinar la actividad fotocatalítica de los LDH's MgAl calcinados.

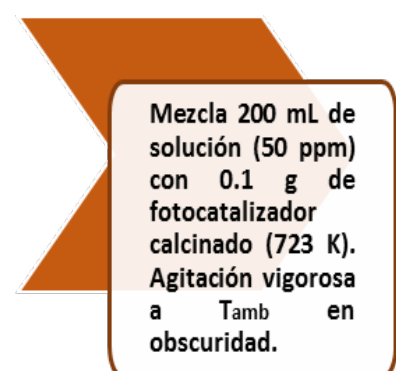

Mezcla $200 \mathrm{~mL}$ de solución $(50 \mathrm{ppm})$ con $0.1 \mathrm{~g} d \mathrm{de}$ calcinado (723 K). Agitación vigorosa obscuridad.

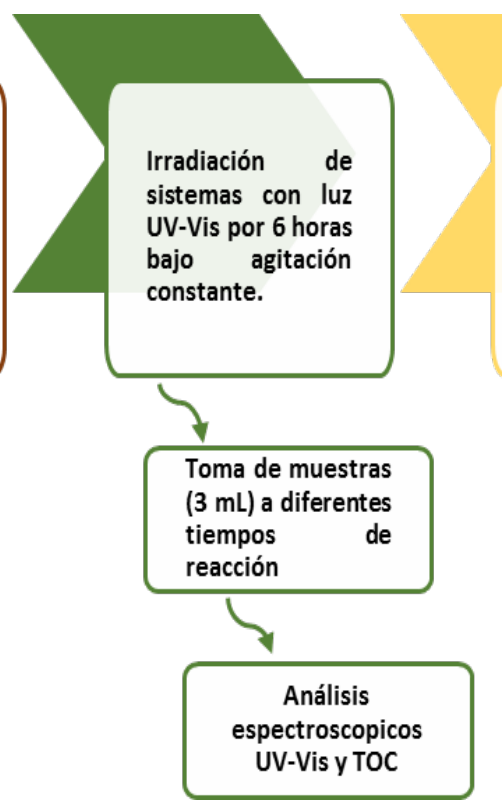

Análisis FTIR de

los

fotocatalizadores,

secados a $323 \mathrm{~K}$

por 24 horas,

después de

reacción

fotocatalítica

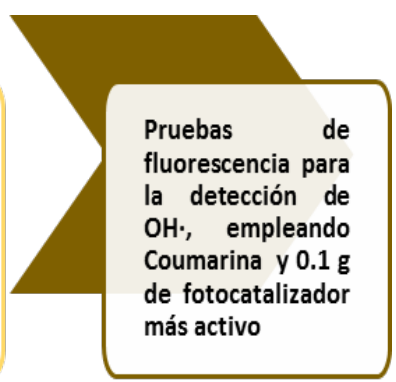

\section{Pruebas de}

OH. empleanc

Coumarina y $0.1 \mathrm{~g}$

fotocatalizado

Fig. 2.2. Diagrama de flujo del proceso fotocatalítico.

\subsubsection{Cinética de reacción}

La determinación de la velocidad con la cual se realiza un procesos fotocatalítico, ha sido uno de los métodos más empleados para medir la actividad catalítica de un material. En específico, se ha encontrado que las reacciones de fotodegradación de contaminantes orgánicos se ajustan al modelo cinético de Langmuir-Hinshelwood [91-93]:

$$
r=-\frac{d C}{d t}=\frac{k K C}{1+K C}
$$

donde $r$ es la velocidad de la fotodegradación, $C$ la concentración del contaminante, t el tiempo de reacción, $\mathrm{k}$ la constante de velocidad de reacción y $\mathrm{K}$ el coeficiente de adsorción de la molécula diana. A concentraciones milimolares de $C \ll 1$, la ecuación anterior puede simplificarse a una velocidad de orden aparente:

$$
\begin{aligned}
& -\int \frac{d C}{k K C}=\int d t \\
& \ln \frac{C_{o}}{C}=k K t=k_{a p p} t
\end{aligned}
$$


donde $C_{0}$ es la concentración inicial de la molécula diana. La expresión 8 es conocida como cinética de pseudo primer orden. El término "pseudo" se emplea para evidenciar el hecho de que en los sistemas fotocatalíticos, la concentración de uno de los reactantes, el fotocatalizador, es relativamente grande

por lo que varía muy poco durante el transcurso de la reacción. La pendiente de la gráfica de $\ln \frac{C_{0}}{C}$ vs $t$, determinará el valor de $k_{a p p}$.

Para determinar la cinética del proceso fotocatalítico, los cambios en la concentración de las moléculas objetivo fueron monitoreados por espectroscopia UV-Vis utilizando un equipo Cary 100 Varian, siguiendo las bandas de absorción a $271 \mathrm{~nm}$ para el naproxeno sódico y $275 \mathrm{~nm}$ para la oxitetraciclina.

Con la finalidad de corroborar la efectiva fotodegradación-mineralización de los fármacos, análisis de carbono orgánico total fueron realizados a diferentes tiempos de reacción, empleando un equipo TOCVs Shimadzu y aplicando el método NPOC (apéndice B)

\subsubsection{Espectroscopia FTIR}

Con la finalidad de descartar la retención de las moléculas diana o cualquier intermediario de reacción en los fotocatalizadores sintetizados, después de concluir el proceso de fotodegradación los materiales fueron removidos, secados por 12 horas y analizados por FTIR empleando un espectrofotometro Perkin Elmer FT1730.

\subsubsection{Espectroscopia de fluorescencia}

La generación de radicales $\mathrm{OH} \cdot$ por los fotocatalizadores sintetizados, fue determinada siguiendo el método descrito en $[94,95]$. Brevemente: una cantidad adecuada de Coumarina (Aldrich) fue disuelta en $\mathrm{NaOH}$ diluido para alcanzar una concentración de $1 \times 10^{-3} \mathrm{M} .0 .1 \mathrm{~g}$ del catalizador más activo fue agregado a $200 \mathrm{~mL}$ de la solución anterior. Bajo agitación vigorosa, el sistema de reacción fue irradiado con luz UV por 1 hora. El espectro de emisión de 7-hidroxicoumarina a diferentes tiempos de reacción fue medido en un espectrofluorometro K2 (ISS Inc., Champaign 1L) usando una longitud de onda de excitación de $332 \mathrm{~nm}$. Como una prueba de control, se realizaron medidas de fluorescencia de la solución de coumarina irradiada con luz UV en ausencia del fotocatalizador. 


\section{ANÁLISIS DE RESULTADOS}

\subsection{Difracción de rayos $X$}

Los patrones de difracción de los LDH's Mg-Al, los cuales fueron secados a $373 \mathrm{~K}$ por 18 horas, se muestran en la figura 3.1. Las tres materiales muestran picos de difracción típicos de fases puras LHD (JCPDS 89-0460) [17, 86, 87, 96].

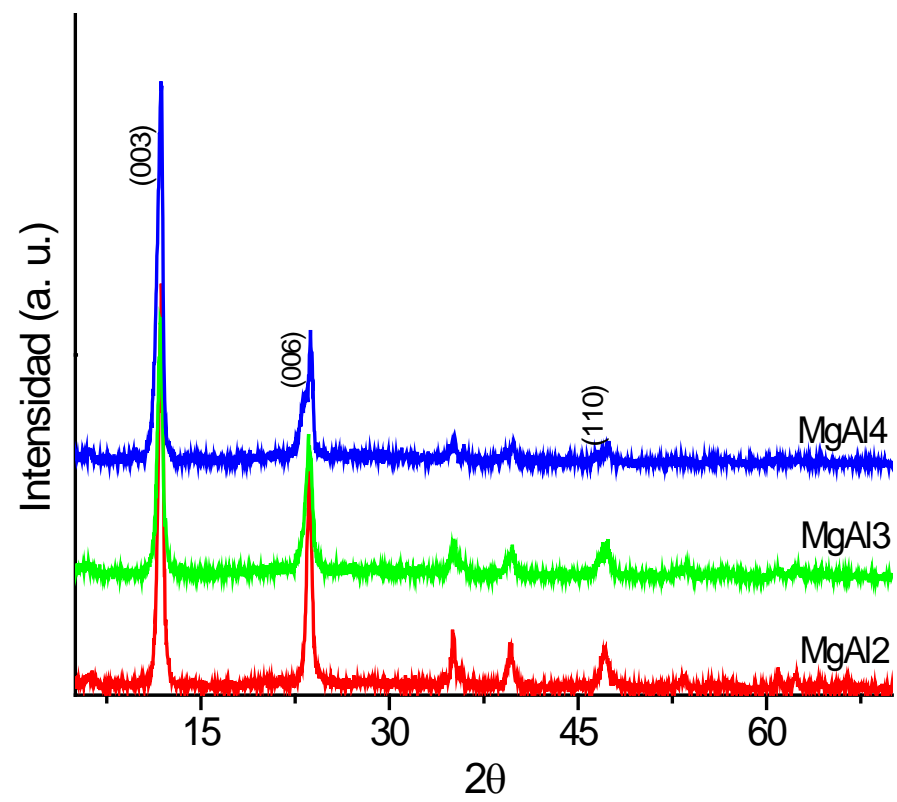

Fig. 3.1. Patrones DRX de los LDH's MgAl sintetizados con diferente razón molar M"'/M"'.

Las reflexiones de los patrones de difracción de rayos-X de los hidróxidos dobles laminares pueden clasificarse en tres grupos:

a) Reflexiones basales intensas (00/) a bajos ángulos. Permiten la determinación de la distancia interlaminar $c_{o}$, la cual equivale al grosor de una lámina tipo brucita más el espacio interlaminar. El parámetro de celda c depende de la secuencia de apilamiento laminar (politipo) y es un múltiplo de $c_{0}$. Para un hidróxido doble laminar n-politipo, donde el ángulo de reflexión más bajo esta indexado como (00n), c puede ser calculado mediante la expresión $c=n c_{0}$.

b) La reflexión (110) ubicada aproximadamente en $\mathbb{Q}=60^{\circ}$, para radiacón $\mathrm{Cu} \quad K_{\alpha}$, es empleada para calcular el parámetro de celda $a_{0}$, mediante la ecuación $a_{0}=2 d_{(110)}$. El valor de este parámetro 
corresponde a la distancia entre dos cationes metálicos, por lo que debe reflejar el radio de estas especies.

c) Las reflexiones (01/) y (10/) en ángulos intermedios pueden ser utilizadas para distinguir el politipo de un LDH. Ausencias sistemáticas de estas reflexiones permiten precisar la simetría de apilamiento de las láminas tipo brucita: en estructuras romboédricas, las reflexiones (01/) y (10/) son inexistentes, al menos que los índices de Miller cumplan con $-h+k+l=3 n$, donde $\mathrm{n}$ es un entero, mientras que reflexiones fuertes, las cuales satisfacen la condición $-h+k+l \neq 3 n$, están presentes en simetrías hexagonales.

Las reflexiones $(00 /)$ presentan una secuencia relativamente simétrica, lo que indica un alto orden en las láminas tipo brucita [97]; las presencia de reflexiones fuertes (012) (015) y (018) con $-h+k+l=$ $3 n$ indica la síntesis de materiales con politipos 3R. Los parámetros de celda de los LDH's sintetizados se muestran en la tabla 3.1.

Tabla 3.1 Parámetros de celda y tamaño de cristalito de los LDH's MgAl sintetizados y secados a $373 \mathrm{~K}$ por $12 \mathrm{~h}$.

\begin{tabular}{|c|c|c|c|c|}
\hline \multirow[t]{2}{*}{ Muestra } & \multirow[t]{2}{*}{$\begin{array}{c}\text { Razón molar } \\
\mathrm{M}^{\prime \prime} / \mathrm{M}^{\prime \prime \prime} \text { experimental }\end{array}$} & $\begin{array}{l}\text { Parámetros de } \\
\text { celda unitaria }\end{array}$ & $(\AA)$ & \multirow{2}{*}{$\begin{array}{c}\text { Tamaño de } \\
\text { cristalito } \\
\mathrm{L}_{003}(\AA ̊) \\
\end{array}$} \\
\hline & & $c$ & $a$ & \\
\hline MgAl2 & 2.1 & 22.336 & 3.041 & 90.139 \\
\hline MgAl3 & 2.3 & 22.504 & 3.043 & 84.959 \\
\hline MgAl4 & 2.8 & 22.566 & 3.045 & 80.034 \\
\hline
\end{tabular}

Se puede observar que el parámetro de celda $\mathrm{a}_{0}$ disminuye al aumentar el contenido de $\mathrm{Al}^{3+}$, debido a que el radio iónico de este catión es menor que aquel que posee el $\mathrm{Mg}^{2+}$. Al igual que $a_{0}$, el parámetro de celda $c$ decrece conforme disminuye la razón molar $M^{\prime \prime} / M^{\prime \prime \prime}$. Aunque, la dimensión del espacio interlaminar depende del tamaño del anión huésped y el número de moléculas de agua presente en la galerías interlaminares, la composición del hidróxido doble laminar influye de manera directa en su valor, debido a que la cantidad de $\mathrm{M}^{3+}$ determina la densidad de carga de las láminas hidroxiladas [13, $15,98]$. En el caso de los materiales analizados, el incremento en la cantidad de $\mathrm{Al}^{3+}$ aumenta la carga positiva en la hojas tipo brucita; de esta manera, los enlaces tipo puente de hidrogeno y las 
interacciones electrostáticas con el anión interlaminar se intensifican, ocasionando una diminución en el parámetro de celda $c$, por lo que el material MgAl2 presenta el espacio interlaminar de menor tamaño.

Por medio de la ecuación de Scherrer (ec. 2.3) se estimó el tamaño de cristalito de los LDH's MgAl, empleando la anchura a media altura del pico de refracción (00/) más intenso. Al igual que ocurre con los parámetros de celda $a_{0}$ y $c$, el tamaño de cristalito de los fotocatalizadores sintetizados es proporcional a la razón molar $\mathrm{M}^{\prime \prime} / \mathrm{M}^{\prime \prime \prime}$, observándose una disminución del tamaño de cristalito a menores cantidades de $\mathrm{Al}^{3+}$ en la muestras (tabla 3.1). De acuerdo a los valores del tamaño de cristalito, los LDH's MgAl sintetizados pueden ser considerados materiales nanoestructurados.

\subsection{Análisis EDS}

La composición química de los fotocatalizadores sintetizados se presenta en la tabla 3.2.

Tabla 3.2. Composición química, área superficial específica y tamaño de poro de los LDH's MgAl sintetizados.

\begin{tabular}{ccc}
\hline Muestra & $\begin{array}{c}\text { Razón molar } \\
\text { M"'/M"' experimental }\end{array}$ & $\begin{array}{c}\mathrm{x} \\
\left(\mathrm{M}^{\prime \prime \prime} / \mathrm{M}^{\prime \prime \prime}+\mathrm{M}^{\prime \prime \prime}\right)\end{array}$ \\
\hline & & \\
MgAl2 & 2.1 & 0.323 \\
MgAl3 & 2.3 & 0.303 \\
MgAl4 & 2.8 & 0.263 \\
\hline
\end{tabular}

Los datos del análisis elemental muestran que las cantidades de $\mathrm{Mg}$ y Al en el material MgAl2, son acordes con la razón molar nominal $\mathrm{M}^{\prime \prime} / \mathrm{M}^{\prime \prime \prime}$ establecida durante la preparación del sólido, evidenciando de esta manera que el proceso de cooprecipitacion fue completado. La razón molar $\mathrm{M}^{\prime \prime} / \mathrm{M}^{\prime \prime \prime}$ experimental para las muestras MgAl3 y MgAl4 fue de 2.5 y 3.0 respectivamente. Este hecho puede atribuirse a una incompleta incorporación de los cationes metálicos en las láminas tipo brucita [86].

Dado que las estructuras tipo hidrotalcita solo pueden ser formadas con razones molares $\mathrm{M}^{\prime \prime} / \mathrm{M}^{\prime \prime \prime}$ en el intervalo de $2-4[13,79,81]$, los valores experimentales indican que los sólidos sintetizados únicamente contienen fases puras LDH. 


\subsection{Análisis termogravimétrico.}

La figura 3.2. muestra los termogramas de los LDH's MgAl sintetizados.

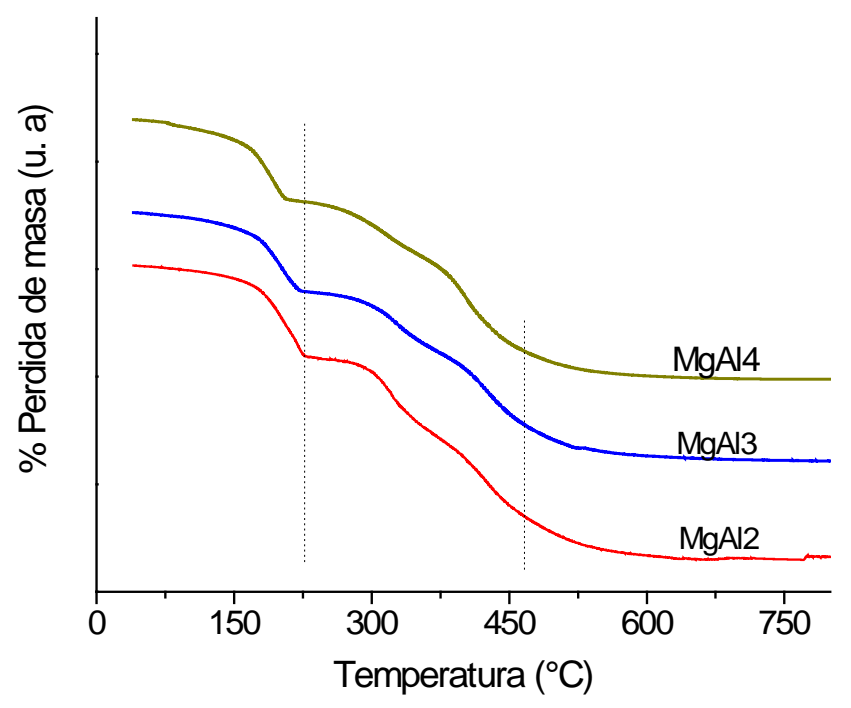

Figura 3.2. Termogramas de los LDH's MgAl sintetizados

En todos los sólidos sintetizados, se pueden observar tres zonas de pérdida de masa. De acuerdo a lo reportado en la literatura $[87,96,99,100]$, en la primera región, aproximadamente de $323-523 \mathrm{~K}$ (50 a $250^{\circ} \mathrm{C}$ ), el decremento en la masa del material esta asociado con la liberación de moléculas de agua fisisorbidas y estructurales, es decir aquellas que se encuentran en el espacio interlaminar; en el intervalo de temperatura de $523-873 \mathrm{~K}\left(250\right.$ a $\left.600^{\circ} \mathrm{C}\right)$, los aniones $\mathrm{CO}_{3}{ }^{2-}$ evolucionan a $\mathrm{CO}_{2}$ mientras que las laminas tipo brucita se deshidroxilan, dando paso a la formación de un oxido mixto MgAl. En esta región, los óxidos derivados de la descomposición térmica pueden reconstruir su estructura laminar al ser colocados en soluciones aniónicas, fenómeno conocido como "efecto memoria". Después de los 823 , los materiales presentan una pérdida de masa muy suave que se atribuye a la deshidratación de grupos $\mathrm{OH}$ restantes y a la remoción de $\mathrm{CO}_{2}$.

Las transiciones térmicas de los sólidos analizados, presentan diferencias en función de la razón molar $\mathrm{M}^{\prime \prime} / \mathrm{M}^{\prime \prime \prime}$. Así, el proceso de perdida de agua fisisorbida y estructural es menos prolongado al disminuir el contenido de aluminio en las muestras. Este hecho puede atribuirse a la densidad de carga global en las láminas: la carga positiva de los materiales decrece al reducirse el $\mathrm{Al}^{3+}$, ocasionando que los enlaces con las moléculas de agua sean más débiles [101]. 
En el intervalo de 523 - $873 \mathrm{~K}$, se observa que la deshidroxilacion de las láminas tipo brucita varía en función del contenido de aluminio: conforme la razón molar $\mathrm{M}^{\prime \prime} / \mathrm{M}^{\prime \prime \prime}$ disminuye, la pérdida de masa es más pronunciada y la meseta que se forma en la tercera zona de los termogramas, se alcanza a temperaturas ligeramente mayores. Se ha encontrado que la deshidroxilacion de las láminas tipo brucita puede ocurrir en dos etapas [13]: en la primera, los grupos $\mathrm{OH}$ enlazados al $\mathrm{Al}^{3+}$ son removidos; en una segunda fase las unidades $\mathrm{Mg}(\mathrm{OH})_{2}$ y el $\mathrm{CO}_{3}{ }^{2-}$ interlaminar sufren un proceso de descomposición térmica. Debido a lo anterior, un mayor contenido de aluminio provoca que la evolución del LDH a Óxido mixto sea más lenta.

\subsection{Análisis textural}

Puesto que la fotocatálisis heterogénea es un fenómeno de superficie, la actividad catalítica de un material depende, entre muchos otros factores, de su área superficial especifica; a su vez, la estructura porosa del sólido influye directamente en el valor de esta propiedad. La adsorción-desorción de gases inertes, es una de las técnicas más comúnmente empleadas para la caracterización textural de diversos sólidos.

Las isotermas de adsorción-desorción de $\mathrm{N}_{2}$ de los materiales calcinados se muestran en la figura 3.4.

De acuerdo a la clasificación de la IUPAC, en el intervalo de presión relativa de $0.1-0.8$, los materiales sintetizados presentan isotermas tipo IV [86, 102], las cuales son características de materiales mesoporosos. En este tipo de isotermas el proceso de formación de monocapa-multicapa es irrestricto, por lo que comúnmente se emplea el punto ubicado al comienzo de la sección aproximadamente lineal, para indicar que ha concluido la cobertura de la monocapa. Para los sólidos analizados, la formación de la monocapa concluye alrededor de $\mathrm{p} / \mathrm{p}_{0}=0.25$.

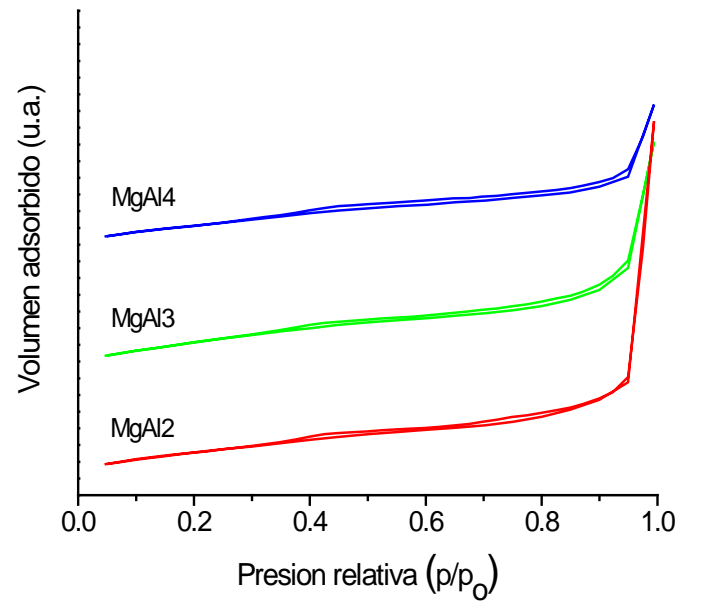

Figura 3.3. Isotermas de adsorción-desorción de $\mathrm{N}_{2}$ de los materiales calcinados 
A presiones altas, $\mathrm{p} / \mathrm{p}_{0}>0.85$, el volumen de gas adsorbido aumenta abruptamente; la forma de las gráficas se asimila a la sección final de la isoterma tipo II, revelando la presencia de poros con tamaño superiores a los $50 \mathrm{~nm}$. Los sólidos obtenidos presentan un loop de histéresis H3, el cual indica la presencia de poros asimétricos en tamaño y/o forma [86, 102].

La distribución de tamaño de poro, PSD por sus siglas en inglés, obtenida mediante la aplicación del método NLDFT (Non Local Density Functional Theory) se muestra en la figura 3.4. Las curvas revelan la existencia de mesoporos para los tres materiales sintetizados. A medida que disminuye la cantidad de aluminio en las muestras se observa una disminución en el tamaño de poro; así para el material MgAl2 el máximo en $3.775 \mathrm{~nm}$ se ha desplazado a $3.537 \mathrm{~nm}$ para MgAl3 y $3.179 \mathrm{~nm}$ para el sólido MgAl4. Asimismo se observa que la distribución PSD del material MgAl4 es menos uniforme respecto a los sólidos con menor razón molar M"/M"'.

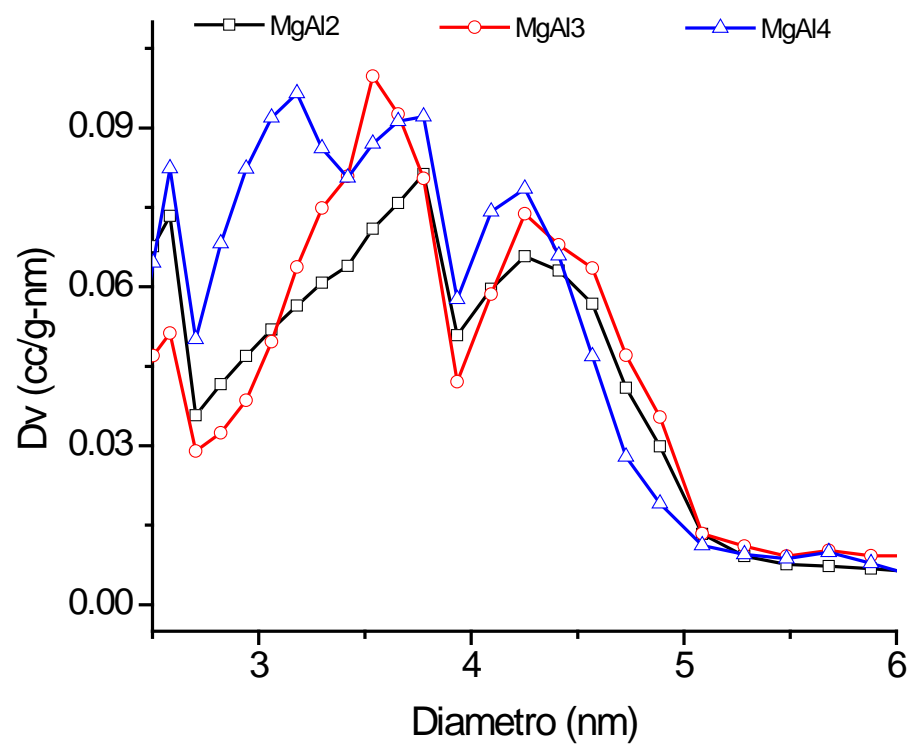

Figura 3.4. Distribución de tamaño de poro de los LDH's MgAl.

El área superficial específica (SSA) de los sólidos sintetizados se muestra en la tabla 3.3. Se observa que el valor del SSA decrece con el incremento de la razón molar $\mathrm{M}^{\prime \prime} / \mathrm{M}^{\prime \prime \prime}$. Diversas investigaciones han reportado que el área superficial específica del $\mathrm{MgO}$ y de $\mathrm{Al}_{2} \mathrm{O}_{3}$, sintetizados por el método de precipitación es de 100-300 m²/g y de 250-460 m²/g respectivamente. De acuerdo a lo anterior, el óxido 
de aluminio tiene una SSA mayor que aquella que presenta el $\mathrm{MgO}$, por lo que se espera que los materiales sintetizados muestren una disminución en el área superficial a medida que disminuye la cantidad de Al en las muestras.

Tabla 3.3. Área superficial específica y tamaño de poro de los óxidos mixtos MgAl

\begin{tabular}{ccc}
\hline Muestra & $\begin{array}{c}\text { Razón molar } \\
\text { M"/M"' experimental }\end{array}$ & $\begin{array}{c}\mathrm{S}_{\mathrm{BET}} \\
\mathrm{m}^{2} / \mathrm{g}\end{array}$ \\
\hline & & \\
MgAl2 & 2.1 & 277 \\
MgAl3 & 2.3 & 251 \\
MgAl4 & 2.8 & 237 \\
\hline
\end{tabular}

\subsection{Energía de banda prohibida}

Entre los diversos métodos que existen para calcular la energía de banda prohibida de un material, la espectroscopia de reflectancia difusa es una de las técnicas más comúnmente aplicadas. Aunque es posible determinar el valor de la Eg extrapolando directamente del espectro UV-Vis DRF, un cálculo más preciso requiere del ajuste de los datos espectroscópicos a la ecuación de Kubelka-Munk (ec. 2.4):

$$
F(R)=\frac{(1-R)^{2}}{2 R}=\frac{\alpha}{S}
$$

Donde $F(R)$ es la función de Kubelka-Munk, R es la reflectancia, $\alpha$ es el coeficiente de extincón y $s$ es el coeficiente de dispersión. Asumiendo que s es independiente de la longitud de onda, entonces $F(R)$ es proporcional al coeficiente de absorción y el ancho de banda prohibida puede ser obtenido mediante la curva de Tauc, cuya expresión matemática es (apéndice B):

$$
\alpha h v \approx\left(h v-E_{g}\right)^{n}
$$

El superíndice de la ecuación anterior, toma un valor de $n=2$ para transiciones indirectas permitidas; para transiciones indirectas prohibidas $n=3$; en transiciones directas permitidas $n=1 / 2$; finalmente $n=$ $1 / 3$ para transiciones directas prohibidas.

La energía de banda prohibida de los LDH's MgAl sintetizados fue obtenida por mediciones de reflectancia difusa (figura 3.6). Aunque las transiciones directas e indirectas pueden ocurrir 
simultáneamente, la transición más grande gobernará el comportamiento del material. Uno de los métodos empleados para determinar el carácter de esta transición, consiste en graficar $(F(R) h v)^{n}$ contra hv tanto para transiciones directas como indirectas; el coeficiente de correlacón lineal más cercano a 1 indicara el tipo de transición electrónica que predomina en el sólido analizado [103-106].

Las gráficas de $(F(R) h v)^{1 / 2}$ contra hv para los tres fotocatalizadores sintetizados, tienen coeficientes de correlación lineal en el intervalo de 0.95-0.97, mientras que para transiciones directas permitidas, $\mathrm{n}=2$, se observa una desviación del comportamiento lineal (valores de $r$ en el intervalo de 0.930.92). Este hecho indica que las principales transiciones en los sólidos sintetizados son indirectas permitidas. Sin embargo, análisis teóricos sobre la estructura electrónica de hidróxidos dobles laminares, han sugerido que las transiciones en estos materiales son de tipo directo [100, 107]. De acuerdo con cálculos sobre la densidad electrónica total y parcial de estados del LDH MgAl, la parte superior de su banda de valencia y la zona más inferior de la de conducción, se componen principalmente de orbitales $3 \mathrm{~s}$ de $\mathrm{Mg}, 3 p$ de Al y $2 p$ de 0 ; la absorción de fotones se atribuye a transiciones electrónicas directas del orbital $2 p$ a niveles ns o np de los cationes metálicos [108].

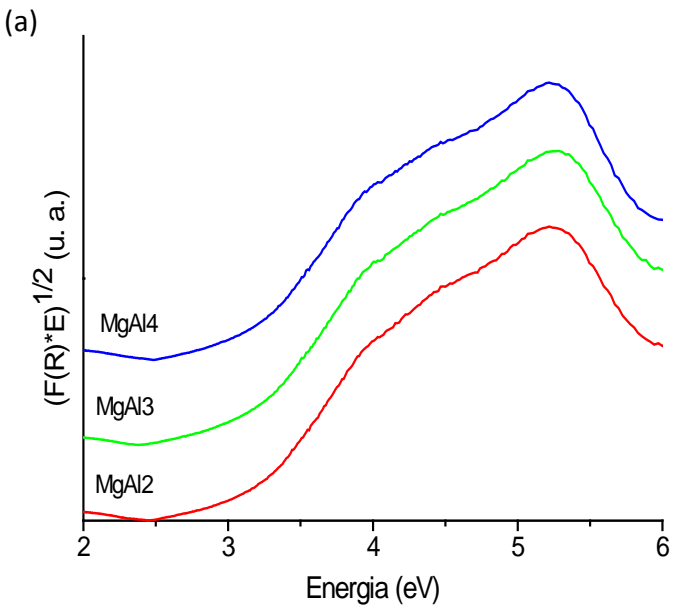

(b)

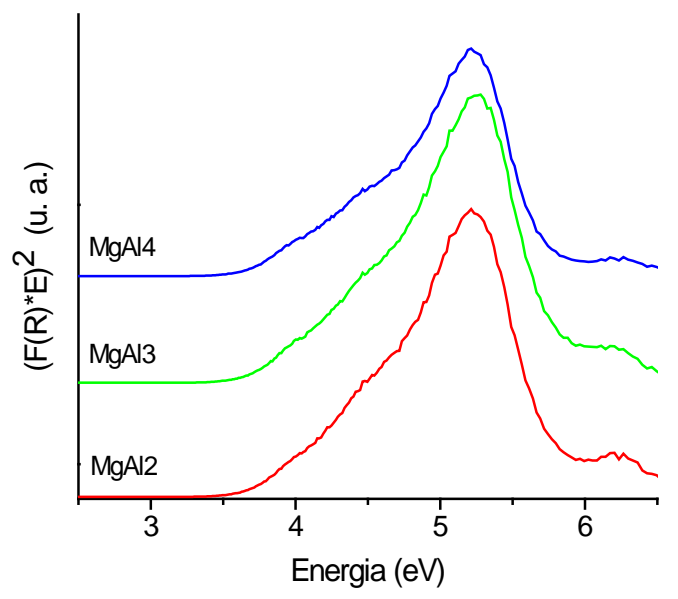

Figura 3.5. Espectro de reflectancia difusa para los LDH's MgAl calcinados considerando: a) transiciones indirectas $y$ b) directas.

El ancho de la energía de banda prohibida de los fotocatalizadores sintetizados, considerando transiciones directas e indirectas, muestra diferencias significativas (tabla 3.4); los valores obtenidos con $(\mathrm{F}(\mathrm{R}) \mathrm{hv})^{2}$ son más cercanos a lo reportado en la literatura, en la cual, debido a su Eg, los LDH's MgAl están clasificados como aislantes $[17,86]$. 
Tabla 3.4. Energía de banda prohibida para los LDH's MgAl

calcinados considerando transiciones indirectas y directas.

\begin{tabular}{ccc}
\hline \multirow{2}{*}{ Muestra } & \multicolumn{2}{c}{ Energía de banda prohibida $(\mathrm{eV})$} \\
\cline { 2 - 3 } & T. indirecta & T. directa \\
& & \\
MgAl2 & 3.083 & 3.726 \\
MgAl3 & 3.054 & 3.655 \\
MgAl4 & 3.077 & 3.678 \\
\hline
\end{tabular}

Aunque la variación de la Eg en función de la razón molar $M^{\prime \prime} / M^{\prime \prime \prime}$ es pequeña, se observa un valor mínimo para el material MgAl3. Este hecho puede atribuirse al tamaño de cristal $[109,110]$. En nanopartículas pequeñas, como en el caso de los materiales sintetizados, una disminución en el tamaño de cristalito genera un aumento en el valor de la Eg debido al confinamiento cuántico [111].

\subsection{Reacciones de fotodegradación}

La actividad fotocatalitica de los materiales sintetizados fue evaluada mediante la degradación de dos sustancia empleadas en medicina humana: naproxeno sódico y clorhidrato de oxitetraciclina.

Previo a las reacciones de fotodegradacion, se realizaron experimentos de adsorción en ausencia de luz UV, de ambas moléculas diana por un lapso de 1 hora. No se observó ninguna variación en la concentración inicial de las moléculas (figuras 3.8 y 3.9), lo cual indica que los fármacos no son adsorbidos en los LDH's MgAl calcinados.

Los espectros UV-Vis del naproxeno sódico y el clorhidrato de oxitetraciclina fueron medidos a diferentes tiempos de reacción. En la figura 3.7 se muestra la absorbancia en función del tiempo para los sistemas naproxeno sódico-MgAl3 y oxiteraciclina-MgAl3; los catalizadores MgAl2 y MgAl4 tienen comportamientos similares. En el caso del naproxeno sódico, las bandas características del compuesto, sufren importantes alteraciones durante la primera hora de irradiación. Este hecho puede atribuirse a la rápida modificación de la estructura química del compuesto. En el sistema fotocatalítico, el valor de la absorbancia decrece conforme el tiempo de reacción se incrementa; después de 5 horas de reacción, la 
absorbancia es muy cercana a cero, suceso que sugiere la efectiva mineralización de la molécula diana. Al igual que para el antiinflamatario, en el espectro UV-Vis del clorhidrato de oxitetraciclina se observan cambios considerables durante las primeras horas de reacción, fenómeno se ocurre con todos los materiales analizados. No obstante que el valor de la absorbancia disminuye conforme transcurre la reacción, el decremento de esta propiedad es más gradual que en el caso del naproxeno sódico, por lo cual, se infiere que la degradación de éste compuesto es más eficaz que la del clorhidrato de oxitetraciclina.
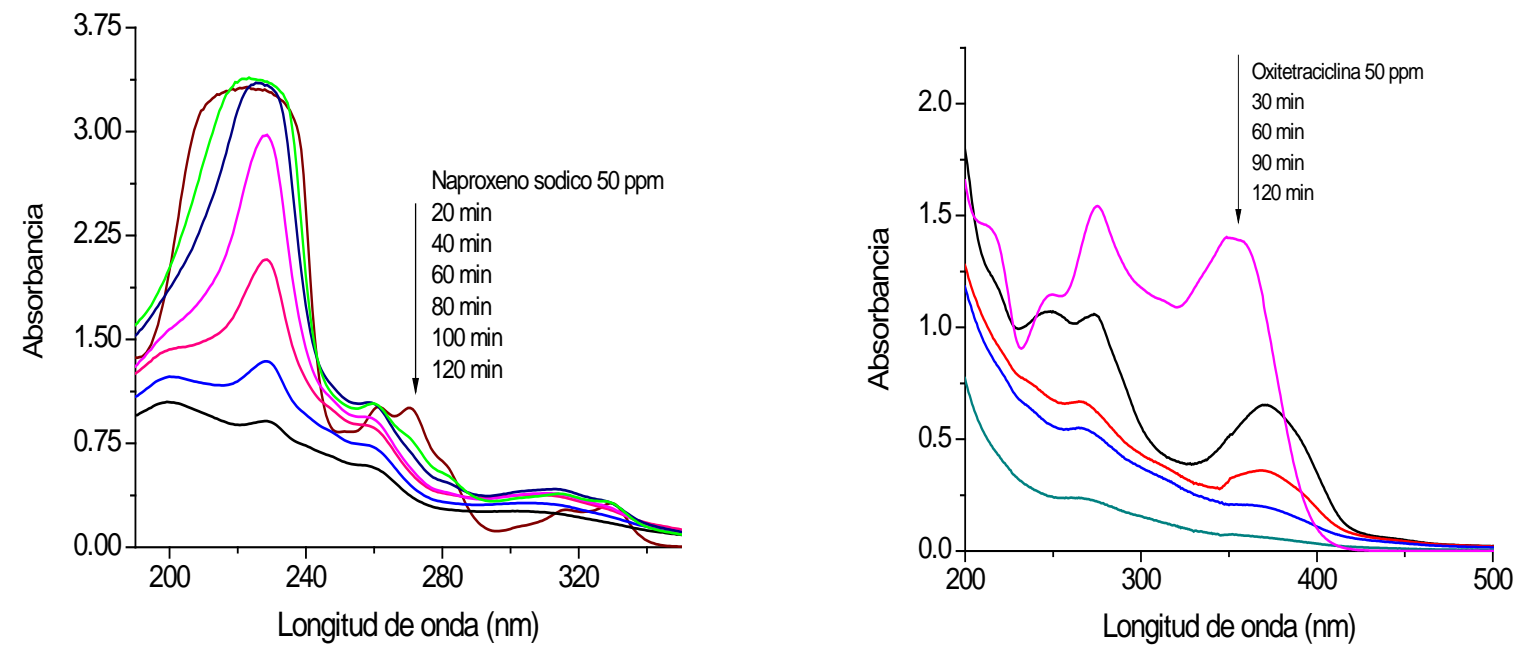

Fig. 3.6. Espectros UV - Vis de a) naproxeno sódico y b) oxitetraciclina remanentes en solución a diferentes tiempos de la reacción de fotodegradacion empleando el material MgAl3.

Debido a la rápida desaparición de las bandas características de absorción, no es factible realizar un estudio cuantitativo de la degradación de los fármacos empleando espectroscopia UV-Vis; en consecuencia, el análisis de carbono orgánico total (TOC), fue empleado para determinar los datos cinéticos de las reacciones fotocatalíticas (figuras 3.8 y 3.9 ). 


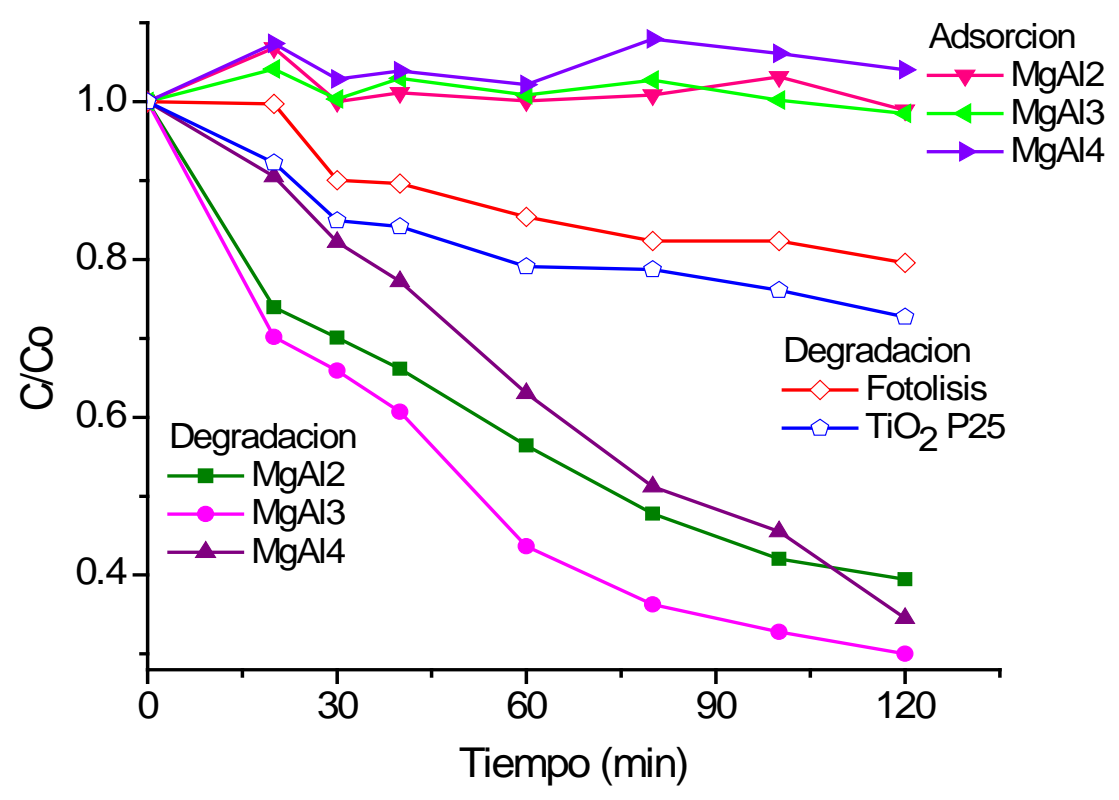

Fig. 3.7. Adsorción y fotodegradación de naproxeno sódico en solución acuosa por hidrotalcitas $\mathrm{MgAl}$ calcinadas con diferente razón molar $\mathrm{M}^{\prime \prime} / \mathrm{M}^{\prime \prime \prime}$; fotolisis $\mathrm{y}$ fotodegradación empleando $\mathrm{TiO}_{2}$.

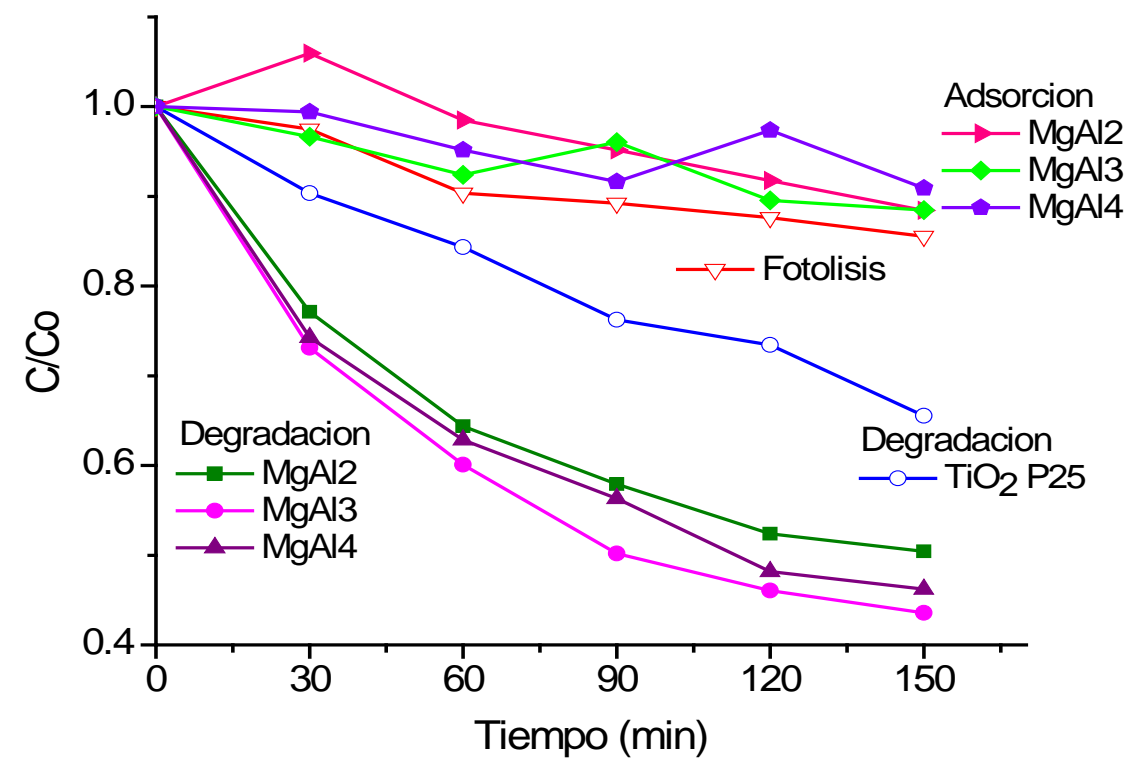

Fig. 3.8. Adsorción y fotodegradación de oxitetraciclina en solución acuosa por hidrotalcitas $\mathrm{MgAl}$ calcinadas con diferente razón molar $\mathrm{M}^{\mathrm{II}} / \mathrm{M}^{\mathrm{III}}$; fotolisis $\mathrm{y}$ fotodegradación empleando $\mathrm{TiO}_{2}$. 
Las mediciones de TOC muestran que poco más del $60 \%$ delnaproxeno sódico es mineralizado por los tres materiales sintetizados en un lapso de 2 horas, en tanto que, se requieren 2.5 horas para degradar aproximadamente $50 \%$ del clorhidrato de oxitetraciclina, confirmándose así que el naproxeno sódico es degradado con mayor eficacia por los LDH's MgAl calcinados. Para ambas fármacos, el material MgAl3 exhibió la mayor actividad catalítica en las reacciones de fotodegradación.

La fotodegradación del naproxeno sódico y del clorhidrato de oxitetraciclina sigue una cinética de pseudo primer orden (figuras 3.10 y 3.11). Al graficar el Ln (C/Co) contra el tiempo de reacción, se obtiene una línea recta cuya pendiente es proporcional al valor de la constante de velocidad aparente $[7,17,72,86]$.

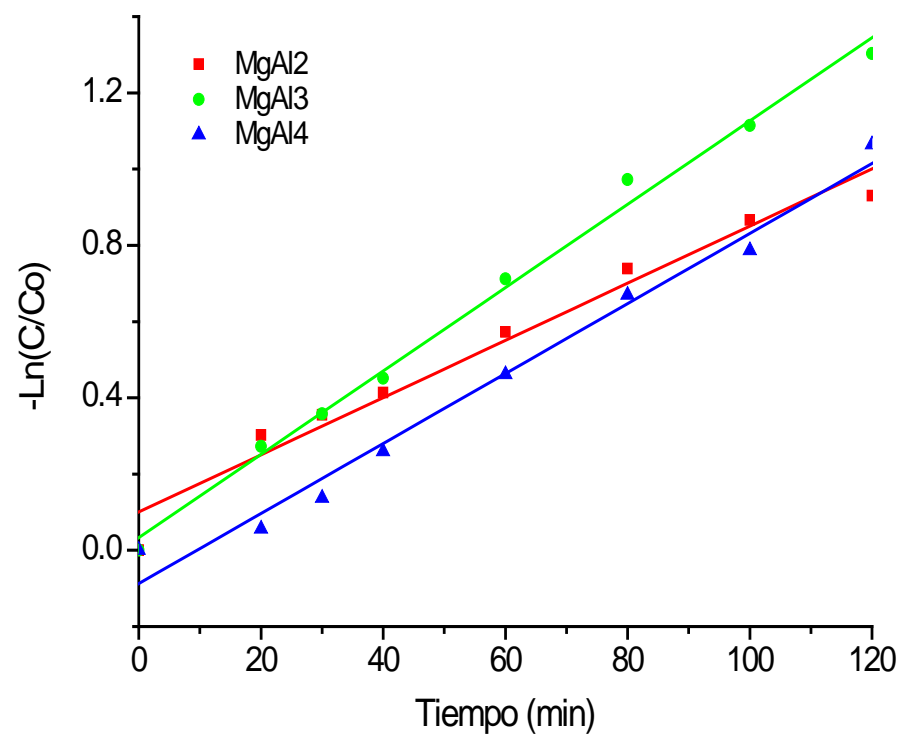

Fig. 3.9. Cinética de pseudo primer orden para la fotodegradación de naproxeno sódico empleando LDH's MgAl calcinados con diferente razón molar M"1"M"'. 


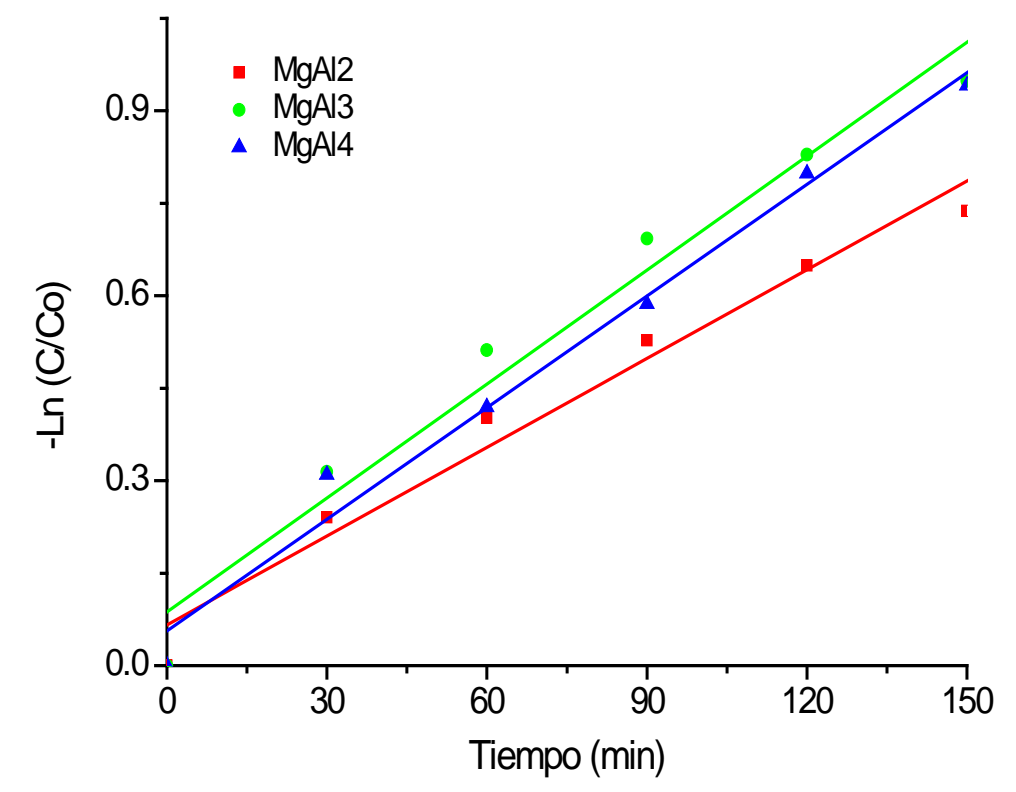

Fig. 3.10. Cinética de pseudo primer orden para la fotodegradación de oxitetraciclina empleando LDH's MgAl calcinados con diferente razón molar n nll /n n III

Las tablas 3.5 y 3.6 contienen los valores de las constantes de velocidad aparente, el tiempo de vida media y el porcentaje de contaminante degradado a las 5 horas de reacción para el naproxeno sódico y el clorhidrato de oxitetraciclina respectivamente.

Tabla 3.5. Constantes aparentes de velocidad, tiempo de vida media y porcentaje de fotodegradación para naproxeno sódico.

\begin{tabular}{cccc}
\hline Muestra & $\begin{array}{c}\mathrm{K}_{\text {app }} \\
\left(\mathrm{h}^{-1}\right)\end{array}$ & $\mathrm{t}_{1 / 2}(\mathrm{~h})$ & $\begin{array}{c}\text { \% degradación } \\
(5 \mathrm{~h})\end{array}$ \\
\hline & & & \\
$\mathrm{MgAl} 2$ & 0.45 & 1.54 & 70.37 \\
$\mathrm{MgAl3}$ & 0.656 & 1.06 & 87.9 \\
$\mathrm{MgAl4}$ & 0.551 & 1.26 & 81.13 \\
Fotolisis & 0.125 & 5.53 & 10.82 \\
$\mathrm{TiO}_{2}$ & 0.142 & 4.87 & 32.54 \\
& & & \\
\hline
\end{tabular}


Tabla 3.6. Constantes aparentes de velocidad, tiempo de vida media y porcentaje de fotodegradación para oxitetraciclina.

\begin{tabular}{cccc}
\hline Muestra & $\begin{array}{c}\mathrm{K}_{\text {app }} \\
\left(\mathrm{h}^{-1}\right)\end{array}$ & $\mathrm{t}_{1 / 2}(\mathrm{~h})$ & $\begin{array}{c}\text { \% degradación } \\
(5 \mathrm{~h})\end{array}$ \\
\hline & & & \\
$\mathrm{MgAl} 2$ & 0.288 & 2.41 & 59.32 \\
$\mathrm{MgAl} 3$ & 0.37 & 1.87 & 65.82 \\
$\mathrm{MgAl} 4$ & 0.362 & 1.92 & 63.87 \\
Fotolisis & 0.061 & 11.33 & 20.14 \\
$\mathrm{TiO}_{2}$ & 0.155 & 4.48 & 48.13 \\
& & & \\
\hline
\end{tabular}

En el caso del naproxeno sódico, el sólido MgAl3 presenta la mayor actividad catalítica con una constante de velocidad de $\mathrm{k}=0.665 \mathrm{~h}^{-1}$; este material puede degradar el $50 \%$ de la concentración inicial del fármaco en poco más de 60 minutos y transcurridas 5 horas de reacción ha logrado mineralizar 90\% del contaminante. El tiempo de vida media del material menos activo, MgAl2, es apenas 0.5 horas mayor que el calculado para el MgAl3; no obstante, después de 5 horas de reacción hay una diferencia del $20 \%$ entre la cantidad del fármaco mineralizado por el sólido menos activo y la muestra MgAl3.

Para el clorhidrato de oxitetraciclina, las constantes de velocidad aparentes tienen valores similares para los tres fotocatalizadores analizados. Aunque el material MgAl3 exhibe la mayor actividad catalítica, el valor de $\mathrm{k}$ es aproximadamente la mitad del aquel obtenido para el naproxeno sódico y al finalizar la reacción fotocatalítica, sólo se ha podido mineralizar 66\% del antibiótico. El sólido MgAl2 presenta la menor actividad en la fotodegradación del clorhidrato de oxitetraciclina; luego de 5 horas de reacción, únicamente ha mineralizado $59 \%$ de la molécula diana.

Con fines de comparación y bajo las mismas condiciones impuestas a los fotocatalizadores sintetizados, se realizaron estudios de fotolisis y fotodegradación empleando $\mathrm{TiO}_{2}$ comercial. En ambas procesos, la molécula de naproxeno sódico exhibe una baja fotodegradación: después de 5 horas de fotolisis, solo $11 \%$ del fármaco ha sido mineralizado mientras que, al emplear el $\mathrm{TiO}_{2}$ comercial se logra degradar únicamente el 32.5\% del contaminante. La degradación del clorhidrato de oxitetraciclina mediante fotolisis, es ligeramente más eficiente que en el caso del naproxeno sódico y al finalizar la reacción, 20.1\% del contaminante ha sido mineralizado. El material sintetizado con menor fotoactividad, MgAl2, degrada cerca del $60 \%$ del antibiótico, lo cual representa una mejora del $40 \%$ respecto al proceso de fotolisis. En el caso de la reacción fotocatalítica con $\mathrm{TiO}_{2}$ comercial, también se observa un incremento 
en la cantidad de fármaco mineralizado respecto al naproxeno sódico; pese a que casi $48 \%$ del antibiótico se ha degradado al finalizar la reacción, los LDH's MgAl presentan porcentajes de mineralización más altos, de tal forma que el material más activo, MgAl3, puede degradar 18\% más de esta sustancia en el mismo intervalo de tiempo.

\subsubsection{Análisis FTIR}

En catálisis, la espectroscopia infrarroja es generalmente empleada para la caracterización de compuestos orgánicos específicos. Debido a la particular naturaleza de las vibraciones moleculares, esta técnica puede arrojar información valiosa sobre la composición estructural del adsorbato en sí mismo y/o su coordinación con la superficie del material. Así, esta técnica espectroscópica permite detectar la presencia de intermediarios de reacción anclados a la superficie del catalizador, en el trascurso o finalización de una reacción química.

Las figura 3.12 muestran el espectro IR de las moléculas diana y de los sólidos recuperados después de la reacción fotocatalítica. 
En el espectro del naproxeno sódico, las bandas más intensas se encuentran en el intervalo de frecuencia de 1600 a $800 \mathrm{~cm}^{-1}$. En esta región, se localizan las señales generadas por los movimientos vibracionales de los anillos aromáticos. Así, a una frecuencia se $1585 \mathrm{~cm}^{-1}$ aparece la banda de alargamiento anular $\mathrm{C}-\mathrm{C}$, mientras que los movimientos de flexión aromáticos C-H dentro y fuera de plano, se ubican en $1029 \mathrm{~cm}^{-1}$ y $812 \mathrm{~cm}^{-1}$ respectivamente. La banda en 1390 cm-1 puede atribuirse a vibraciones de alargamiento simétrico del anión carboxilato en tanto que, el alargamiento asimétrico $\mathrm{C}-\mathrm{O}-\mathrm{C}$ de grupo éter genera una banda de absorción a $1213 \mathrm{~cm}^{-1}$. Las señales poco intensas en el intervalo de 2960-2900 $\mathrm{cm}^{-1}$, puede ser atribuidas a movimientos vibraciones de grupos $\mathrm{C}-\mathrm{H}$ en el fármaco.
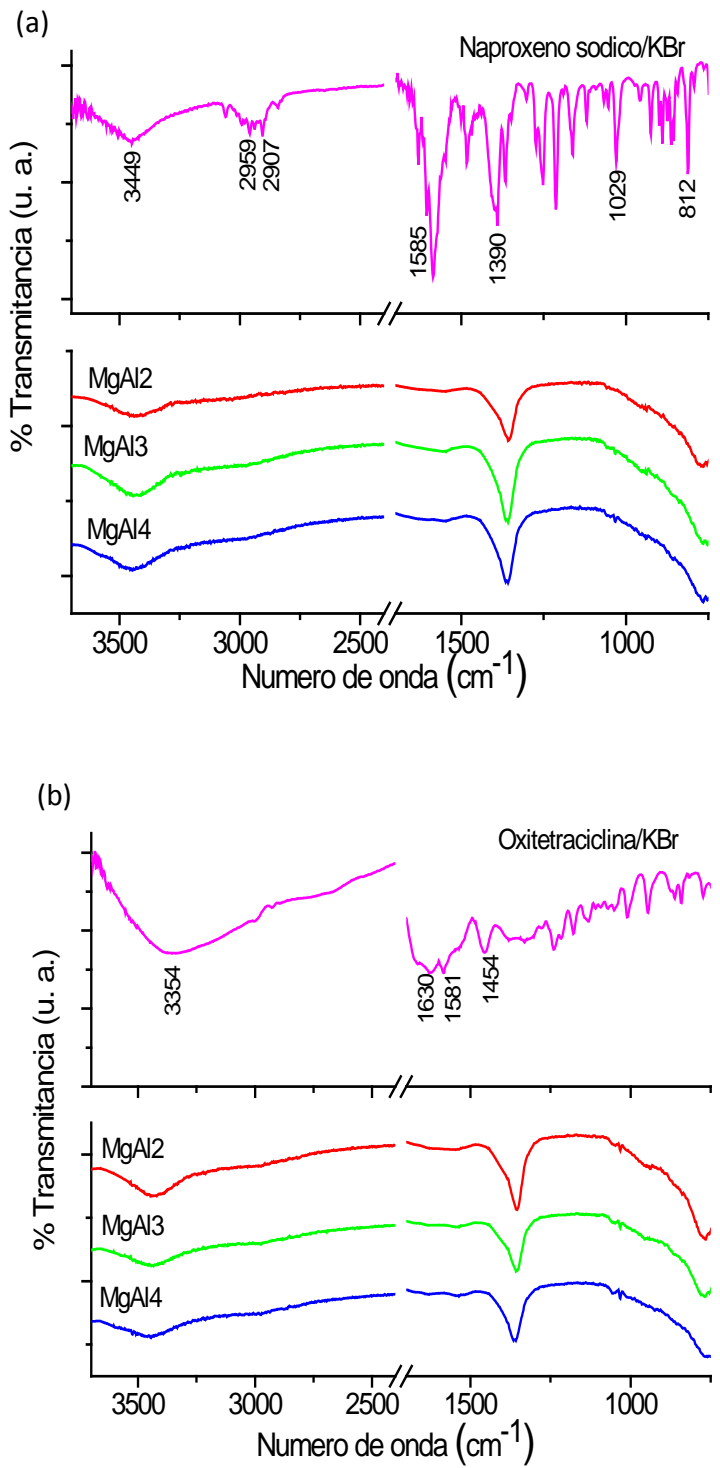

Fig. 3.11. Espectro FTIR de los LDH's MgAl calcinados después de la fotodegradación de (a) naproxeno sódico y (b) oxitetraciclina.

A diferencia del naproxeno sódico, el espectro de la oxitetraciclina presenta una banda amplia y de mediana intensidad en el intervalo de $3600-3300 \mathrm{~cm}^{-1}$. Debido a que las vibraciones de alargamiento O$\mathrm{H}$ de alcoholes y $\mathrm{N}-\mathrm{H}$ de aminas y amidas se localizan en esta región, las bandas sufren un traslape y no es posible la diferenciación inequívoca de señales. La banda a $1630 \mathrm{~cm}^{-1}$ puede estar generada por vibraciones de flexión $\mathrm{N}-\mathrm{H}$ de aminas y amidas. Las vibraciones de alargamiento $\mathrm{C}-\mathrm{C}$ del anillo aromático se ubican en $1581 \mathrm{~cm}^{-1}$. 
En el espectro de los sólidos recuperados, no se observa ningún pico correspondiente al naproxeno sódico, al clorhidrato de oxitetraciclina o a algún intermediario de reacción, lo cual sugiere que las moléculas diana y los posibles subproductos de reacción son mineralizados por los fotocatalizadores sintetizados o su concentración es muy baja. Las bandas en $1360 \mathrm{~cm}^{-1}$ y alrededor de $3450 \mathrm{~cm}^{-1}$, atribuidas a vibraciones de alargamiento $\mathrm{C}-\mathrm{O}$ y $\mathrm{O}-\mathrm{H}$ respectivamente, indican que durante el proceso fotocatalítico, $\mathrm{CO}_{3}{ }^{2-}$ y moléculas de agua fueron adsorbidas por los $\mathrm{LDH}^{\prime} \mathrm{s} \mathrm{MgAl}$ calcinados.

\subsubsection{Pruebas de fluorescencia}

De acuerdo a diversas investigaciones, el radical $\mathrm{OH}$ - es una especie clave en la foto-oxidación de contaminantes orgánicos. Aunque la detección de estos radicales es complicada, su presencia en procesos fotocatalíticos ha sido detectada mediante la aplicación de técnicas de fluorescencia.

Como se describió en la parte experimental de este trabajo, la generación de radicales $\mathrm{OH} \cdot$ por medio de los materiales sintetizados, fue seguida mediante la formación de un compuesto hidroxilado fluorescente, la 7-hydroxicoumarina. Este fluoroforo se produce a partir de la reacción entre la coumarina, molécula aromática con bajo rendimiento cuántico, y un radical $\mathrm{OH}$. La reacción global es:

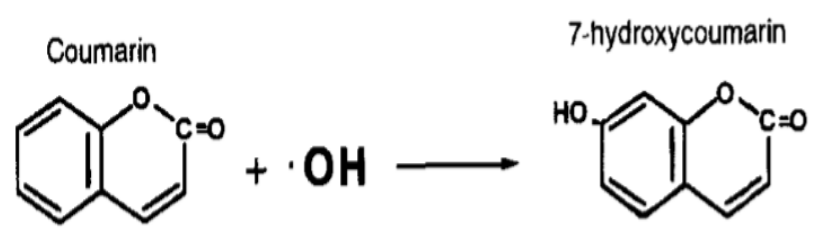

Fig. 3.12. Formación de un producto hidroxilado fluorescente a partir de la reacción entre la coumarina y radicales $\mathrm{OH} \cdot$ Tomado de [112] 
La figura 3.14 muestra los espectros de emisión de la 7-hydroxicoumarina, excitada a $332 \mathrm{~nm}$, para los sistemas coumarina-luz UV y coumarina-MgAl3- luz UV. En el espectro de coumarina irradiada con luz UV, se observa que una cantidad considerable de 7hidroxicoumarina se produce en los primeros minutos del proceso; sin embargo la concentración del fluoroforo permanece prácticamente constante conforme la reacción procede. Debido a que la concentración del fluoroforo es directamente proporcional a la producción de radicales $\mathrm{OH} \cdot$, se infiere que, la generación de estas especies disminuye rápidamente al incrementarse el tiempo de irradiación. Este fenómeno puede explicar el bajo rendimiento que se obtuvo en la fotolisis de los fármacos.

Para el sistema Coumarina-MgAl3-luz UV, la concentración del fluoroforo es superior a aquella registrada en el sistema que no contiene fotocatalizador, por lo cual se deduce que la producción de radicales $\mathrm{OH} \cdot$ aumenta significativamente con la presencia del LDH calcinado. La cantidad de 7-hydroxicoumarina aumenta conforme se incrementa el tiempo de reacción, indicando de esta manera, que la generación de radicales continua durante todo el proceso fotocatalítico.

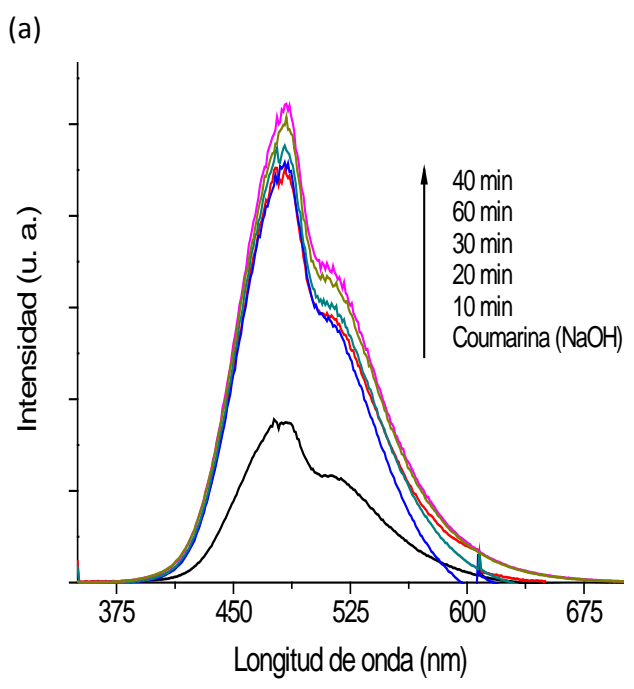

(b)

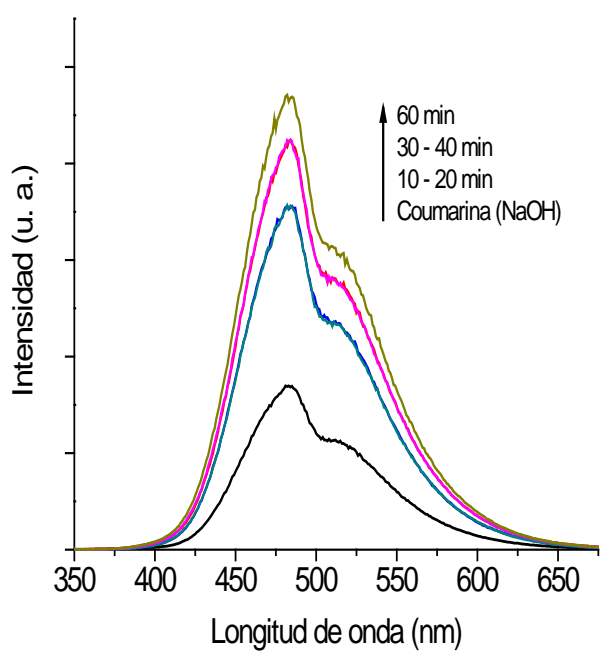

Fig. 3.13. Espectro de fluorescencia usando una longitud de onda de excitación de $332 \mathrm{~nm}$ para los sistemas: (a) coumarina irradiada con luz UV y (b) coumarina-MgAl3-luz 
La figura 3.15 muestra la variación en la intensidad de la fluorescencia como función del tiempo, para los sistemas Coumarina irradiada con luz UV y Courmarina-MgAl3-luz UV.

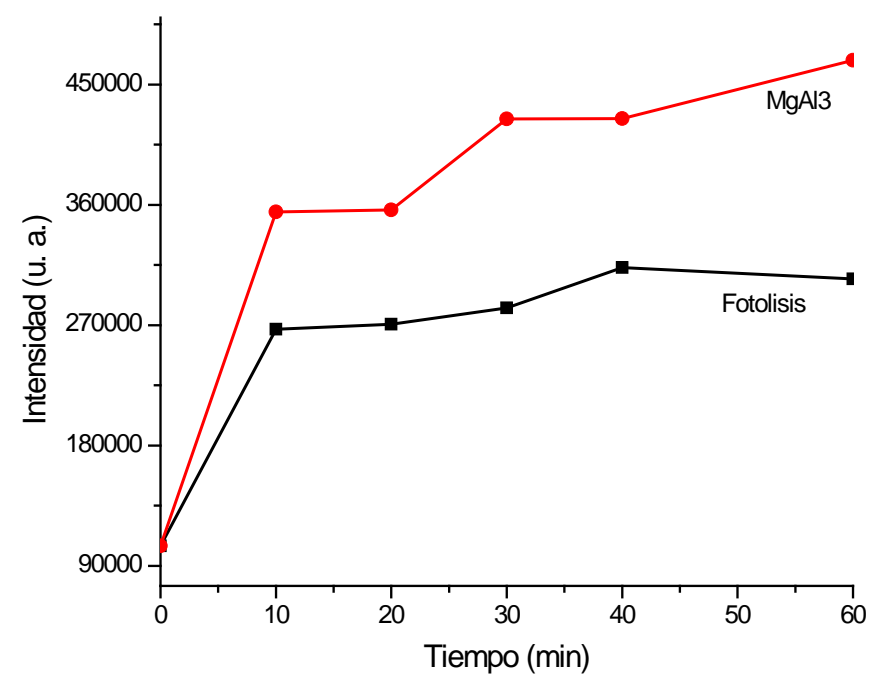

Fig. 3.14. Intensidad de fluorescencia de 7-hidroxicoumarina en función del tiempo para los sistemas Coumarina-luz UV y Coumarina-MgAl3-luz UV.

El grafico anterior, corrobora lo observado en los espectros de la figura 3.14: al irradiar con luz UV la solución de Coumarina, hay una rápida producción de 7-hidroxicoumarina, es decir la generación de altas concentraciones de radicales $\mathrm{OH}$. Conforme la reacción procede el aumento en la intensidad de fluorescencia es pequeño hasta que a los 60 minutos del proceso hay una disminución de ésta. En presencia de MgAl3, la intensidad es superior a la registrada para la fotólisis en todo momento; asimismo, no se registra una caída en la generación de radicales $\mathrm{OH} \cdot$, lo que permite inferir que los catalizadores sintetizados fotodegradan eficientemente a las moléculas de prueba, por la continua por la producción de radicales $\mathrm{OH}$. 


\subsubsection{Elucidación del comportamiento fotocatalítico de los óxidos mixtos MgAl}

Aunque las moléculas objetivo pueden ser degradadas por los tres fotocatalizadores sintetizados, el naproxeno sódico es mineralizado con mayor eficiencia que el clorhidrato de oxitetraciclina. Este hecho puede estar relacionado con la estructura química de los fármacos policíclicos. En general, para que un contaminante orgánicos policíclicos pueda ser degradado a sustancias menos toxicas y biodegradables, e incluso mineralizarse a $\mathrm{CO}_{2}$ y $\mathrm{H}_{2} \mathrm{O}$, debe experimentar una serie de reacciones químicas que incluyen la apertura de anillos. Se ha observado que, si una molécula policíclica contiene sustituyentes reactivos, los radicales $\mathrm{OH} \cdot$ reaccionan primeramente con estos grupos antes de atacar la estructura cíclica [113]. De acuerdo a lo anterior, la fotodegradación de naproxeno sódico es más rápida debido a que contiene un menor número de sustituyentes que el clorhidrato de oxitetraciclina. Diversos estudios enfocados en los mecanismos de fotodegradación del naproxeno sódico, han encontrado que, uno de los primeros pasos en la reacción, consiste en el ataque de los radicales $\mathrm{OH} \cdot$ al grupo $-\mathrm{COOH}$, generando productos en los cuales la estructura cíclica permanece inalterada $[8,114]$. En el caso de la oxitetraciclina, se ha sugerido que la fotodegradación de la molécula comienza con las reacciones entre radicales $\mathrm{OH} \cdot$ y los grupos sustituyentes ceto-enol, amino y amida; la gran cantidad de subproductos formados en esta fase del proceso, presentan el núcleo tetraciclina (estructura de 4 anillos) [32, 115]. Finalmente, la apertura de los anillos puede ser más eficiente para los subproductos del naproxeno sódico, debido a que su estructura cíclica contiene dobles enlaces cuya reactividad favorece la interacción química con los radicales $\mathrm{OH}$.

La variación de la razón molar M"/M"' en los fotocatalizadores sintetizados tienen un efecto directo en la banda de energía prohibida y, consecuentemente, en la actividad catalítica. Un gran número de investigaciones han mostrado que el valor de la Eg, determina las propiedades electrónicas de los materiales semiconductores. En los procesos fotocatalíticos, la energía de banda prohibida determina la frecuencia mínima requerida para que la luz incidente sea absorbida por el catalizador y, de esta manera puedan generarse pares electrón-hueco. Los huecos fotoinducidos reaccionaran con iones hidróxido o moléculas de agua para formar radicales $\mathrm{OH}$, altamente reactivos, los cuales son los principales oxidantes de los contaminantes orgánicos. Se ha encontrado que, en general, los materiales con energía de banda prohibida pequeña, absorben fuertemente la luz e incrementan la eficiencia del proceso fotocatalítico $[86,116,117]$. La Eg de los fotocatalizadores sintetizados, varía con la cantidad de $\mathrm{Al}^{3+}$ en la muestra y presenta un mínimo en el sólido MgAl3; este hecho puede explicar su mayor actividad catalítica en la mineralización de ambos fármacos. El material con la menor razón molar $\mathrm{M}^{\prime \prime} / \mathrm{M}^{\prime \prime \prime}$, tienen 
la energía de banda prohibida más alta, y en consecuencia exhibe la menor eficiencia en las reacciones de fotodegradación.

El comportamiento fotocatalítico de los óxidos mixtos MgAl en la degradación de los fármacos objetivo, puede ser explicado a partir del esquema 3.16.

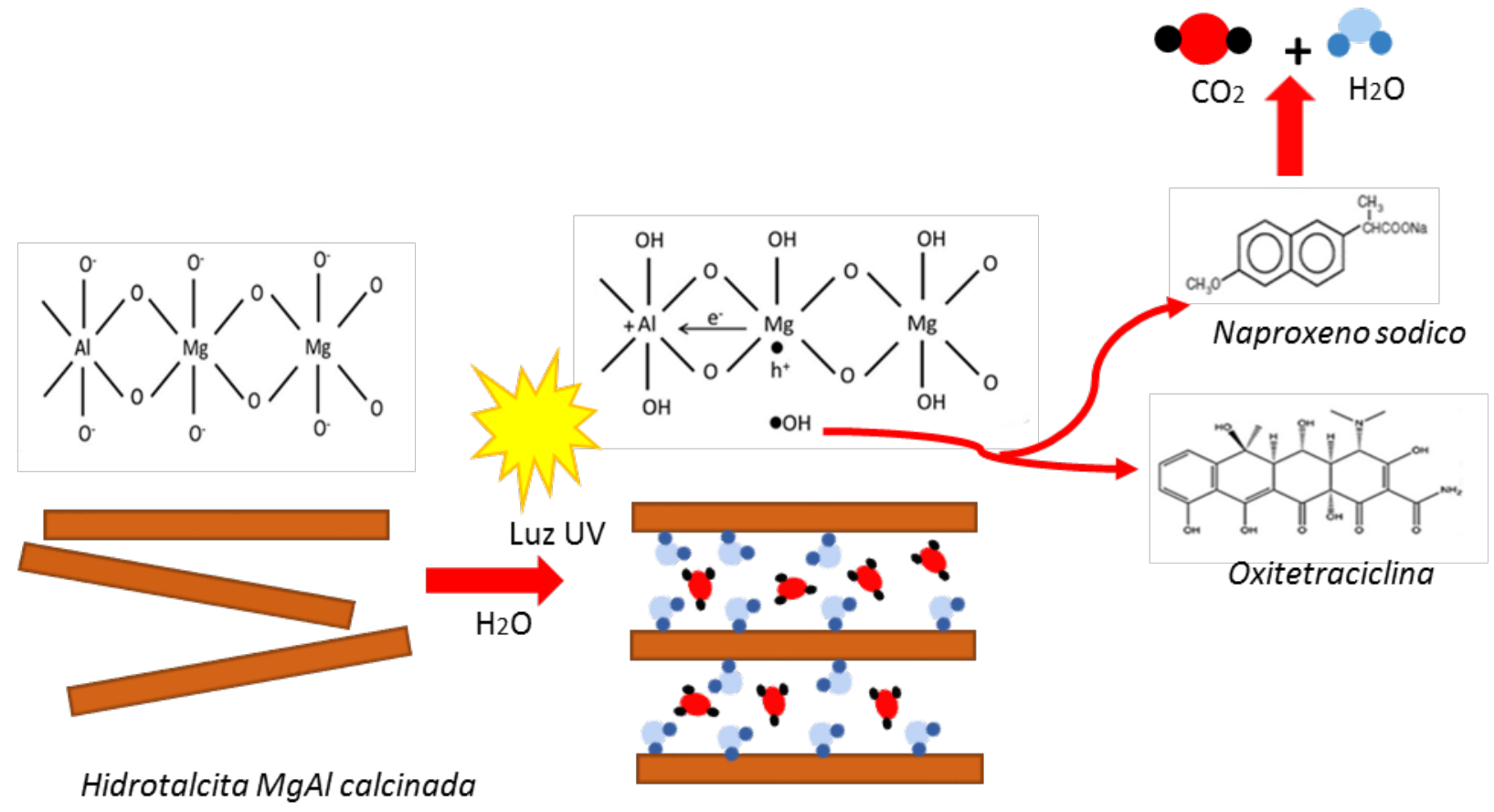

Fig. 3.15. Representación esquemática del comportamiento fotocatalítico de los materiales calcinados en las fotodegradación de naproxeno sódico y oxitetraciclina.

De acuerdo a la temperatura de calcinación, los hidróxido dobles laminares pueden regenerar su estructura laminar, parcial o totalmente, al ser situados en medio acuoso. Al ser colocados en agua, los $\mathrm{LDH}^{\prime} \mathrm{s} \mathrm{MgAl}$ calcinados $\left(450^{\circ} \mathrm{C}\right)$ interactúan con las moléculas del solvente, provocando la hidroxilación gradual del material. Aunque se ha reportado que el $\mathrm{MgO}$ y $\mathrm{Al}_{2} \mathrm{O}_{3}$ presentan energías de banda prohibida anchas, la síntesis de sólidos que contengan ambos cationes metálicos, $\mathrm{Mg}^{2+}$ y $\mathrm{Al}^{3+}$, resulta en la obtención de nuevos materiales con propiedades semiconductoras, por lo que la irradiación de los sistemas con luz UV, ocasiona la generación de pares electrón-hueco, donde el electrón es deslocalizado a través de la deficiencia de carga $\mathrm{Al}^{3+}$ y el hueco oxida a los grupos hidroxilo [118], permitiendo la formación de radicales $\mathrm{OH} \cdot$ y el subsecuentemente ataque a las moléculas diana. 
Los datos experimentales evidencian que la actividad fotocatalítica de los LDH's MgAl calcinados es superior a la del $\mathrm{TiO}_{2} \mathrm{P} 25$. Si se considera el valor de la Eg calculada para transiciones indirectas, todos los fotocatalizadores analizados presentan energías de banda prohibida, 3.050 a $3.080 \mathrm{eV}$, menores a aquella reportada para el dióxido de titanio comercial, circunstancia que podría explicar el mejor desempeño de los materiales sintetizados en las reacciones de fotodegradación.

Los valores de la energía de banda prohibida para transiciones directas son más altos que la $\mathrm{Eg}$ del $\mathrm{TiO}_{2}$ P25 por lo cual, podría esperarse que exhibieran porcentajes de degradación menores al catalizador comercial. Sin embargo, los materiales sintetizados presentan áreas superficiales grandes, 255-235 $\mathrm{m}^{2} / \mathrm{g}$, lo que implica una gran disposición de sitios activos. Aunado a lo anterior, el tamaño de cristalito de los LDH's MgAl se encuentra en el orden de los nanómetros, por lo que sus superficies contienen átomos muy reactivos. 


\section{CONCLUSIONES Y PERSPECTIVAS}

Mediante el método de coprecipitación se sintetizaron tres hidróxidos dobles laminares MgAl a partir de los nitratos de los iones metálicos y soluciones de $\mathrm{K}_{2} \mathrm{CO}_{3} / \mathrm{KOH}$. Con la finalidad de observar el efecto de la composición en la actividad fotocatalítica de los materiales, la razón molar $\mathrm{M}^{\prime \prime} / \mathrm{M}^{\mathrm{II}}$ fue variada en cada muestra.

De acuerdo con el análisis de difracción de rayos-X, los sólidos sintetizados presentaron fases puras LDH, con tamaños de cristalito en el intervalo de $80-90 \mathrm{~nm}$. Al incrementarse la cantidad de aluminio en las muestras, los parámetros de celda disminuyen debido al radio iónico inferior del catión trivalente y al incremento de la carga positiva de las láminas hidroxiladas.

Todos los materiales sintetizados presentaron mesoporosidad y áreas superficiales altas, cuyo valor fue de los 245 a $248 \mathrm{~nm}$. Se observó un incremento de la porosidad y consecuentemente del área superficial específica, al disminuir la razón molar M"'/M"'.

Aunque la variación de la banda de energía prohibida en función de la razón molar $M^{\prime \prime} / M^{\prime \prime \prime}$ fue pequeña, se observó un mínimo en el material MgAl3. Este comportamiento influyó de manera directa en la actividad fotocatalítica de los materiales. Los valores obtenidos para la Eg, mostraron que los sólidos sintetizados tienen carácter semiconductor.

Los resultados del proceso de fotocatalítico indican que los LDH's MgAl calcinados, son eficientes en la fotodegradación de naproxeno sódico y oxitetraciclina en medio acuoso. Más del $80 \%$ del antiinflamatorio fue mineralizado al cabo de 5 horas de reacción en tanto que, alrededor del 65\% del antibiótico fue eliminado en el mismo periodo. La menor eficacia en la fotodegradación de oxitetraciclina, puede deberse a que este compuesto presenta una estructura química más compleja que la del naproxeno sódico. Aunque la actividad catalítica de un material depende de diversos factores, se observó que el sólido con menor energía de banda prohibida, MgAl3, exhibió la mayor fotoactividad. La fotolisis de ambos fármacos fue ineficaz mientras que la actividad catalítica del $\mathrm{TiO}_{2}$ P25, fue inferior respecto a la de los fotocatalizadores sintetizados.

El análisis FTIR de los sólidos recuperados después del proceso fotocatalítico, no mostro alguna señal atribuible a los fármacos en su forma nativa y/o posible intermediarios de reacción, lo cual es puede ser un indicativo de la mineralización de todas las sustancias presentes en el sistema de reacción o una muy baja concentración de éstos en los sólidos. 
Las pruebas de fluorescencia evidenciaron la generación de radicales $\mathrm{OH} \cdot$ por medio de los LDH's MgAl calcinados. Lo anterior confirma que los fotocatalizadores calcinados, al regenerar su estructura laminar en presencia de luz UV, producen pares electrón-hueco, en donde el electrón es deslocalizado a través de la deficiencia de carga del $\mathrm{Al}^{3+}$ y el hueco permite la formación de radicales $\mathrm{OH}$, especies responsables de la oxidación de los fármacos.

\subsection{Perspectivas}

Ante la inminente escasez de agua, el desarrollo de tecnologías que permitan su purificación y reutilización, es cada vez más indispensable. Aunque en la actualidad, las plantas de tratamiento se han incrementado a nivel mundial, los métodos empleados resultan ineficientes para la remoción de contaminantes poco biodegradables y altamente tóxicos, lo cual obstruye la reutilización del agua residual y representa un grave problema de salud para los seres humanos y los ecosistemas.

Diversos estudios, han mostrado que la fotocatálisis heterogénea es una técnica altamente eficiente en la degradación de contaminantes orgánicos, entre los que se incluyen los productos farmacéuticos. Pese a algunas plantas piloto han implementado este proceso de oxidación avanzada, es necesario la multiplicación de estos proyectos para su pronta incorporación en la industrial.

La versatilidad de los hidróxidos dobles laminares MgAl, su obtención mediante síntesis de bajo costo, la posibilidad de modificar sus parámetros estructurales y su alta actividad catalítica en reacciones de fotodegradación de moléculas orgánicas, hacen de ellos uno de los materiales más promisorios para el tratamiento de agua residual.

Estudios posteriores de los materiales sintetizados, pueden incluir pruebas sobre la influencia del pH en las reacciones de fotodegradación y su modificación estructural para obtener catalizadores capaces de absorber luz visible y, de esta forma, disminuir el costo del proceso fotocatalítico. 


\section{Apéndice A. Estudios de adsorción}

\section{A.1. Introducción}

La adsorción es hasta ahora una de los métodos más comúnmente empleados en la remoción de fármacos. Numerosos adsorbentes, que van desde los sólidos inorgánicos hasta los polímeros, han sido probados con éxito en la eliminación en medio acuoso de antibióticos sulfa, naproxeno sódico, carbamazepina, ketoprofeno y ciclotetraciclina; no obstante, muchos de estos materiales no pueden ser empleados en procesos subsecuentes que permitan la destrucción del contaminante después del proceso de adsorción. Los hidróxidos dobles laminares (LDH por sus siglas en inglés) pueden representar una alternativa viable a este problema ya que además de ser materiales reutilizables, de síntesis sencilla y económica, han mostrado una alta eficacia en la fotodegradación de diversos compuestos orgánicos.

La adsorción es un fenómeno por el cual un soluto (adsorbato), que puede estar en fase liquida o gaseosa, se adhiere a la superficie de un sólido (adsorbente) debido a la insaturación del campo de fuerzas del material. Este fenómeno puede ser origen físico o químico. En la adsorción física, el adsorbato se une al adsorbente mediante fuerzas intermoleculares débiles tales como Fuerzas de van der Waals. Existe más de una capa de adsorción, ya que al cubrirse completamente la superficie del sólido, las moléculas del soluto siguen interaccionando y acumulándose sobre el material. Por otra parte en la adsorción química, el adsorbato se une al adsorbente por medio de un enlace químico. Debido a lo anterior, sólo existe una capa de adsorción y el calor de adsorción es del orden de $200 \mathrm{Kcal} / \mathrm{mol}$. [119]

Uno de los parámetros más importantes en los fenómenos de adsorción, es la cantidad máxima de soluto que se puede adsorber sobre el material. El método más utilizado para la determinación experimental de esta variable se basa en la construcción de isotermas, proceso en el cual se mide la variación de soluto adsorbido al modificar la presión, manteniendo constante la temperatura del sistema.

Existen diversos modelos matemáticos que permiten calcular la cantidad máxima de soluto adsorbido por un material. Uno de los más importantes es el obtenido por Langmuir al estudiar la adsorción de gases en superficies sólidas. Otros modelos han surgido a partir de modificaciones a la ecuación de ésta isoterma. A continuación se discuten algunos de los modelos más representativos en la teoría de la adsorción.

1.- Isoterma de Langmuir. Esta es una de las ecuaciones más empleadas en estudios de adsorción. Para su derivación Langmuir consideró que la adsorción de gases en superficies sólidas es fenómeno químico 
en el cual la superficie es energéticamente homogénea; las moléculas del adsorbato no interaccionan entre ellas por lo cual la adsorción termina con la formación de la monocapa; se establece un equilibrio entre las moléculas en fase gaseosa y las adsorbidas. Así, la expresión matemática es de la isoterma de Langmuir es:

$$
a=a_{m} \frac{K P}{1+K P}
$$

donde $a$ es la cantidad de sustancia adsorbida, $a_{m}$ la cantidad máxima de soluto adsorbido, $K$ es la constante de equilibrio de la reacción de adsorción y $P$ la presión de equilibrio

Al tratar con solutos en fase líquida, la expresión anterior puede ser modificada para dar la siguiente ecuación,

$$
Q_{e}=Q_{t h}^{e} \frac{K_{e q} C_{e}}{1+K_{e q} C_{e}}
$$

donde $Q_{e}$ es la capacidad de adsorción en el equilibrio, $Q_{t h}^{e}$ es la capacidad de adsorción máxima, $K_{e q}$ es la constante de equilibrio de la reacción de adsorción y $C_{e}$ es la concentración de adsorbato en el equilibrio.

\section{2.- Isoterma de Freundlich}

Freundlich propuso una ecuación empírica para describir una isoterma de adsorción cuya expresión matemática es:

$$
Q_{e}=k_{F} C_{e}^{1 / n_{F}}
$$

donde $k_{f}$ y $n_{F}$ son constantes que dependen de la temperatura. Esta ecuación no es válida a presiones altas ya que la cantidad de soluto adsorbido tendería a infinito.

3.- Isoterma de Fowler-Guggenheim. Esta isoterma se emplea cuando existen interacciones fuertes entre las moléculas del adsorbato. El grado de cobertura se vuelve función del coeficiente de actividad, 


$$
\gamma_{a}=e^{-k \theta}
$$

Por lo tanto la ecuación de la isoterma de Fowler-Guggenheim es

$$
P=\frac{\theta}{K(1-\theta) e^{-k \theta}}
$$

donde $P$ es presión, $K$ es la constante de equilibrio para la reacción de adsorción, $\theta$ es el grado de cobertura y $k$ caracteriza la interacción adsorbato-adsorbato.

Otros modelos empleados en la teoría de la adsorción son la Isoterma de Sips, Isoterma de Böer-Folmer, Isoterma de Gil de Böer, Isoterma de Redlich-Peterson, Isoterma de Khan, Isoterma de Tóth, Isoterma de Frumkin, Isoterma de Radke-Prausnitz, Isoterma de Dubinin-Radushkevich e Isoterma de Flory-Huggins [120].

Los modelos matemáticos anteriormente mencionados se emplean en la adsorción monomolecular, pero si al adsorber un soluto en la superficie de un sólido, se presenta la formación de 2 o más capas (multicapas), dichas ecuaciones no pueden describir el fenómeno de adsorción. En tales casos se emplea la ecuación de BET, cuyo nombre se deriva de los apellidos de los científicos que desarrollaron dicho modelo, Brunauer, Emmett y Teller. Basados en el modelo de Langmuir y en la teoría potencial de adsorción (Polanyi, 1915), la ecuación BET considera que la superficie posee cierto número de centros con la misma energía, que no existe interacción entre las moléculas del adsorbato en ninguna de las capas que se forman y que cada molécula que se encuentra en una determinada capa es un centro activo posible para la formación de una capa más. Su expresión matemática es:

$$
a=\frac{a_{m} C\left(P / P_{s}\right)}{\left[1-\left(\frac{P}{P_{s}}\right)\right]\left[1+(C-1)\left(\frac{P}{P_{s}}\right)\right]}
$$

donde $a$ es la cantidad de soluto adsorbido por el sólido, $a_{m}$ es la cantidad de adsorbato en una capa compacta, $P / P_{s}$ es la presión relativa, y $C$ es una constante obtenida de la razón $K^{\prime \prime} / K_{L}$ ( $K^{\prime}=$ constante total de la reacción de adsorción, $K_{L}=$ inverso de la presión del vapor saturado $P_{S}$ ). 


\section{Cinética de adsorción}

La adsorción involucra la interacción química entre el adsorbato y el adsorbente, por lo cual un factor determinante es la velocidad o rapidez con la cual se forman enlaces químicos entre las moléculas y la superficie. En general, tres modelos se han empleado para describir las cinéticas de adsorción: pseudo primer orden, pseudo segundo orden y el modelo de difusión intraparticular [9, 26, 120, 121].

La ecuación cinética de pseudo-primer orden fue derivada originalmente por Lagergren al estudiar la adsorción de ácido oxálico y malónico en carbón vegetal. Su expresión matemática es:

$$
\frac{d q_{t}}{d t}=k_{1}\left(q_{e}-q_{t}\right) \quad \text {.... (7-A) }
$$

donde $q_{e}$ es la cantidad de adsorbato adsorbido en el equilibrio $(\mathrm{mg} / \mathrm{g}), q_{t}$ es su valor a un tiempo $t$ ( $\mathrm{mg} / \mathrm{g})$ y $k_{1}$ es la constante de velocidad de pseudo-primer orden $(1 / \mathrm{s}, 1 / \mathrm{min}, 1 / \mathrm{h}$, etc.). Al integrar la expresión anterior considerando que a $t=0, q_{t}=0$ se tiene la siguiente ecuación

$$
\operatorname{Ln}\left(\frac{q_{e}}{q_{e}-q_{t}}\right)=k_{1} t
$$

Colocando en forma lineal la expresión integrada de pseudo-primer orden se obtiene:

$$
\operatorname{Ln}\left(q_{e}-q_{t}\right)=\operatorname{Ln}\left(q_{e}\right)-k_{1} t
$$

La cinética de pseudo-segundo orden fue primeramente propuesta por Blanchard y otros colaboradores. Esta ecuación ha sido ampliamente utilizada en el estudio de cinéticas de adsorción. Su expresión matemática es:

$$
\frac{d q_{t}}{d t}=k_{2}\left(q_{e}-q_{t}\right)^{2}
$$

donde $q_{e}$ es la cantidad de adsorbato adsorbido en equilibrio $(\mathrm{mg} / \mathrm{g}), q_{t}$ es su valor a un tiempo t (mg/g) y $k_{2}$ es la constante de velocidad de pseudo-segundo orden. Al integrar la ecuación diferencial de pseudo-segundo orden se obtiene:

$$
q_{t}=\frac{q_{e}^{2} k_{2} t}{1+q_{e} k_{2} t}
$$


La forma lineal de la ecuación anterior es:

$$
\frac{1}{q_{t}}=\frac{1}{k_{2} q_{e}^{2}}+\frac{1}{q_{e}} t
$$

El modelo de difusión intraparticular, se basa en el transporte del soluto a través de la estructura interna de los poros del adsorbente y en la difusión en el sólido. Su expresión matemática es [122]:

$$
q_{t}=k_{3} t^{0.5}
$$

donde $q_{t}$ es la cantidad de soluto adsorbido a un tiempo $\mathrm{t}(\mathrm{mg} / \mathrm{g})$ y $k_{3}$ es la constante de velocidad del modelo cinético.

\section{A.2. Metodología}

Para realizar los estudios de adsorción, los LDH's MgAl sintetizados fueron previamente calcinados a $450^{\circ} \mathrm{C}$ por $12 \mathrm{~h}$. El siguiente esquema muestra el procedimiento empleado para remover las moléculas objetivo.

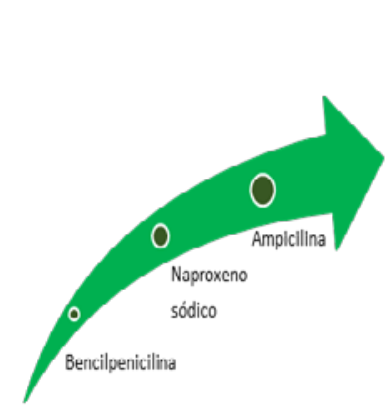

Soluciones del fármaco $(50$

ppm) se ponen en contacto

con $0.1 \mathrm{~g}$ del adsorbente. Los

cambios en la concentración

se siguen por espectroscopia

- Experimentos

de equilibrio

UV-Visy TOC

Los sólidos secos $\left(55^{\circ} \mathrm{C}\right.$ por

$72 \mathrm{~h})$ se analizan en un

Difractometro Siemens D500

- Estudios de difracción

de rayos- $X$ 


\section{A.3. Resultados y discusión}

\section{A.3.1. Bencilpenicilina}

Los gráficos a) y b) muestran los espectros UV-Vis para la adsorción de bencilpenicilina en los sólidos MgAl-2 y MgAl-4.

a)

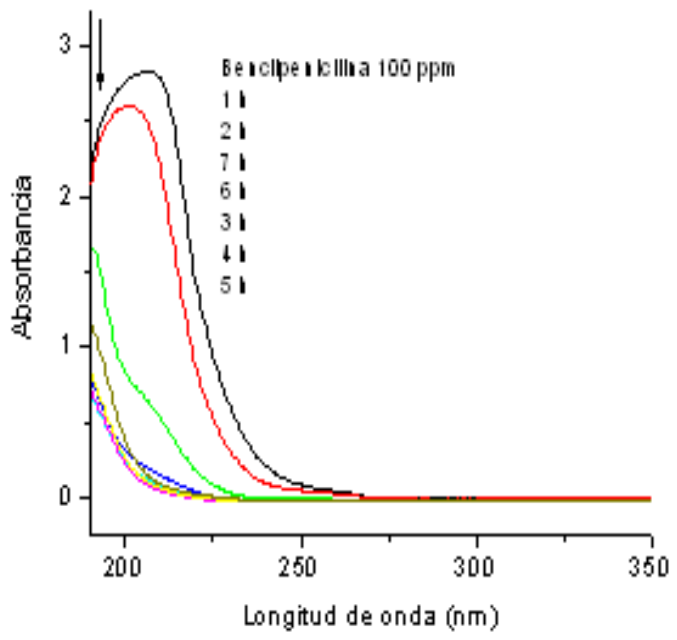

b)

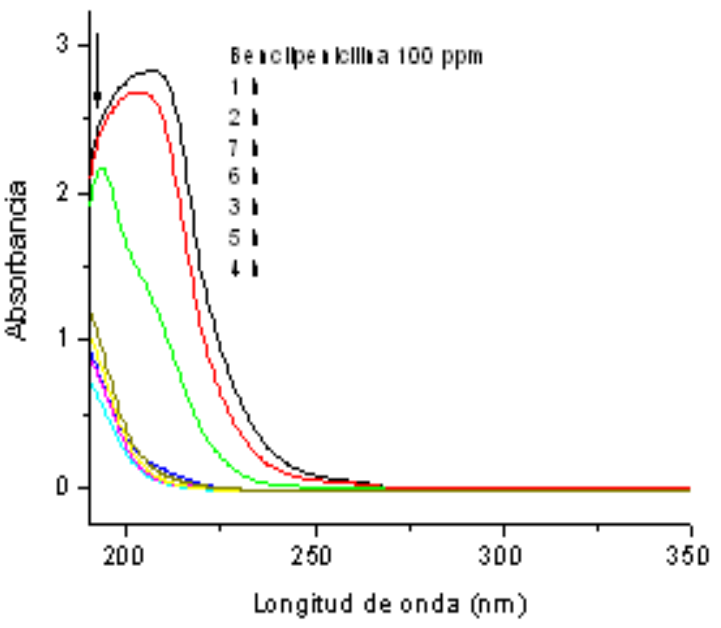

Fig. A1. Adsorción de bencilpenicilina por los materiales a)MgAl2 y b)MgAl4.

Aunque los gráficos de espectroscopia UV-Vis para el material MgAl-3 fueron omitidos, se observa que al incrementar la razón molar $\mathrm{M}^{2+} / \mathrm{M}^{3+}$ la capacidad de adsorción de los materiales sintetizados disminuye, por lo que al termino de 5 horas, el sólido $\mathrm{MgAl}-2$ ha logrado remover del medio una mayor cantidad de la molécula de prueba.

\section{A.3.2. Naproxeno sódico}

A continuación se presentan los espectros UV-Vis obtenidos para la adsorción de Naproxeno sódico (50 ppm) empleando 50 mg MgAl2 y MgAl4. 


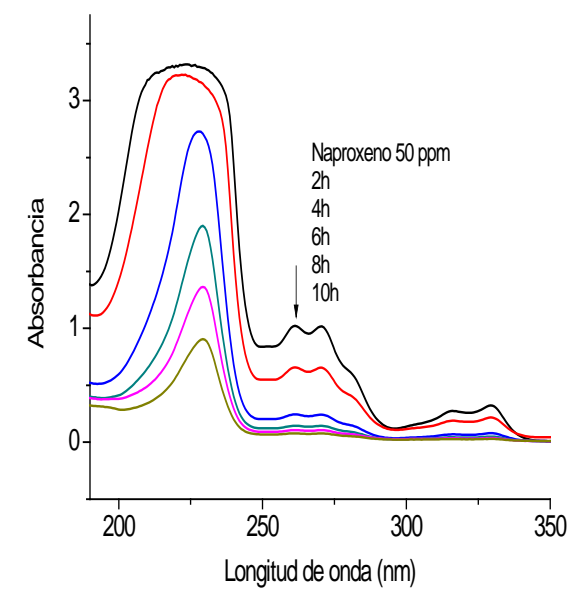

Fig.A2. Espectro UV-Vis para la adsorción de de Naproxeno (50 ppm) con MgAl2.

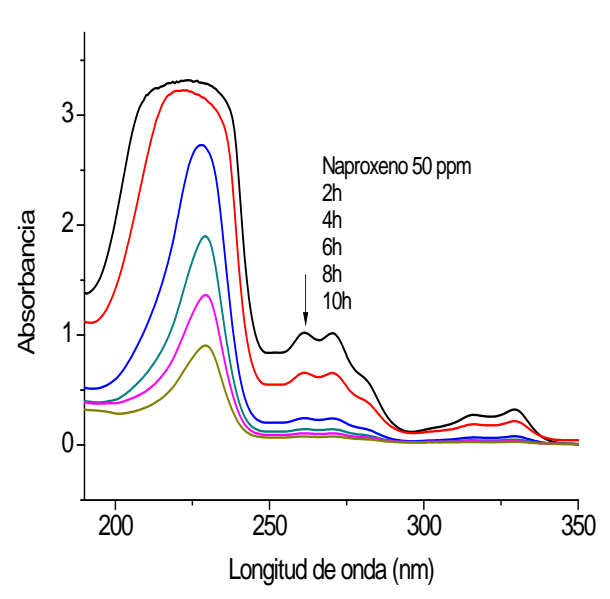

Fig.A3. Espectro UV-Vis para la adsorción de de Naproxeno (50 ppm) con MgAl4.

En ambos gráficos se observa que las bandas de absorción disminuyen al aumentar el tiempo de contacto entre la solución y el adsorbente. De acuerdo a la ley de Beer-Lambert, la absorbancia es directamente proporcional a la concentración, por lo cual se infiere que la disminución de naproxeno sódico en solución es debida a su adsorción en los materiales sintetizados.

Haciendo uso de la ley de Beer-Lambert, la concentración de naproxeno sódico en función del tiempo fue calculada a una longitud de onda de $270.612 \mathrm{~nm}$. Una vez obtenidos estos valores, la cantidad de fármaco adsorbido por los sólidos sintetizados fue determinada mediante la siguiente ecuación [9, 26, $122,123]:$

$$
q_{t}=\left(C_{0}-C_{t}\right) \frac{V}{W}
$$

donde $C_{o}$ y $C_{t}$ son la concentración inicial y a un tiempo $t$ en fase acuosa del Naproxeno sódico (ppm) respectivamente, $V$ es el volumen de la solución y $W$ es la cantidad de adsorbente empleado.

De acuerdo a datos de absorbancia contra tiempo, el equilibrio se alcanza en aproximadamente 10 horas para el hidróxido doble laminar MgAl2 y en 24 horas para MgAl4, por lo cual en la ecuación (14A), $C_{t}$ corresponde a la concentración de Naproxeno sódico determinada a 600 minutos para MgAl2 y 1440 minutos para MgAl4. 
Una vez calculados $C_{e}$ (concentración al equilibrio) y $q_{a d s}$ (cantidad de adsorbato por gramo de adsorbente), se construye una isoterma que permita saber cual es la cantidad máxima de fármaco removida por los materiales sintetizados y la obtención de información sobre el tipo de interacciones adsorbato-adsorbente.

A continuación se presentan gráficos de $C_{\mathrm{e}}$ contra $q_{\text {ads }}$ para la adsorción de Naproxeno sódico con MgAl2 y MgAl4.

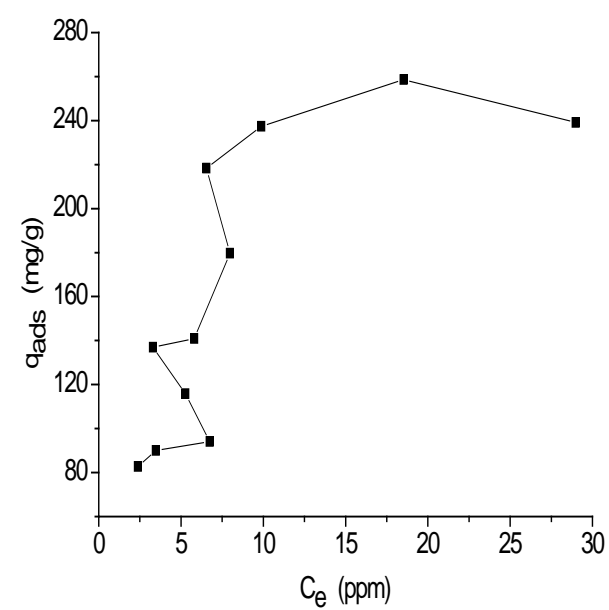

Fig. A4. Adsorción de Naproxeno sódico empleando diferentes cantidades de MgAl2

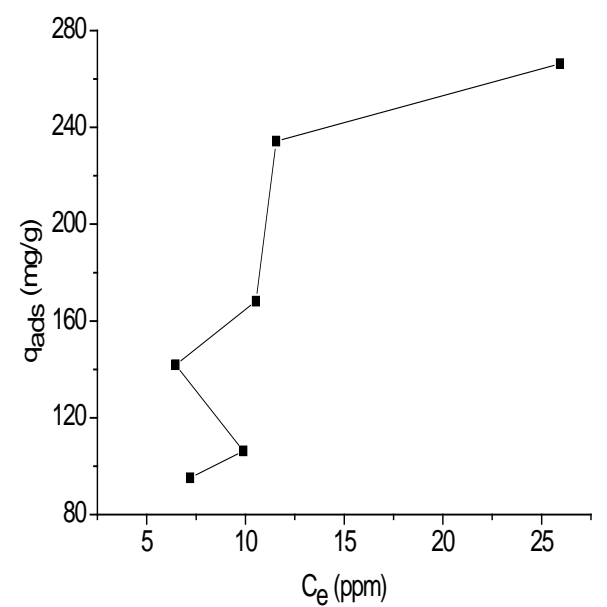

Fig. A5. Adsorción de Naproxeno sódico empleando empleando diferentes cantidades de MgAl4.

De la figuras A4 y A5 se observa que las isotermas presentan discontinuidades periódicas, lo cual puede indicar la formación de multicapas debido a la fuerte interacción entre moléculas del adsorbato. De acuerdo a su forma pueden ser clasificadas como isotermas tipo S, las cuales se obtienen si [124]:
a) El solvente es fuertemente adsorbido
b) Hay una fuerte interacción intermolecular dentro de la capa adsorbida
c) El adsorbato es monofuncional.

Como se menciono anteriormente en la metodología, los hidróxidos dobles laminares MgAl fueron calcinados antes de llevar a cabo el proceso de adsorción. Debido a lo anterior, el solvente (agua) debe ser fuertemente adsorbido para llevar acabo la reconstrucción laminar, lo cual puede ser un factor 
determinante en el tipo de isoterma obtenida. Las discontinuidades pueden deberse a la formación de multicapas provocadas por una fuerte atracción entre moléculas del adsorbato.

La cantidad máxima de soluto adsorbida por los LDH es 258.5913876 mg/g para MgAl2 y 266.2684211 mg/g para MgAl4, observándose un ligero incremento en la capacidad de adsorción al incrementarse la razón molar $\mathrm{M}^{2+} / \mathrm{M}^{3+}$.

Cinética de adsorción

Para determinar la velocidad de adsorción de naproxeno sódico en los LDH MgAl sintetizados, fueron empleados tres modelos cinéticos para ajustar los datos experimentales [26, 122, 123]:

1. Pseudo-primer orden (ec. 9-A)

2. Pseudo-segundo orden (ec. 12-A)

3. Modelo de difusión intraparticular (ec. 13-A)

Las figuras A6, A7 Y A8, muestran el ajuste de datos experimentales con los modelos cinéticos antes mencionados.

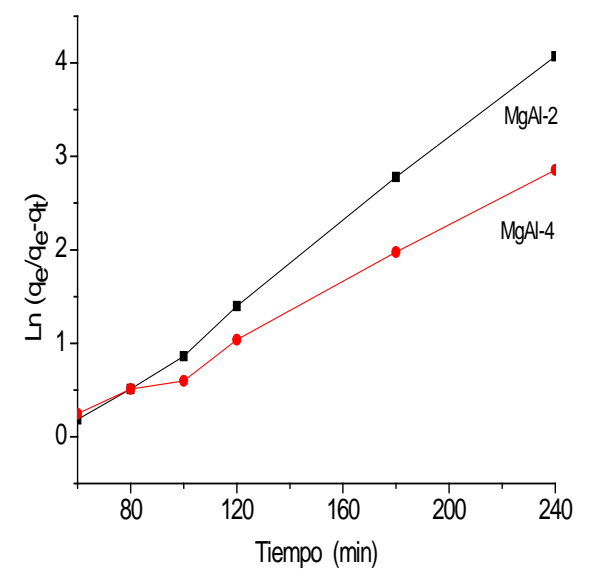

Fig. A6. Cinética de pseudo-primer orden para la adsorción de naproxeno (50 pppm) con LDH's MgAl.

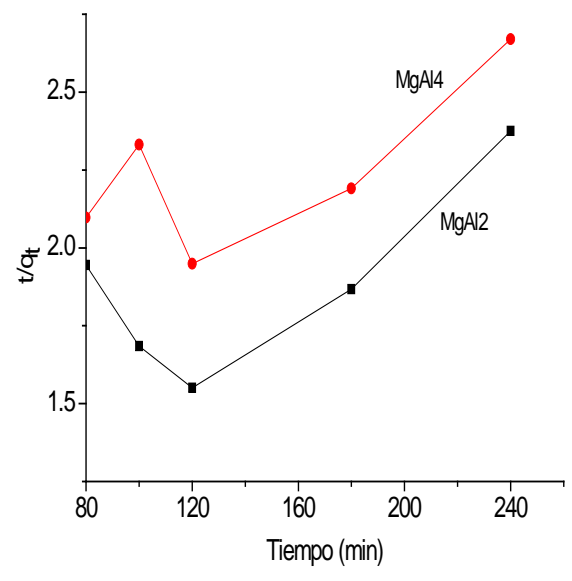

Fig. A7. Cinética de pseudo-segundo orden para la adsorción de naproxeno (50 ppm) con LDH's MgAl. 


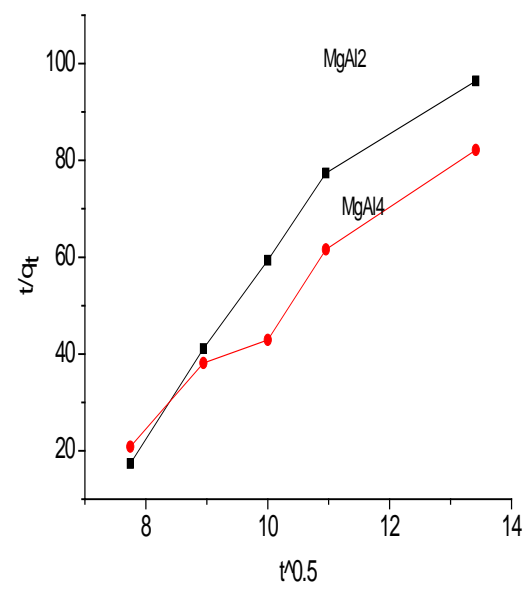

Fig. A8. Modelo de difusión de intraparticular para adsorción de naproxeno (50 ppm) con LDH MgAl.

Las constantes de velocidad y los coeficientes de correlación para cada modelo cinético se presentan en la tabla A1.

Tabla A1. Parámetros cinéticos y factores de correlación para los tres modelos cinéticos analizados

\begin{tabular}{|c|c|c|c|c|c|c|}
\hline \multirow[t]{2}{*}{ Material } & \multicolumn{2}{|c|}{ Primer orden } & \multicolumn{2}{|l|}{ Segundo orden } & \multicolumn{2}{|c|}{ Difusión intraparticular } \\
\hline & $\mathrm{k}_{1}\left(\mathrm{~min}^{-1}\right)$ & $r^{2}$ & $\mathrm{k}_{2} \times 10^{-4}(\mathrm{~g} / \mathrm{mg} \min )$ & $r^{2}$ & $\mathrm{k}_{3}\left(\mathrm{mg} / \mathrm{g} \mathrm{min}^{0.5}\right)$ & $r^{2}$ \\
\hline MgAl2 & 0.0221 & 0.9979 & 0.9244 & 0.8763 & 13.9515 & 0.936 \\
\hline MgAl4 & 0.0149 & 0.9929 & 0.7556 & 0.8717 & 10.7867 & 0.971 \\
\hline
\end{tabular}

De acuerdo a los gráficos de qads en función del tiempo y a los datos de la tabla A1, la adsorción de naproxeno sódico en los LDH sintetizados sigue una cinética de pseudo-primer orden y el material con mayor contenido de aluminio (MgAl2) adsorbe con mayor rapidez a la molécula de prueba. 
Una vez finalizado el proceso de adsorción, los sólidos fueron secados a temperaturas suaves $\left(55^{\circ} \mathrm{C}\right)$ por 72 horas y posteriormente se analizaron mediante difracción de Rayos-X. A continuación se muestran los difractogramas obtenidos para la adsorción de naproxeno sódico con 50 mg de MgAl2 y MgAl4.

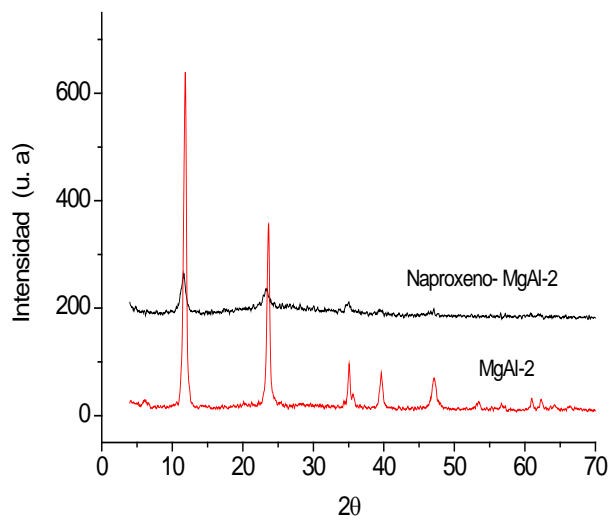

Fig. A9. Patrones DRX del MgAl2 sintetizado y seco después del proceso de adsorción de naproxeno.

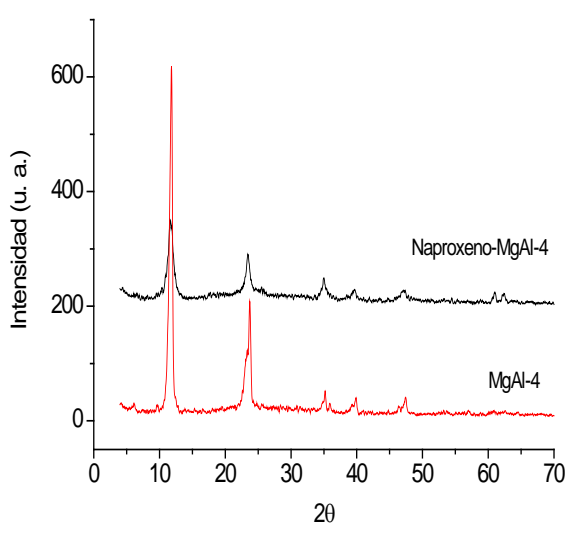

Fig. A10. Patrones DRX de MgAl4 sintetizado y seco después del proceso de adsorción de naproxeno.

De acuerdo a los patrones de difracción de rayos- $\mathrm{X}$, la arcilla aniónica MgAl4 recupera su estructura laminar y la secuencia relativamente simétrica de las reflexiones de los planos (00/) indica que el material logra un alto nivel de ordenamiento de las laminas tipo brucita [3]. Aunque el material con menor razón molar $\mathrm{M}^{2+} / \mathrm{M}^{3+}$ recupera su estructura laminar, las reflexiones de los planos son de muy baja intensidad por lo cual se infiere que el MgAl2 presenta un nivel de ordenamiento espacial bajo.

Las reflexiones (003) y (110) empleadas para calcular parámetros de celda, no presentan desplazamientos del ángulo $2 \theta$ con respecto a los difractogramas de los materiales puros, lo cual puede indicar que la molécula de prueba no es adsorbida en la zona interlaminar de los LDH MgAI [125, 126]. Cabe mencionar que la concentración de la molécula de prueba es baja (50 ppm), lo cual puede impedir que se obtenga información clara sobre la interacción adsorbato-adsorbente al emplear técnicas como difracción de rayos-X o espectroscopia infrarroja. 


\section{A.3.3. Ampicilina}

A continuación se muestran los gráficos UV-Vis para la adsorción de Ampicilina (50ppm) con 50 mg de MgAl2 y MgAl4.

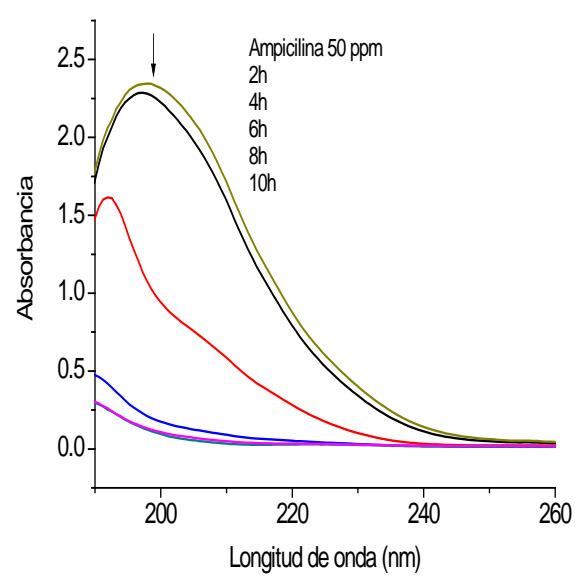

Fig. A11. Espectro UV-Vis para la adsorción de ampicilina con MgAl2.

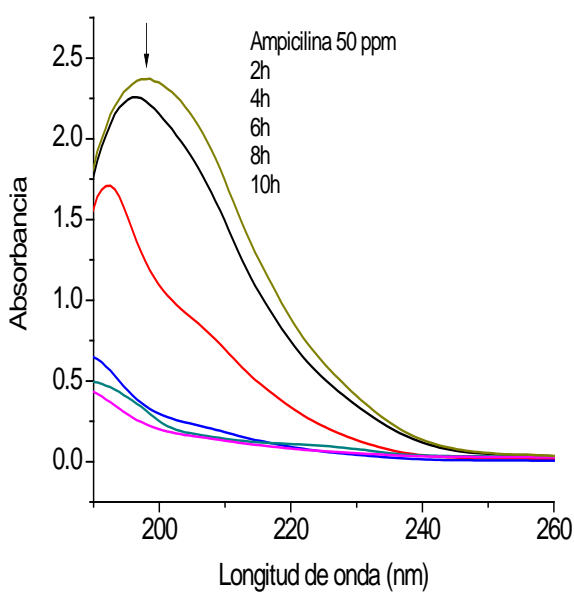

Fig. A12. Espectro UV-Vis para la adsorción de Ampicilina con MgAl4.

Para la Ampicilina solo se observa una banda de absorción, cuya intensidad disminuye al incrementarse el tiempo de contacto entre la solución y los adsorbentes (Fig. 10 y 11). Sin embargo esta banda sufre un desplazamiento hipsocrómico con los cambios de concentración, por lo cual no es posible aplicar la ley de Beer-Lambert.

Debido a lo anterior la concentración de ampicilina durante el proceso de adsorción se determinó por análisis de carbono orgánico total (Fig. A13) 


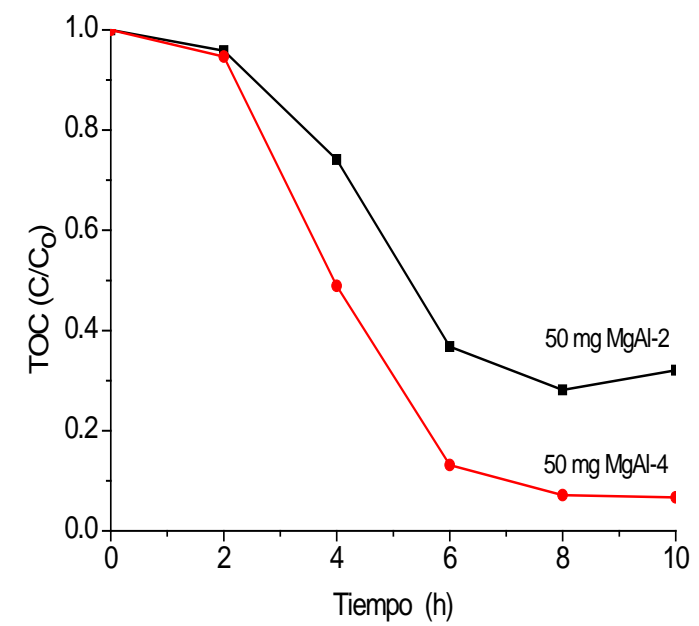

Fig. A13. TOC para la adsorción de Ampicilina (50 ppm) con LDH's MgAl.

Una vez calculados $C_{e}$ (concentración al equilibrio) y $q_{a d s}$ (cantidad de adsorbato por gramo de adsorbente), se procede a construir las isotermas de adsorción.

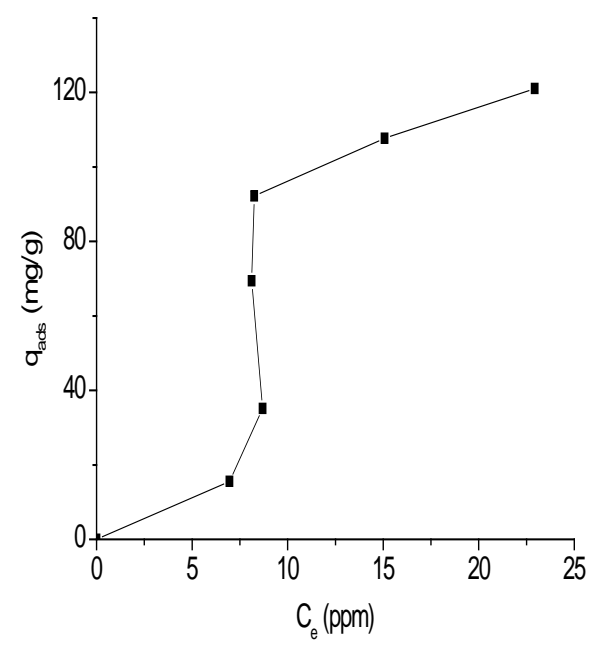

Fig. A14. Isoterma para la adsorción de ampicilina empleando MgAl2

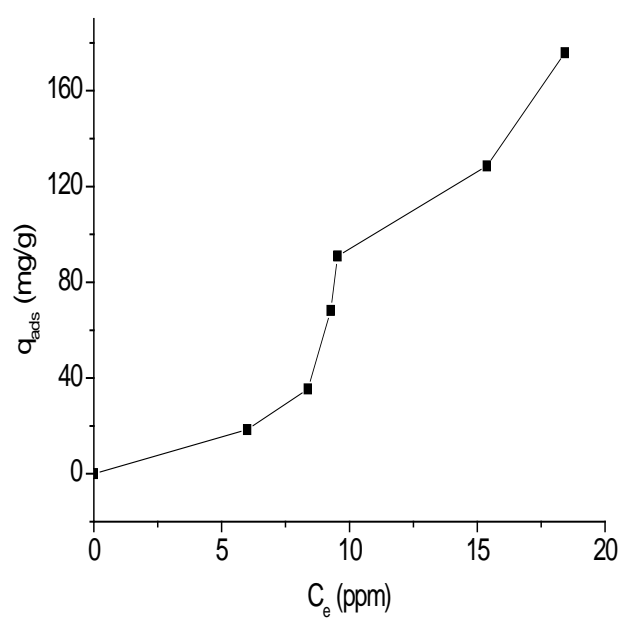

Fig. A15. Isoterma para la adsorción de ampicilina empleando MgAl4. 
La isoterma de Ampicilina sódica con MgAl2 puede ser clasificada como tipo S, y al igual que en el caso del Naproxeno sódico, la forma de ésta puede estar relacionada con una fuerte adsorción del solvente (agua) o con la formación de multicapas debido a la interacción entre moléculas del adsorbato. Aunque la isoterma Ampicilina-MgAl4 puede ser clasificada como tipo S, cae dentro de un subgrupo en el cual no se presenta un límite de adsorción, probablemente debido a la cristalización del soluto [124]. 


\section{Apéndice B. Técnicas de caracterización}

\section{B.1. Difracción de rayos $-\mathrm{X}$}

La difracción de rayos-X (DRX) es hasta ahora la técnica más viable para determinar la estructura cristalina de numerosos compuestos, que van desde los óxidos inorgánicos, polímeros y aleaciones hasta proteínas y ácidos nucleicos.

El método DRX se basa en el fenómeno de dispersión que ocurre cuando haces de rayos-x interaccionan con muestras cristalinas. Los rayos pueden ser reflejados en diversas direcciones y sufrir interferencia constructiva (difracción), en cuyo caso la intensidad de la dispersión es fuerte, o destructiva, es decir cuando la radiación reflejada es prácticamente nula. Los ángulos a los cuales se presenta el fenómeno de difracción están determinados por la ley de Bragg. La figura B1 muestra un haz de rayos-x monocromático que choca con una familia de planos de un cristal.

El haz tiene una longitud de onda $\lambda$ e incide con un ángulo $\theta$ sobre el cristal. Una parte del haz incidente es reflejado especularmente por el primer plano, mientras que la radiación restante penetra y choca con planos adyacentes. Para que ocurran fenómenos de interferencia, las ondas reflejadas deben estar en fase; las diferencia en la trayectoria de los rayos dispersados por los átomos de la familia de planos, ocasiona divergencias en fase. De

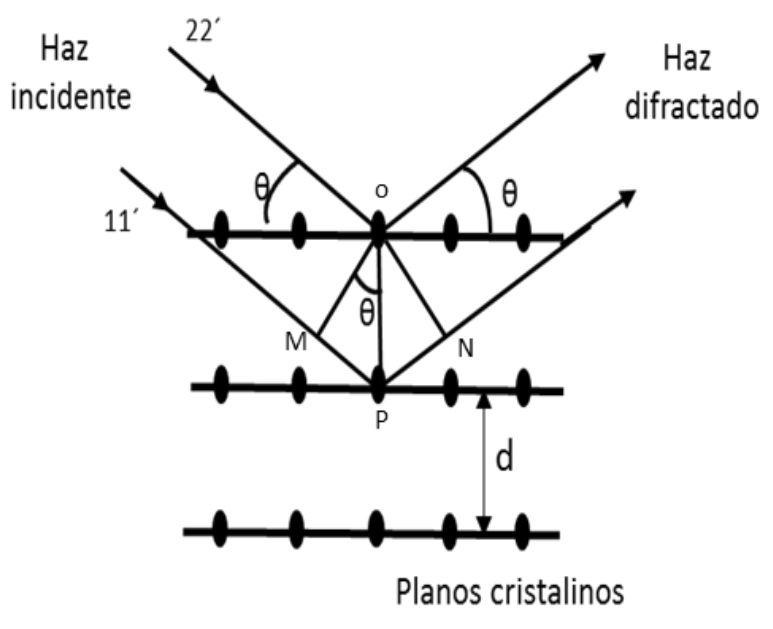
acuerdo al esquema 3.2, las relaciones geométricas entre las distancias recorridas por

Fig. B1. Difracción de rayos X por un cristal.

$$
M P+P N=d \sin \theta+d \sin \theta
$$


Estas ondas sufrirán interferencia constructiva si la diferencia en su trayectoria es igual a un número entero de longitudes de onda, es decir:

$$
n \lambda=2 d \sin \theta
$$

Esta relación fue formulada por el científico inglés W. L. Bragg y establece la condición esencial a la cual se presentan fenómenos de difracción en sólidos cristalinos [127, 128].

La difracción de rayos-X también puede ser empleada para el cálculo del tamaño promedio de cristalito o grano mediante el uso de la ecuación de Debye-Scherrer, cuya expresión matemática es:

$$
D=\frac{K \lambda}{\beta \cos \theta}
$$

donde $K$ es una constante relacionada a la forma del cristal y tiene un valor de $0.891, \lambda$ es la longitud de onda de los rayos $X$ incidentes (en $\mathrm{nm}$ ), $\beta$ es en ancho del pico de difracción a la altura máxima media y $\theta$ es el ángulo de Bragg. Pese a que la ecuación subestima el tamaño del cristalito por no tomar en cuenta las tensiones del material, es el procedimiento más común para calcular este parámetro. En los procesos fotocatalíticos, la determinación del tamaño de cristalito permite un análisis más detallado del comportamiento de un material en una reacción específica.

\section{B.2. Análisis textural}

El área superficial específica y la porosidad de los materiales empleados en procesos catalíticos heterogéneos, tienen un papel fundamental en la eficiencia de la reacción, ya que determinan el número de sitios activos del sólido, la velocidad de difusión de reactivos y productos y la desactivación del catalizador por deposición de contaminantes [129]. Estas dos propiedades se encuentran estrechamente ligadas, de tal manera que el tamaño de los poros disminuye o aumenta el valor del área superficial especifica. La distribución del tamaño de poro en un material puede ser muy compleja, sin embargo, con base a su diámetro, los poros se han clasificado dentro de tres categorías:

Microporos. Diámetro promedio de poro es $d<2 \mathrm{~nm}$.

$>$ Mesoporos. El tamaño del poro se encuentra en el intervalo $2<d<50 \mathrm{~nm}$.

$>$ Macroporos. Los poros tienen un tamaño superior a $d>50 \mathrm{~nm}$ 
Uno de los métodos más comúnmente empleados para la caracterización del área superficial y la porosidad de un material, es la construcción de isotermas de adsorción-desorción a partir del registro de los cambios de volumen que experimenta un gas inerte, típicamente $\mathrm{N}_{2}$, en función de su presión parcial cuando es adsorbido por un sólido previamente desgasificado. La forma que adquiere una isoterma de adsorción-desorción queda determinada por la estructura porosa del material y debido a la diversidad en forma y tamaño de los poros, se han identificado seis tipos de isotermas de acuerdo a la IUPAC [130]. Sólo cuatro de ellas son comúnmente encontradas en caracterizaciones de solidos catalíticos. Estas son:

* Isoterma tipo I. Frecuente en la caracterización de materiales microporosos (carbones activados, zeolitas, óxidos), en donde el llenado de los poros ocurre a bajas presiones sin que haya condensación capilar, por lo que este proceso es indistinguible de la formación de la monocapa.

* Isoterma tipo II. Típica de sólidos no porosos o macroporosos. Se caracteriza por la formación de una monocapa a bajas presiones hasta llegar a un punto de inflexión en el cual comienza la adsorción de multicapas (Punto B).
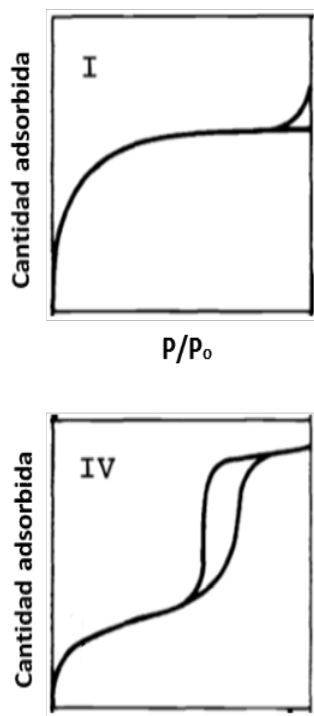

$\mathrm{P} / \mathrm{P}_{\mathrm{o}}$

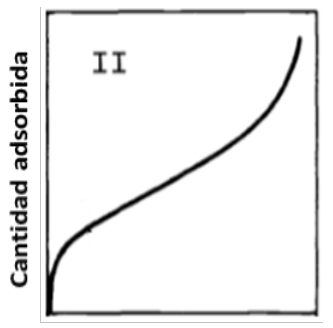

$\mathrm{P} / \mathrm{P}_{\mathrm{o}}$

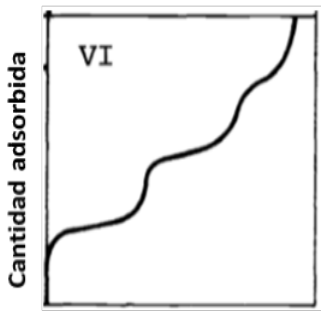

$\mathrm{P} / \mathrm{P}_{\mathrm{o}}$

Fig. B2. Isotermas de adsorción más comunes en la caracterización de sólidos catalíticos. Imagen adaptada de [94].

* Isoterma tipo IV. Características de adsorbentes mesoporosos. Al igual que en las isotermas tipo II, la formación de la monocapa-multicapa ocurre a presiones bajas. La superposición de multicapas continúa con el incremento de la presión hasta un valor $\mathrm{P} / \mathrm{P}_{0}$, determinado por las reglas de Kelvin, en la cual tiene lugar la condensación del adsorbato en los poros del material.

* Isoterma tipo VI. Se obtienen al caracterizar adsorbentes ultramicroporosos uniformes. La presión a la cual se lleva a cabo la adsorción depende de la interacción adsorbato-adsorbente, por lo cual se 
forma una isoterma escalonada en donde cada nivel corresponde a la adsorción de un grupo de sitios energéticamente uniformes.

El proceso de desorción consiste en retirar de la superficie todas aquellas moléculas de gas que han sido adsorbidas. En los materiales mesoporosos, este proceso ocurre a presiones menores que la condensación capilar, dando paso a la formación de histéresis [131]. Conforme a la clasificación de IUPAC, existen cuatro tipos de histéresis, las cuales son:

* Histéresis $H 1$ y $H 2$. Características de sólidos que contienen poros cilíndricos abiertos o cerrados, o que consisten en aglomerados de partículas esféricas. En el caso de la histéresis $H 1$, la distribución de forma y tamaño de los poros es aproximadamente uniforme, fenómeno que no ocurre en el caso de la histéresis tipo $\mathrm{H} 2$.

Histéresis $\mathrm{H} 3$ y $H 4$. Se presentan en materiales formados por partículas tipo platos, cuya aglomeración da lugar a la formación de poros tipo ranura. En la histéresis $H 3$, el tamaño de poro en el sólido no es uniforme, caso contrario a la histéresis tipo H4, en la cual la distribución del tamaño
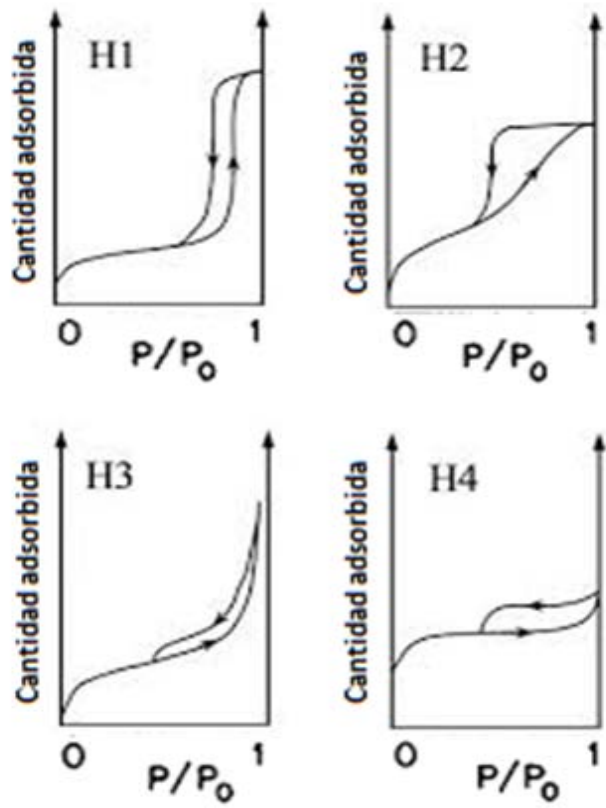
de poro está en el rango de los microporos.

Fig. B3. Tipos de histéresis en las isotermas de adsorción de $\mathrm{N}_{2}$. Imagen tomada de [94]

Aunque se han desarrollado diversos modelos para el análisis de los datos proporcionados por las isotermas de adsorción-desorción, BET y BJH son hasta ahora los métodos más frecuentemente empleados para la determinación del área superficial específica y la distribución del tamaño de poro en un material.

El método desarrollado por Brunauer, Emmett y Teller (BET) en 1938 para el cálculo del área superficial específica de un sólido, es una extensión del modelo desarrollado por Langmuir para la formación de la 
monocapa en procesos de adsorción de gases en sólidos. En la derivación de éste método, se asume que, para la generación de multicapas en superficies energéticamente homogéneas, las interacciones entre las moléculas del adsorbato solo se dan de manera vertical y que cada molécula que se encuentra en una capa determinada es un posible centro activo de adsorción. La ecuación resultante es:

$$
\frac{P}{V\left(P_{0}-P\right)}=\frac{1}{c V_{m}}+\frac{c-1}{c V_{m}}\left(\frac{P}{P_{0}}\right)
$$

Donde $\mathrm{P}$ es la presión experimental de equilibrio, $\mathrm{P}_{0}$ es la presión de vapor del adsorbato a la temperatura experimental, $\mathrm{V}$ es el volumen experimental del gas adsorbido por gramo de adsorbente $\mathrm{y}$ c es la constante BET, la cual está relacionada con el calor de adsorción de primera capa fisisorbida.

Por otra parte el método BJH, propuesto por los científicos Barnett, Joyner y Halenda, permite determinar la distribución de tamaño de poro considerando que: la adsorción en sólidos porosos ocurre en multicapa con condensación capilar; la tensión superficial y el volumen especifico del condensado son iguales a aquellos que presenta el adsorbato en estado líquido; los poros son cilíndricos de extremo abierto y los que tienen radios iguales responden de manera idéntica a los cambios de presión relativa del adsorbato; la ecuación de Kelvin es válida para calcular el radio del capilar.

\section{B.3. Análisis termogravimétrico}

Los métodos térmicos miden los cambios en alguna propiedad fisicoquímica de un sistema (sustancia, mezcla o material) en función de la temperatura. Debido a su versatilidad, estos métodos han encontrado una amplia aplicación en diversas áreas de la investigación científica y en procesos industriales.

Aunque existe una gran variedad de métodos clasificados como térmicos, los cuales difieren principalmente en la propiedad medida y en el programa de temperatura empleado, el análisis termogravimétrico (TGA por sus siglas en inglés), es uno de lo más frecuentemente empleados en la caracterización de materiales sólidos. Información tan valiosa como la pureza de una sustancia, su composición química, entalpías de reacción, cambios de fase y cinéticas de oxidación y descomposición, pueden ser determinados mediante la aplicación de esta técnica $[132,133]$. 
En el análisis termogravimétrico se mide la variación en la masa de una muestra en función de la temperatura o del tiempo, mientras se le somete a un programa de calentamiento controlado. EI proceso de descomposición térmica se muestra un gráfico llamado termograma (fig. B4).

El análisis TGA es una herramienta ampliamente utilizada en la ciencia de materiales y ha permitido la caracterización de sólidos tan diversos como polímeros, silicatos, vidrios, cerámicos, arcillas y óxidos.

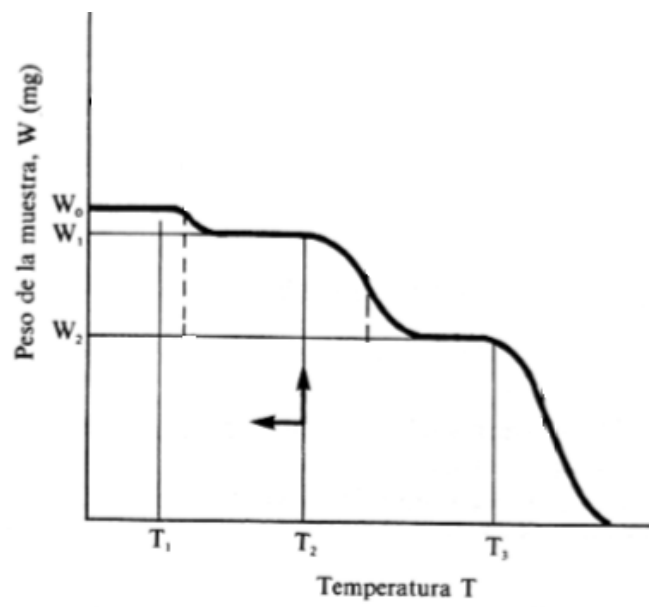

Fig. B4. Termograma convencional. Imagen tomada de [96]

\section{B.4. Espectroscopia de reflectancia difusa UV-Vis}

Una de las técnicas más comúnmente empleadas para determinar la energía de banda prohibida $\left(E_{g}\right)$ de diversos materiales, es la espectroscopia de reflectancia difusa. Al igual que en la espectroscopia UVVisible, se emplean lámparas en la región de 200-830 nm del espectro electromagnético para producir fotones que interaccionen con muestras sólidas, sin embargo, en esta configuración el espectrofotometro mide la luz reflejada difusamente en lugar de aquella que es trasmitida.

Entre los diversos fenómenos ópticos que ocurren cuando un haz de fotones incide sobre una muestra sólida, se encuentran la reflexión especular y la difusa [134]. El primer fenómeno físico se presenta cuando un haz luminoso choca contra la superficie de un material y es reflejado en un ángulo que es igual al de incidencia. La luz que es reflejada especularmente, no sufre un proceso de absorción, por lo que no proporciona información relevante sobre los estados electrónicos del material. Por el contrario, en la reflexión difusa, el haz penetra la superficie de la muestra, es parcialmente absorbido y una fracción de ésta radiación es re-emitida (reflejada) en diversos ángulos no incidentes, posibilitando de esta forma el cálculo de la energía de banda prohibida. 
Debido a que los haces reflejados difusamente no convergen en un punto determinado, el uso de esferas de integración es común en mediciones de reflectancia (fig. B5). Estos dispositivos están diseñados para recolectar todos los fotones dispersados por la muestra y se fabrican con materiales altamente reflectivos, tales como politetrafluoroetileno (PTFE) O $\mathrm{Ba}_{2} \mathrm{SO}_{4}$. Algunas esferas de integración contienen una apertura o "plug" que minimiza el ruido causado por la reflexión especular del sólido.

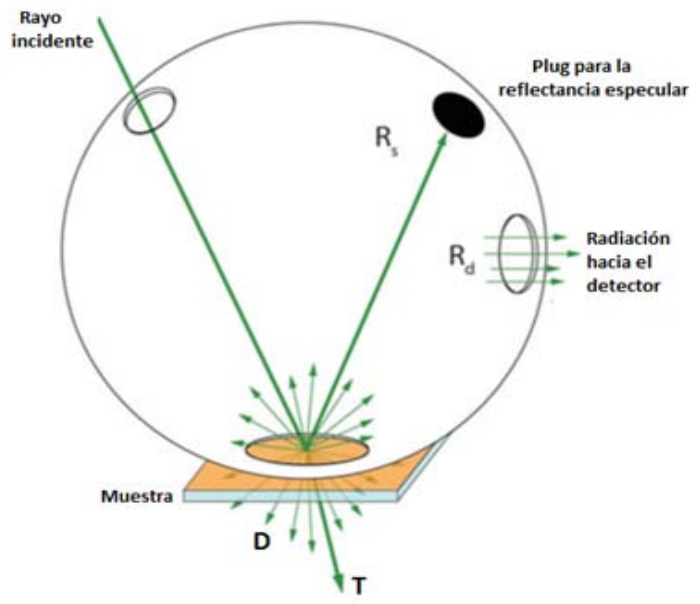

Fig. B5. Esfera de integración con plug para reflectancia especular empleada en mediciones espectroscópicas de reflectancia difusa. Imagen tomada de [98].

El modelo desarrollado por Jean Tauc (curva Tauc), y más tarde respaldado por Davis y Mott, permite la determinación de la $E_{g}$, haciendo uso de la siguiente relación matemática

$$
(\alpha h v)^{1 / n}=A\left(h v-E_{g}\right)
$$

donde $\alpha$ es el coeficiente de absorción de material y $n$ denota el tipo de transición electrónica que ocurre en el material. El exponente $n$ puede tomar valores de $3,2,3 / 2$ y $1 / 2$ que corresponden a transiciones indirectas prohibidas, indirectas permitidas, directas prohibidas y directas permitidas respetivamente. La curva Tauc, resultado de graficar $(\alpha h v)^{1 / n}$ contra $h v$, contendrá una región lineal cuya extrapolación a absorción cero $\left((\alpha h v)^{1 / n}=0\right)$ proporcionará el valor de la $E_{g}[103,104,135]$.

En medidas de reflectancia difusa, el método Kubelka-Munk puede ser empleado para obtener el coeficiente de absorción de la muestra sólida, mediante la ecuación:

$$
f(R)=\frac{(1-R)^{2}}{2 R}=\frac{\alpha}{s}
$$


donde $f(R)$ es la función de Kubelka-Munk, $s$ es el coeficiente de dispersión y $\alpha$ es el coeficiente de absorción. Si se asume que el coeficiente de dispersión es independiente de la longitud de onda, entonces $f(R)$ es proporcional a $\alpha$, por lo cual la curva Tauc puede realizarse sustituyendo el coeficiente de absorción por la función de Kubelka-Munk (fig. B6).

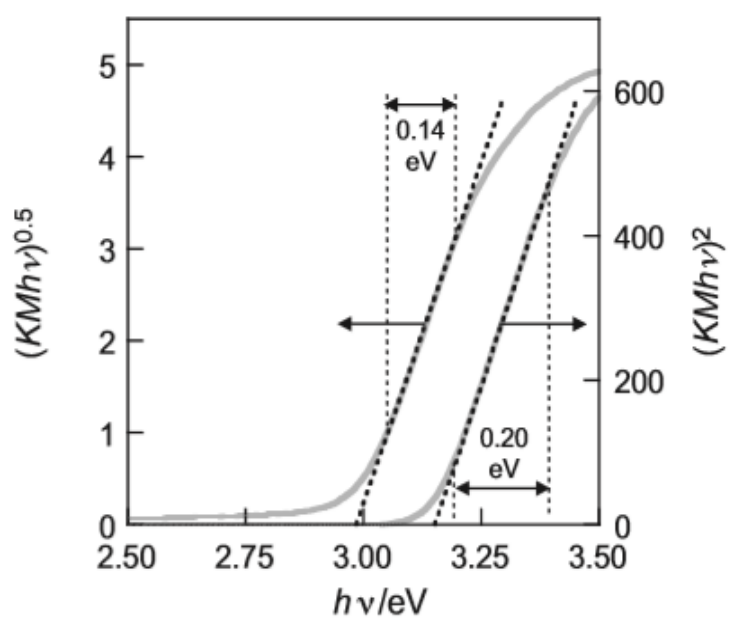

Fig. B6. Determinación de energía de banda prohibida para un material semiconductor. Imagen tomada de [72].

\section{B.5. Microscopia electrónica de barrido/Espectroscopia de energía dispersiva}

En diversos campos de la ciencia e ingeniería, tales como los procesos catalíticos heterogéneos, la fabricación de semiconductores de película delgada, el análisis de dureza y el estudio de fenómenos de corrosión y adhesión, la composición y morfología de la superficie tiene mayor relevancia que la estructura en el seno del material.

Las técnicas basadas en el uso de haces de electrones, son altamente viables para el estudio de superficies debido a que estas partículas sólo pueden penetrar o escapar de las capas más externas de un sólido. La microscopia electrónica de barrido (SEM, por sus siglas en inglés) es uno de estos poderosos métodos de análisis superficial; mediante su empleo es posible determinar la morfología de una superficie, los elementos que la constituyen y la proporción relativa entre estos.

En la microscopia SEM, un haz de electrones emitido por un filamento incandescente, es dirigido y focalizado por lentes magnéticas, sistema de barrido, hacia el espécimen que se encuentra situado en un portamuestras móvil con giro universal. La interacción entre el haz y la muestra origina la emisión de electrones secundarios, aquellos que pertenecen al material y son emitidos al colisionar con el haz incidente, electrones retrodispersados, electrones del haz reflejados por el espécimen y de rayos $\mathrm{X}$ característicos de los elementos presentes en el material. Los detectores presentes en el microscopio 
reciben a los electrones secundarios y retrodispersados provenientes de diversos sectores de la muestra; la amplificación de la señal genera la imagen final de la muestra.

El microscopio electrónico de barrido puede incorporar un dispositivo que detecta la energía de los rayos $\mathrm{X}$ emitidos por la muestra $\mathrm{y}$, por consiguiente, permite la identificación de los elementos presentes en ésta. Esta técnica analítica recibe el nombre de Espectroscopia de Energía Dispersiva (EDS, por sus siglas en inglés).

Durante las colisiones el haz incidente puede arrancar electrones de las capas más internas de los elementos químicos presentes en la muestra, siempre que la energía de éste sea superior al umbral de ionización de la capa en cuestión. La vacante generada en un átomo determinado, será ocupada rápidamente por algún electrón de las capas superiores, emitiendo radiación electromagnética de una longitud de onda especifica. Un espectro continuo de rayos $X$ se genera en pocos segundos y la identificación de cada elemento es inmediata, de manera que el método es práctico en tiempo y costo. Aunado a lo anterior, la corriente de sonda que se emplea para el análisis puede ser muy baja, lo que evita daños severos a la muestras [136-138]. Finalmente, la espectroscopia EDS puede emplearse para determinar la composición química de cierto volumen del material, en función de que la intensidad de los rayos $\mathrm{X}$ producidos por cada elemento es proporcional a su concentración en la muestra.

\section{B.6. Espectroscopia UV-Visible}

La espectroscopia Ultravioleta-Visible es hasta ahora, uno de los métodos ópticos más útiles para el análisis cuantitativo de muestras; asimismo es una valiosa herramienta auxiliar en la elucidación de estructuras químicas.

Una gran cantidad de compuestos de origen orgánico e inorgánico absorben radiación electromagnética del tipo visible y ultravioleta (longitud de onda 190-800 nm). La absorción de fotones con la frecuencia correcta, puede promover electrones que se encuentran en orbitales de enlace a orbitales anti-enlace. Las transiciones electrónicas más frecuentes $[115,139]$ se muestran en la figura B7. 
Gran parte de las aplicaciones de la espectroscopia UV-Vis se basan en las transiciones tipo es $n \rightarrow \pi^{*}$ y $\pi \rightarrow \pi^{*}$ debido a que la energía requerida para la promoción del electrón es relativamente baja. La presencia de grupos funcionales insaturados que proporcionen orbitales $\pi$, es un requerimiento para que ocurran ambas transiciones; en el caso de la transición electrónica $n \rightarrow \pi^{*}$, el compuesto insaturado debe poseer átomos con pares de electrones

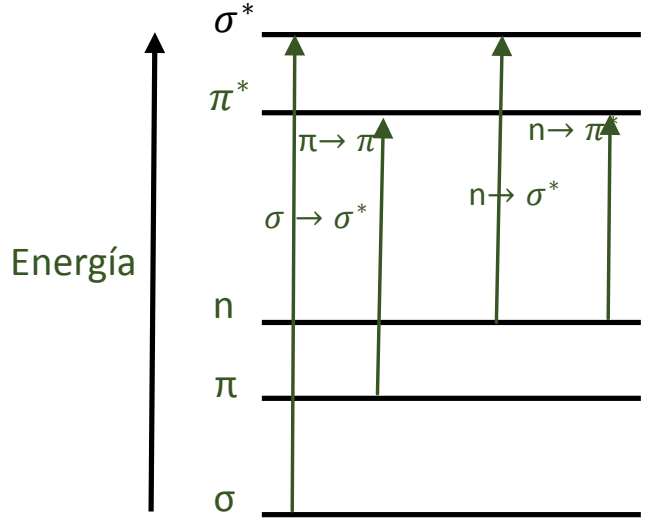
no compartidos, tales como $\mathrm{O}, \mathrm{N}$ y $\mathrm{Cl}$.
Fig. B7. Niveles de energía y transiciones electrónicas más frecuentes. Imagen adaptada de [108].

La interacción entre el haz y la muestra (análito en solución), ocasionará la disminución de la intensidad del rayo incidente. La transmitancia mide la proporción de radiación que es absorbida por la muestra y se define como:

$$
T=\frac{I}{I_{0}}
$$

Por aspectos prácticos, en las mediciones espectroscópicas UV-Vis se emplea la absorbancia en sustitución de la trasmitancia, y se define como $A=\log \frac{I_{0}}{I}$. La absorbancia de una muestra es directamente proporcional a la trayectoria de la radiación a través de la solución, al coeficiente de absorción $(\epsilon)$ y a la concentración del análito, es decir:

$$
A=\epsilon C b
$$

donde $\epsilon$ es el coeficiente de absorción del análito, $C$ su concentración y $b$ la longitud de la trayectoria a través de la muestra. La ecuación (8-B) es una expresión de la ley de Beer-Lambert y permite calcular la concentración de una sustancia o de diversos análitos en solución de manera precisa.

Aunque la espectroscopia UV-Vis de líquidos tiene pocas aplicaciones en la caracterización de materiales, esta técnica es una herramienta muy útil para determinar la concentración de compuestos orgánicos que son sometidos a procesos catalíticos heterogéneos, tales como reacciones de fotodegradación, fotoreducción, absorción y síntesis. 


\section{B.7. Análisis de carbono orgánico total}

El análisis de carbono orgánico total (TOC, por sus siglas en inglés) es uno de los métodos más importantes para determinar la eficiencia de un proceso fotocatalítico; por medio de esta técnica es posible cuantificar de manera directa la mineralización de los contaminantes orgánicos.

Uno de los objetivos principales de la fotodegradación de sustancia toxicas orgánicas, es su trasformación a $\mathrm{CO}_{2}$, agua y ácidos minerales. Sin embargo, la oxidación de este tipo de contaminantes conlleva una serie de pasos, en los cuales se forman subproductos de reacción no benignos e incluso más tóxicos que

la molécula inicial [140]. Puesto que, por definición, el carbono orgánico total es aquel que se encuentra ligado a toda la materia orgánica presente en un sistema [141] los valores cercanos a cero en muestras de reacciones fotocatalíticas, garantizan la mineralización del contaminante sin la formación de subproductos recalcitrantes.

Los ensayos correspondientes, ya sea manuales o instrumentales, para la detección de carbono orgánico se basan en la oxidación del carbono presente en los compuestos orgánicos a $\mathrm{CO}_{2}$ y agua. En la mayoría de los analizadores instrumentales modernos, la materia orgánica sufre una reacción de combustión en hornos a alta temperatura $\left(600-800^{\circ} \mathrm{C}\right)$, empaquetados con catalizadores de platino; una corriente de aire, empleada como gas oxidante-trasportador, arrastra al $\mathrm{CO}_{2}$ resultante a un detector infrarrojo. Finalmente, el equipo proporciona datos de TOC en unidades de concentración.

Debido a que el carbono de origen inorgánico (carbonatos, bicarbonatos y $\mathrm{CO}_{2}$ disuelto) presente en una muestra, puede interferir en las mediciones de TOC, los equipos cuentan con diversos métodos que permiten la cuantificación exclusiva de carbono orgánico. Uno de ellos es el análisis NPOC (NonPurgeable Organic Carbon), procedimiento por el cual, previo a la reacción de combustión, la muestra es acidificada y burbujeada. La adición de pequeñas cantidades de $\mathrm{HCl}$ convierte todo el carbono inorgánico en dióxido de carbono; mediante el burbujeo, el gas es arrastrado fuera de la muestra. Una de las principales desventajas de las mediciones NPOC, es que cualquier sustancia orgánica volátil puede ser purgada durante el burbujeo. 


\section{B.8. Espectroscopia infrarroja}

La espectroscopia infrarroja tiene diversas aplicaciones en catálisis heterogénea, que van desde la caracterización de los materiales sintetizados, información sobre la coordinación de especies adsorbidas hasta la identificación de intermediarios de reacción [142]. Esta técnica espectroscópica se basa en las transiciones rotacionales y vibracionales que pueden producirse en diversas moléculas cuando absorben radiación infrarroja.

Los movimientos de las moléculas son de tres tipos: traslacional, rotacional y vibracional [143]. El movimiento traslacional consiste en el desplazamiento del centro de masa de la molécula a través del espacio; por su parte, la rotación es el giro que puede realizar una molécula, respecto a su centro de masa, alrededor de ejes mutuamente perpendiculares; finalmente las movimientos vibracionales son el resultado de las oscilaciones de los átomos con respecto a sus posiciones de equilibrio.

El número y la naturaleza de las movimientos vibracionales de una molécula depende de la cantidad de átomos que contiene y de la disposicion tridimensional de estos. Sin embargo, existen dos tipos fundamentales de vibración molecular, el alargamiento y la reflexión, caracterizados por la ausencia de un cambio en el centro de gravedad de la sustancia (Fig. B8).

Las vibraciones de alargamiento suponen un cambio continuo en la distancia interatómica a lo largo del enlace que une a dos átomos, mientras que en las vibraciones de flexión se presenta un cambio en el ángulo de dos enlaces, dando lugar a cuatro clases de modos vibracionales: oscilación, torsión, sacudida y

\section{Vibraciones de alargamiento}

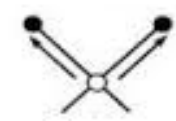

Simétrica

Vibraciones

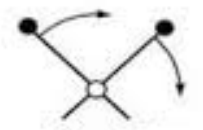

Oscilación en el plano

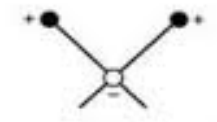

Sacudida fuera del plano

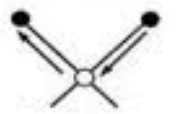

Antisimétrica de flexión

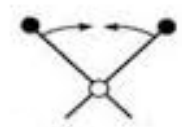

Tijereo en el plano

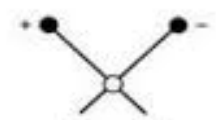

Torsión fuera del plano

Fig. B8. Tipos de vibraciones moleculares. $+y$ - indican movimientos perpendiculares al plano de la página. Imagen tomada de [135]

Los movimientos vibracionales y rotacionales de las moléculas tienen niveles de energía discretos, por lo que se requiere de una radiación de frecuencia especifica para que ocurran transiciones vibratorias 
rotatorias. La región infrarroja del espectro electromagnético posee la energía adecuada para producir cambios en los estados vibracionales rotacionales de las sustancias.

La radiación infrarroja se divide en tres secciones, de acuerdo a su relación con el espectro visible: infrarrojo cercano, medio y lejano. la absorcion de radiación del infrarrojo cercano, longitudes de onda mayores a $100 \mathrm{~nm}$, provoca transiciones rotacionales en las molécula; la región del infrarrojo medio,

número de onda en el intervalo de $4000-200 \mathrm{~cm}^{-1}$ causa transiciones vibraciones, las cuales siempre se acompañan de cambios en la energía rotacional de la sustancia. La mayoría de las aplicaciones análiticas utilizan un sector considerable del infrarrojo intermedio, $4000-670 \mathrm{~cm}^{-1}$. Vibraciones armónicas y sobretonos ocurren en una molécula, cuando esta absorbe radiación del infrarrojo lejano, número de onda en el intervalo de $200-10 \mathrm{~cm}^{-1}$.

En las mediciones de espectroscopia IR, la muestra es irradiada con luz infarroja; la absorción de radiación se lleva acabo cuando el haz contiene una onda con una frecuencia coincidente con la energía de excitación de un enlace o grupo de enlaces. Las moléculas activas en IR, experimentan un cambio neto en su momento dipolar como consecuencia de la transicion vibratoria o rotatoria. El espectrofotometro registrará la cantidad de luz absorbida o trasmitida por el análito.

En la actualidad, los espectrofotometros IR emplean la transformada de Fourier (FTIR) para medir simultaneamente todas las frecuencias de la radiación emitida por la muestra.

\section{B.9. Espectroscopia de fluorescencia}

En los procesos de fotodegradación, las especies reactivas de oxigeno (ROS, por sus siglas en inglés) juegan un papel fundamental en la eliminación de las moléculas contaminantes. Investigaciones enfocadas en los mecanismos de reacción, han detectado la presencia de ROS en diversos sistemas fotocatalíticos $y$, en base a la evidencia experimental, se ha concluido que estas especies son las causantes directas de la oxidación de los compuestos diana.

Aunque existe una gran variedad de especies clasificadas como reactivas de oxígeno, que van desde $\mathrm{O}_{2}{ }^{2-}$, $\mathrm{ROO}^{-}$, $\mathrm{RO}^{-}$hasta $\mathrm{H}_{2} \mathrm{O}_{2}$ y $\mathrm{HOCl}$, el radical $\mathrm{OH}$. ha sido frecuentemente considerado, el principal oxidante en reacciones de fotodegradación; se asume que la oxidación de un grupo hidroxilo adsorbido sobre la superficie de un catalizador o de una molécula de agua por un hueco fotogenerado da lugar a la formación de esta especie altamente reactiva. Sin embargo, debido al corto tiempo de vida media de 
estos radicales, existen pocas técnicas viables para su detección y cuantificación en medio acuoso [144]. La espectroscopia de fluorescencia ha probado ser un excelente método para la detección de diversas especies reactivas de oxígeno, debido a su alta sensibilidad, su respuesta lineal en intervalos de concentración amplios y a la simplicidad en la recolección de datos.

La fluorescencia es un fenómeno físico en el cual una sustancia que ha sido excitada mediante la incidencia de fotones, regresa a su estado basal emitiendo radiación electromagnética de una longitud de onda mayor que aquella que absorbió. La vida media del ciclo de fluorescencia es muy breve, del orden de $10^{-8}$ segundos, por lo cual se considera un proceso instantáneo.

El mecanismo básico de éste fenómeno puede ser explicado mediante el uso de un diagrama de energía (fig. B9). El proceso comienza mediante la promoción de electrones, ubicados en el estado basal So, a niveles electrónicos superiores, $S_{1}$. La transición electrónica se produce cuando la molécula fluorescente absorbe radiación de una longitud de onda determinada, por lo general radiación ultravioleta. Si la radiación incidente tiene una frecuencia mayor a la necesaria para la transición $\mathrm{S}_{0}-\mathrm{S}_{1}$, el exceso de energía llevará a la molécula a niveles vibracionales excitados [135,

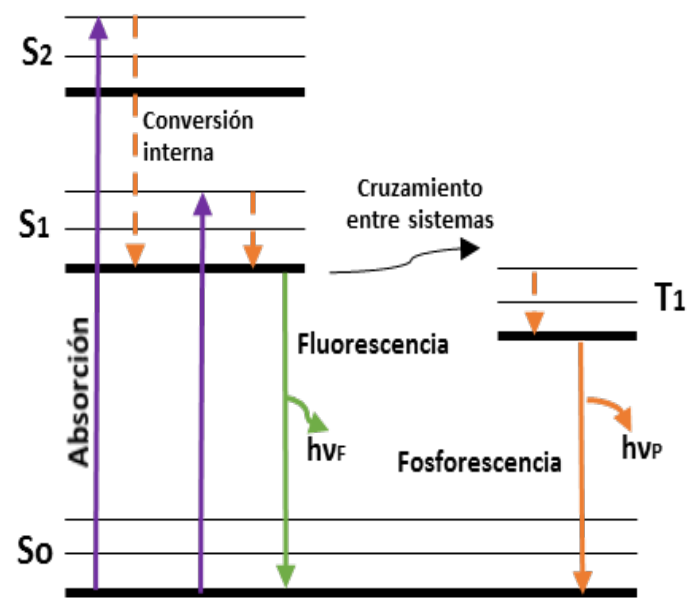
145].

Esta energía de vibración se perderá rápidamente a consecuencia de colisiones con otros fluoroforos excitados o con moléculas del solvente, si el proceso se lleva a cabo en solución, hasta llegar al nivel vibracional más bajo de $S_{1}$. El posterior retorno de la molécula al estado electrónico $S_{o}$ se produce emitiendo un fotón (fluorescencia) o mediante procesos no radiativos. La energía de la radiación emitida será menor que aquella que fue absorbida debido a que fracciones de ésta se han perdido durante el regreso de la molécula al estado fundamental.

Las pruebas de espectroscopia de fluorescencia para la identificación de radicales $\mathrm{OH} \cdot$ consisten en la formación de compuestos hidróxilados fluorescentes, a partir de reacciones entre ésta especie reactiva 
de oxígeno y moléculas orgánicas no fluorescentes o con bajos rendimientos cuánticos, tales como el tereftalato de sodio, derivados de la fluorosceína, 1,3-ciclohexanodiona y la coumarina [146]. 


\section{Referencias}

[1] Kim I., Yamashita N. Tanaka H. Photodegradation of pharmaceuticals and personal care products during UV and UV/ $\mathrm{H}_{2} \mathrm{O}_{2}$ treatments. Chemosphere 77 (2009), 518-525.

[2] Koyuncu I. Arikan O. A., Wiesner M. R., Rice C. Removal of hormones and antibiotics by nanofiltration membranes. Journal of Membrane Science, 309 (2008), 94-101.

[3] Quesada-Peñate I., Julcour-Lebigue C., Jáuregui-Haza U. J., Wilhelm A. M., Delmas H. Comparative adsorption of levodopa from aqueous solution on different activated carbons. Chemical Engineering Journal, 152 (2009), 183-188.

[4] Banasiak L. J., Schäfer A. I. Sorption of steroidal hormones by electrodialysis membranes. Journal of Membrane Science, 365 (2010), 198-205.

[5] Zhaohui L., Po-Hsiang C., Jiin-Shuh J., Wei-The J., Chih-Jen Wang W. Interaction between tetracycline and smectite in aqueous solution, Journal of Colloid and Interface Science, 341 (2010), 311-319.

[6] Rivera-Utrilla J., Prados-Joya G., Sánchez-Polo M., Ferro-García M. A., Bautista-Toledo I. Removal of nitroimidazole antibiotics from aqueous solution by adsorption/bioadsorption on activated carbon. Journal of Hazardous Materials, 170 (2009), 298-305.

[7] Basha S., Barr C., Keane D., Nolan K., Morrissey A., Oelgemöller M., Tobin J. M. On the adsorption/photodegradation of amoxicillin in aqueous solutions by an integrated photocatalytic adsorbent (IPCA): experimental studies and kinetics analysis. Photochemical and Photobiological Sciences, 10 (2011), 1014-1022.

[8] Marotta R., Spasiano D., Di Somma I., Andreozzi R. Photodegradation of naproxen and its photoproducts in aqueous solution at $254 \mathrm{~nm}$ : a kinetic investigation. Water Research, 47 (2013), 373383.

[9] Önal Y., Akmil-Basar C., Sarıcı-Özdemir C. Elucidation of the naproxen sodium adsorption onto activated carbon prepared from waste apricot: Kinetic, equilibrium and thermodynamic characterization. Journal of Hazardous Materials, 148 (2007), 727-734. 
[10] Klavarioti M., Mantzavinos D., Kassinos D. Removal of residual pharmaceuticals from aqueous systems by advanced oxidation processes. Environmental International, 35 (2009), 402-417.

[11] Yu Z., Peldszus S., Huck P. M., Adsorption characteristics of selected pharmaceuticals and an endocrine disrupting compound-Naproxen, carbamazepine and nonylphenol-on activated carbon. Water Research, 42 (2008), 2873-2882.

[12] Musa K. A. K., Eriksson L. A. Photochemical and photophysical properties, and photodegradation mechanism, of the non-steroid anti-inflammatory drug Flurbiprofen. Journal of Photochemistry and Photobiology A: Chemistry, 202 (2009), 48-56.

[13] Cavani F., Trifiro F. Vaccari A. Hydrotalcite-type anionic clays: preparation, properties and applications. Catalysis Today 11 (1991), 173-301.

[14] Morimoto K., Tamura K., lyi N., Ye J., Yamada H. Adsorption and photodegradation properties of anionic dyes by layered double hydroxides. Journal of Physics and Chemistry of Solids, 72 (2011), 10371045.

[15] Seftel E. M., Popovici E., Mertens M., De Witte K., Tendeloo G. V., Cool P., Vansant E. F. Zn-Al layered double hydroxides: Synthesis, characterization and photocatalytic application, Microporous and Mesoporous Materials, 113 (2008), 296-304.

[16] Mantilla A., Tzompantzi F., Fernández J. L., Díaz Góngora J. A. I., Gómez R. Photodegradation of phenol and cresol in aqueous medium by using $\mathrm{Zn} / \mathrm{Al}+$ Fe mixed oxides obtained from layered double hydroxides materials. Catalysis Today, 150 (2010), 353-357.

[17] Mantilla A., Jacome-Acatitla G., Morales Mendoza G., Tzompantzi F., Gomez R. Photoassisted degradation of 4-chlorophenol and p-cresol using MgAl hydrotalcites. Industrial and Engineering Chemistry Research, 50 (2011), 2762-2767.

[18] Erazo Parga M., Cárdenas Romero R. Ecología: impacto de la problemática ambiental actual sobre la salud y el ambiente. Ecoe Ediciones, Colombia, 2013. pp. 133-140.

[19] Estadísticas del agua en México, cap. 6. SEMARNAT, México, 2011. pp. 258-302. 
[20] Prevención de la contaminación del agua por la agricultura y actividades afines. FAO, Chile, 1993. pp. 19-23.

[21] Zhang Y., Yang Y., Zhang Y., Zhang T., Ye M. Heterogeneous oxidation of naproxen in the presence of $\alpha-\mathrm{MnO}_{2}$ nanostructures with different morphologies. Applied Catalysis B: Environmental, 127 (2012), 182-189.

[22] Loddo V., Yurdakal S., Augugliaro V., Berber H., Palmisano G., Palmisano L. Photodegradation of pharmaceuticals drugs in aqueous $\mathrm{TiO}_{2}$ suspensions: mechanism and kinetics. Catalysis Today, 129 (2007), 9-15.

[23] Estrategia Mundial de la OMS para contener la Resistencia a los antimicrobianos. Organización Mundial de la Salud, Suiza, 2001.

[24] Mompelat S. et al. Occurrence and fate of pharmaceutical products and by-products, from resource to drinking water. Environment International, 35 (2009), 803-814.

[25] Rehman M. S. U., Rashid N., Ashfaq M., Saif A., Ahmad N., Han J-I. Global risk of pharmaceutical contamination from highly populated developing countries. Chemosphere, 2013.

[26] Domínguez Joaquín R., González T., Palo P., Cuerda-Correa E. M. Removal of common pharmaceuticals present in surface water by Amberlite XAD-7 acrylic-ester-resin: influence of pH and presence of other drugs. Desalination, 269, 2011, 231-238.

[27] Evgenidou Eleni N., Konstantinou I. K. Lambropoulou D. A. Occurrence and removal of transformation products of PPCPs and illicit drugs in wastewaters: a review. Science of the Total Environment, 505 (2015), 905-926.

[28] Segura P. A., Takada H., Correa J. A., El Saadi K., Koike T., Onwona-Agyeman S., Ofusu-Anim J., Sabi E. B., Wasonga O. V., Mghalu J. M., dos Santos Junior A. M., Newman B., Weerts S., Yargeau V. Global occurrence of anti-infectives in contaminated surface waters: impact of the income inequality between countries. Environment International, 80 (2015), 89-97.

[29] Wilson, B. A., Smith V. H., deNoyelles F., Larive C. K. Effect of three pharmaceuticals and personal care products on natural freshwater algal assemblages. Environmental Science and Technology, 37 (2003), 1713-1719. 
[30] Gust M., Gélinas M., Fortier M., Fournier M., Gagné F. In vitro immunotoxicity of environmentally representative antibiotics to the freshwater mussel Elliptio complanata. Environmental Pollution, 169, 50-58.

[31] Martínez J. L. Environmental pollution by antibiotics and antibiotic resistance determinants. Environmental Pollution, 157 (2009), 2893-2902.

[32] Pereira J. H. O. S., Vilar V. J. P., Borges M. T., González O., Esplugas S., Boaventura R. A. R. Photocatalytic degradation of oxytetracycline using $\mathrm{TiO}_{2}$ under natural and simulated solar radiation. Solar Energy, 85 (2011), 2732-2740.

[33] Defillo M. Bernarfo A. Farmacología médica. Volumen 1. República Dominicana, INTEC, 1985, pp. 72-16.

[34] Gennaro Alfonso R. Remington farmacia. Volúmen 2. Editorial médica panamericana, Uruguay, 2000. pp. 1835

[35] Kulshrestha P., Giese R. F., Aga D. S. Investigating the molecular interactions of oxytetracycline in clay and organic matter: insights on factors affecting its mobility in soil. Environmental Science and Technology, 38 (2004), 4097-4105.

[36] Velasco Martin A., Álvarez González F. J. Compendio de psiconeurofarmacologia. Ediciones Díaz de Santos S. A., Madrid, España, 1988. pp. 263-269.

[37] Cleuvers M. Mixture toxicity of the anti-inflammatory drugs diclofenac, ibuprofen, naproxen and acetylsalicylic acid. Ecotoxicology and Environmmental Safety, 59 (2004), 309-315.

[38] Brozinski J. M., Lahti M., Meierjohann A., Oikari A., Kronberg L. The anti-inflammatory drugs diclofenac, naproxen and ibuprofen are found in the bile of wild fish caught downstream of a wastewater treatment plant. Environmental Science and Technology, 47 (2013), 342-348.

[39] Park Y., Ayoko G. A., Frost R. L. Application of organoclays for the adsoption of recalcitrant organic molecules from aqueous media. Journal of Colloid and Interface Science, 354 (2011), 292-305. 
[40] Cuerda-Correa E. M., Domínguez-Vargas J. R., Olivares-Martín F. J., Beltrán de Heredia J. On the use of carbon blacks as potencial low-cost adsorbents for the removal of non-steroidal anti-inflammatory drugs from river water. Journal of Hazardous Materials. 177 (2010), 1046-1053.

[41] Jiao S., Zheng S., Yin D., Wang L., Chen L. Aqueous oxytetracycline degradation and the toxicity change of degradation compounds in photoirradiation process. Journal of Environmental Sciences, 20 (2008), 806-813.

[42] Pereira V. J., Weinberg H. S., Linden K. G., Singer P. C. UV degradation kinetics and modeling of pharmaceuticals compounds in laboratory grade and surface water via direct and indirect photolysis at 254 nm. Environment Science Technology, 41-b (2007), 1682-1688.

[43] DellaGreca M., Brigante M., Isidori M., Nardelli A., Previtera L., Rubino M., Temussi F. Phototransformation and ecotoxicity of the drug Naproxen-Na. Environmental Chemistry Letters 1 (2004), 237-241.

[44] Isodori M, Lavorgna M., Nardelli A., Perella A., Previtera L., Rubino M. Ecotoxicity of naproxen and its photo transformation products. Science of the Total Environment, 348 (2005), 93-101.

[45] Rivera Utrilla J., Sánchez-Polo M., Ferro-García M. A., Prados-Joya G., Ocampo-Pérez R. Pharmaceuticals as emerging contaminants and their removal from water. A review. Chemosphere, 93 (2013), 1268-1287.

[46] Méndez-Arriaga F., Esplugas S., Giménez J. Degradation of the emerging contaminant Ibuprofen in water by photo-Fenton. Water Research, 44 (2010), 589-595.

[47] Gonzales O., Sans C., Esplugas S. Sulfamethoxazole abatement by photo-Fenton. Toxicity, inhibition and biodegradability assessment of intermediates. Journal of Hazardous Materials, 146 (2007), 459-464.

[48] Pereira J.H. O. S., Queirós D. B., Reis A. C., Nunes O. C., Borges M. T., Boaventura R. A. R., Vilar V. J. P. Process enhancement at near neutral $\mathrm{pH}$ of a homogeneous photo-Fenton reaction using ferricarboxylate complexes: application to oxytetracycline degradation. Chemical Engineering Journal, 253 (2014), 217-228. 
[49] Trovó A. G., Nogueira R. F. P., Agüera A., Fernandez-Alba A. R., Malato S. Degradation of the antibiotic Amoxicillin by photo-Fenton process: chemical and toxicological assessment. Water Research 45 (2011), 1394-1402.

[50] Wang W., Zhang H., Zhang J., Lu C., Huang Q., Wu J., Liu F. Degradation of tetracycline in aqueous media by ozonation in an internal-loop-lift reactor. Journal of Hazardous Materials, 192 (2011), 35-43.

[51] Illés E. Szabó E., Takács E., Wojnárovits L., Dombi A., Gajda-Schrantz K. Ketoprofen removal by $\mathrm{O}_{3}$ and $\mathrm{O}_{3} / \mathrm{UV}$ processes: Kinetics, transformation products and ecotoxicity. Science of the Total Environment, 472 (2014), 178-184.

[52] Lin A. Y.-C., Lin C.-F., Chiou J.-M. Hong P. K. A. $\mathrm{O}_{3}$ and $\mathrm{O}_{3} / \mathrm{H}_{2} \mathrm{O}_{2}$ treatment of sulfonamide and macrolide antibiotics in wastewater. Journal of Hazardous Materials, 171 (2009), 452-458.

[53] Quero-Pastor M. Valenzuela A., Quiroga J. M. Acevedo A. Degradation of drugs in water with advanced oxidation processes and ozone. Journal of the Environmental Management, 137 (2014), 197203.

[54] Skoumal M. Cabot P.-L., Centellas F., Arias C., Rodríguez R. M. Garrido J. A., Brillas E. Mineralization of paracetamol by ozonation catalyzed with $\mathrm{Fe}^{2+}, \mathrm{Cu}^{2+}$ and UVA light. Applied Catalysis B: Environmental, 66 (2006), 228-240.

[55] Méndez-Arriaga F., Esplugas S., Giménez J. Photocatalytic degradation of non-steroidal antiinflammatory drugs with $\mathrm{TiO}_{2}$ and simulated solar irradiation. Water Research, 42 (2008), 585-594.

[56] Yang H. Li G., An T., Gao Y., Fu J. Photocatalytic degradation kinetics and mechanism of environmental pharmaceuticals in aqueous suspension of $\mathrm{TiO}_{2}: \mathrm{A}$ case of sulfa drugs. Catalysis Today, 153 (2010), 200-207.

[57] Carabin A. Drogui P., Robert D. Photo-degradation of carbamazepine using $\mathrm{TiO}_{2}$ suspended photocatalysts. Journal of the Taiwan Institute of Chemical Engineers, 2015, 1-9.

[58] Niu J. Ding S., Zhang L., Zhao J., Feng C. Visible-light-mediated $\mathrm{Sr}^{-} \mathrm{Bi}_{2} \mathrm{O}_{3}$ photocatalysis of tetracycline: kinetics, mechanisms and toxicity assessment. Chemosphere, 93 (2013), 1-8. 
[59] Ji Y. Zhou L., Ferronato C., Yang X., Salvador A., Zeng C., Chovelon J.-M. Photocatalytic degradation of atenolol in aqueous titanium dioxide suspensions: kinetics, intermediates and degradation pathways. Journal of Photochemistry and Photobiology A: Chemistry, 254 (2013), 35-44.

[60] Zhang Y., Zhou J. L., Ning B. Photodegradation of estrone and 176-estradiol in water. Water Research, 41 (2007), 19- 26.

[61] Andreozzi R., Caprio V., Insola A. Marotta R. Advanced oxidation processes (AOP) for water purification and recovery. Catalysis Today, 53 (1999), 51-59.

[62] Legrini O., Oliveros E., Braun A. M. Photochemical Processes for Water Treatment. Chemical Reviews. 93 (1993), 671-698.

[63] Sillanpää M. E. T., Kurniawan T. A., Lo W. Degradation of chelating agents in aqueous solution using advanced oxidation process (AOP). Chemosphere 83 (2011), 1443-1460

[64] Litter M. I., Candal R. J., Meichtry M. Advanced oxidation technologies: sustainable solution for environmental treatments, CR Press Taylor and Francis Group, 2014. pp. 1-20.

[65] Osorio Robles F., Torres Rojo J. C, Sánchez Bas M. Tratamiento de aguas para la eliminación de microrganismos y agentes contaminantes, pp. 47-69.

[66] Coronado J. M., Fresno F., Hernández-Alonso M. D, Portela R. Design of advanced photocatalytic materials for energy and environmental applications. Springer-Verlag, Londres, 2013. pp. 1-20.

[67] Hashimoto K., Irie $\mathrm{H}$., Fujishima $\mathrm{A}$. $\mathrm{TiO}_{2}$ photocatalysis: a historical overview and future prospects. Japanese Journal of Applied Physics, 44 (205), 8269-8285.

[68] Herrmann J. M. Fundamentals and misconceptions in photocatalysis. Journal of photochemistry and photobiology A: Chemistry, 216 (2010), 85-93.

[69] McNaught A. D., Wilkinson A. IUPAC. Compendium of Chemical Terminology. 2nd ed. Blackwell Scientific Publications, Oxford (1997). XML on-line corrected version: http://goldbook.iupac.org.

[70] Herrmann J. M. Heterogeneous photocatalysis: fundamentals and applications to the removal of various types of aqueous pollutants. Catalysis Today, 53 (1999), 115-129. 
[71] Konstantinou K. I., Albanis T. A. $\mathrm{TiO}_{2}$-assisted photocatalytic degradation of azo dyes in aqueous solution: kinetic and mechanistic investigations: A review. Applied Catalysis B: Environmental, 49 (2004), $1-14$.

[72] Ohtani B. Photocatalysis A to Z-What we know and what we do not know in a scientific sense. Journal of Photochemistry and Photobiology C: Photochemistry reviews, 11 (2010), 157-178.

[73] Halliday D., Resnick R. Krane K. S. Física Vol. 2. Compañía Editorial Continental, México, 2003. pp. 581-595

[74] Candal R. J., Bilmes S. A., Blesa M. A. Eliminación de contaminantes por fotocatálisis heterogénea. Madrid, 2004. pp. 79-101.

[75] Coronado J. M, Fresno F., Hernández-Alonso M. D., Portela R. Design of advanced photocatalytic materials for energy and environmental. Springer, London, 2013. pp. 11-23.

[76] Polshettiwar V., Asefa T. Nanocatalysis: synthesis and applications. Wiley, New Jersey, 2013. Chapter 14.

[77] Hernández-Ramírez A., Medina-Ramírez I. Photocatalytic semiconductors: synthesis, characterization and environmental applications. Springer, London. pp. 6-13.

[78] Rodríguez J., Candal R. J., Solís J., Estrada W., Blesa M. A. El fotocatalizador: síntesis, propiedades y limitaciones. Solar Safe Water, 2005, 9. 135-152.

[79] Vaccari A., Preparation and catalytic properties of cationic and anionic clays. Catalysis Today 41 (1998), 53-71.

[80] Bookin A. S., Drits V. A. Polytype diversity of the hydrotalcite-like minerals. I. Possible polytypes and their diffraction features. Clays and Clay Minerals, 41 (1993), 551-557.

[81] Evans D. G., Duan X. Layered double hydroxides. Springer, Alemania, 2006. Pp. 2-22, 90-100, 193210.

[82] Wu J.-S., Xiao Y.-K., Wan J.-Y., Wen L.-R. The grown mechanism of hydrotalcite crystal. Science China. Technological Sciences, 55 (2012) No. 4, 872-878. 
[83] Del Hoyo C. Layered double hydroxides and human health: an overview. Applied Clay Science 36 (2007), 103-121.

[84] Goh K., Lim T., Dong Z. Application of layered double hydroxides for removal of oxyanions: A review. Water Research 42 (2008), 1343-1368.

[85] Intercalation of hydrophilic and hydrophobic antibiotics in layered double hydroxides. International Journal of Pharmaceutics 332 (2007), 176-184.

[86] Valente J. S., Tzompantzi F., Prince J., Cortez J. G. H., Gomez R. Adsorption and photocatalytic degradation of phenol and 2,4 dichlorophenoxiacetic acid by $\mathrm{Mg}-\mathrm{Zn}-\mathrm{Al}$ layered double hydroxides, Applied Catalysis B: Environment, 90 (2009), 330-338.

[87] Mokhtar M., Inayat A., Ofili J., Schwieger W. Thermal decomposition, gas phase hydration and liquid phase reconstruction in the system $\mathrm{Mg} / \mathrm{Al} /$ hydrotalcite/mixed oxide: a comparative study. Applied Clay Science 50 (2010), 176-181

[88] Centi G. Perathoner S. Catalysis by layered materials: a review. Microporous and Mesoporous Materials, 107 (2008), 3-15.

[89] Zhu J., Fan H., Sun J., Ai S. Anion-exchange precipitation of $\alpha-A g 2 W O 4 / Z n-C r$ layered double hydroxides composite with enhanced visible-light-driven photocatalytic activity. Separation and Purification Technology, (2013).

[90] Xia S.-J., Lui F.-X., Ni Z.-M., Xue J.-L., Qian P.-P. Layered double hydroxides as efficient photocatalysts for visible light degradation of Rhodamine B. Journal of Colloid and Interface Science 405 (2013), 195-200.

[91] Rajeshwar K., Osugi M. E., Chanmanee W., Chenthamarakshan C. R., Zanoni M. V. B., Kajitvichyanukul P., Krishnan-Ayer R. Heterogeneous photocatalytic treatment of organic dyes in air and aqueous media. Journal of Photochemistry and Photobiology C: Photochemistry Reviews, 9 (2008), 171192.

[92] Heterogeneous photocatalytic degradation of organic contaminants over titanium dioxide: a review of fundamentals, progress and problems. Journal of Photochemistry and Photobiology C: Photochemistry Reviews, 9 (2008), 1-12. 
[93] Khezrianjoo S., Revanasiddappa H. D.Langmuir-Hinshelwood kinetic expression for the photocatalytic degradation of metanil yellow aqueous solutions by $\mathrm{ZnO}$ catalyst. Chemical Sciences Journal, Vol. 2012, CSJ-85, 1-7.

[94] Ishibashi K., Fujishima A., Watanabe T., Hashimoto K. Detection of active oxidative species in $\mathrm{TiO}_{2}$ photocatalysis using the fluorescence technique. Electrochemistry Communications, 2 (2000) 207-210.

[95] Bandara J., Hadapangoda C. C., Jayasekera W. G. $\mathrm{TiO}_{2} / \mathrm{MgO}$ composite photocatalyst: the role of $\mathrm{MgO}$ in photoinduced charge carrier separation. Applied Catalysis, B: Environmental, 50 (2004) 83-88.

[96] Valente J. S., Rodríguez-Gattorno G., Valle-Orta M. Torres-García E. Thermal decomposition kinetics of MgAl layered double hydroxide. Materials Chemistry and Physics, 133 (2012), 621-629.

[97] Carriazo D. del Arco M., García-López E., Marcì G., Martín C., Palmisano L., Rives V. Zn, Al hydrotalcites calcined at different temperatures: Preparation, characterization and photocatalytic activity in gas-solid regime. Journal of Molecular Catalysis A: Chemistry, 342-343 (2011), 83-90.

[98] Jitianu M, Gunness D. C., Aboagye D. E., Zaharescu M., Jitianu A. Nanosized Ni-Al layered double hydroxides: Structural characterization. Materials Research Bulletin, 48 (2013), 1864-1873.

[99] López Salinas E., Pedraza Archila F. Hidrotalcitas: Precursores de materiales adsorbentes de SOx. Instituto Mexicano del Petróleo, Subdirección de Transformación Industrial. pp. 91-96.

[100] Ahmed A. A. A. Talib Z. A., bin Hussein M. Z. Thermal, optical and dielectric properties of Zn-Al layered double hydroxide. Applied Clay Science, 56 (2012), 68-76.

[101] Mascolo G., Marino O. A new synthesis and characterization of magnesium-aluminium hydroxides. Mineralogical Magazine, 43 (1980), 619-621.

[102] Carja G. Nakamura R., Aida T., Niiyama H. Textural properties of layered double hydroxides: effect of magnesium substitution by copper or iron. Microporous and Mesoporous Materials, 47 (2001), 275284.

[103] Valencia S., Marín J. M., Restrepo G., Study of the bandgap of synthesized titanium dioxide nanoparticules using the sol-gel method and hydrothermal treatment, The Open Materials Science Journal, 4 (2010), 9-14. 
[104] López R., Gómez R. Band-gap energy estimation from diffuse reflectance measurements on sol-gel and commercial $\mathrm{TiO}_{2}$ : a comparative study. Journal of Sol-Gel Science and Technology, 61 (2012), 1-7.

[105] Huang H., He Y., He R., Jiang X., Lin Z., Zhang Y., Wang S. Novel Bi-based iodate photocatalysts with high photocatalytic activity. Inorganic Chemistry Communications, 40 (2014), 215-219.

[106] Zhang K.-L. Liu C.-M., Huang F.-Q., Zheng C., Wang W.-D. Study of the electronic structure and photocatalytic activity of the BiOCl photocatalyst. Applied Catalysis B: Environmental, 68 (2006), 125129.

[107] Ahmed A. A. A., Talib Z. A., bin Hussein M. Z., Zakaria A. Zn-Al layered double hydroxides prepared at different molar ratios: preparation, characterization, optical and dielectric properties. Journal of Solid State Chemistry, 191 (2012), 271-278.

[108] Liu X., Zhao X., Zhu Y., Zhang F. Experimental and theoretical investigation into the elimination of organic pollutants from solution by layered double hydroxides. Applied Catalysis B: Environmental, 140141 (2013), 241-248.

[109] Chayed N. F., Badar N., Rusdi R., Azahidi A., Kamarulzaman N. Band gap energies of $\operatorname{Li}_{2} x \mathrm{Mg}_{(1-X)} \mathrm{O}$ materials synthesized by the sol-gel method. Journal of Crystal Growth, 362 (2013), 268-270.

[110] Kumar A., Kumar J. On the synthesis and optical absorption studies of nano-size magnesium oxide powder. Journal of Physics and Chemistry of Solids, 69 (2008), 2764-2772.

[111] Marotti R. E., Giorgi P., Machado G., Dalchiele E.A. Crystallite size dependence of band gap energy for electrodeposited ZnO grown at different temperatures. Solar Energy Materials and Solar Cells, 90 (2006), 2356-2361.

[112] Ishibashi K., Fujishima A., Watanabe T., Hashimoto K. Detection of active oxidative species in $\mathrm{TiO}_{2}$ photocatalysis using the fluorescence technique, Electrochemistry Communications, 2 (2000) 207-210.

[113] Kim I., Hiroaki T. Photodegradation characteristics of PPCPs in water with UV treatment. Environmental International, 35 (2009) 793-802.

[114] Jiménez M. C., Miranda M. A., Tormos R. Photochemistry of naproxen in the presence of $\beta$ cyclodextrin. Journal of Photochemistry and Photobiology A: Chemistry, 104 (1997) 119-121. 
[115] Mboula V. M. et al. Assessment of the efficiency of photocatalysis on tetracycline biodegradation. Journal of Hazardous Materials, $209-210$ (2012) 355- 364.

[116] Sun J., Chen G., Xiong G., Pei J., Dong H. Hierarchical microarchitectures of $A g G a_{1-x} \ln _{x} S_{2}$ : Long chain alcohol assisted synthesis, band gap tailoring and photocatalytic activities of hydrogen generation. International Journal of Hydrogen Energy, 38 (2013) 10731-10738.

[117] Lee H., Woo C. S., Youn B. K., Kim S. Y., Oh S. T., Sung Y. E., Lee H. I. Bandgap modulation of TiO 2 and its ffect on photocatalytic activity in photocatalytic oxidation of 2-isopropyl-6-methyl-4pyrimidinol. Topics in Catalysis, 35 (2005), 255-260.

[118] Tzompantzi F. Mantilla A., Buñelos F., Fernández J. L., Gómez R. Improved photocatalytic degradation of phenolic compounds with ZnAl mixed oxides obtained from LDH Materials. Topics in Catalysis, 54 (2011) 257-263.

[119] Aguilar G. Adsorción y Catálisis. Universidad Autónoma de Puebla. 1985. pp. 9-38

[120] Liu Y., Liu Y.-J. Biosorption isotherms, kinetics and thermodynamics. Separation and Purification Technology. 61 (2008), 229-242.

[121] Fukahori S., Fujiwara T., Ito R., Funamizu N. pH-Dependent adsorption of sulfa drugs on high silica zeolite: Modeling and kinetic study. Desalination. 275, 2011, 237-242.

[122] Wan D., Liu H., Liu R., Qu J., Li S., Zhang J. Adsorption of nitrate and nitrite from aqueous solutions onto calcined (Mg-Al) hydrotalcite of different Mg/Al ratio. Chemical Engineering Journal, 195 (2012), 241-247.

[123] Pinzón-Bedoya M. L., Vera Villamizar L. E. Modelamiento de la cinética de bioadsorción de Cr (III) usando cáscara de naranja. Dyna, Vol. 76, Núm. 160 (2009), pp. 95-106.

[124] Kipling, J. J. Adsorption from solutions of non-electrolytes. Academic Press Inc. LTD, Great Britain, 1965. pp. $90-130$

[125] Wang S.-L., Wang P.-C. In situ XRD and ATR-FTIR study on the molecular orientation of interlayer nitrate in Mg/Al-layered double hydroxides in water. Colloids and surfaces, A-physicochemical and engineering aspects. 292, (2007), 131-138. 
[126] Anbarasan R., Lee W. D., Im S. S. Adsorption and intercalation of anionic surfactants onto layered double hydroxides-XRD study. Bulletin of Materials Science 28, (2005), 145-149.

[127] Cullity B. D. Elements of X-ray diffraction. Addison-Wesley, United States of America, 1978. pp. 3$12,21-28,81-91$.

[128] Willard H. H. Métodos instrumentales de análisis. Compañía Editorial Continental. México, 1986.

[129] Pichat P. Photocatalysis and water purification: from fundamentals to recent applications. WileyVCH, Gran Bretaña, 2013. Capítulo 4.6.

[130] Sing K. S. W. Reporting physisorption data for gas/solid systems with special reference to the determination of surface area and porosity. Pure and Applied Chemistry, 11 (1982), 2201-2218.

[131] Sing K. S. W., Gregg S. J. Adsorption, surface area and porosity. Academic Press, Londres, 1991. pp. 21-36, 111-132

[132] Skoog, Douglas. Análisis Instrumental. McGraw-Hill, México, 1989. pp. 158-162, 179-183, 220-226, 229-231, 293-303, 447-454.

[133] Zhang S., Li L., Kumar A. Materials characterization techniques. CRC Press, U. S. A., 2008. pp. 286292.

[134] Chen Z., Dinh H. N., Miller E. Photoelectrochemical water splitting: standars, experimental methods and protocols. Springer. UV-Vis spectroscopy. pp. 49-61

[135] Che M., Védrine J. C. Characterization of solids materials and heterogeneous catalysis: from structure to surface reactivity. Vol. 1. Wiley-VCH, Alemania, 2012. pp. 89-106.

[136] Melgarejo Joan Carles, Proenza Joaquín A., Galí Salvador, Llovet Xavier, Técnicas de caracterización mineral y su aplicación en exploración y explotación minera, Boletín de la Sociedad Geológica Mexicana, Vol. 62, núm. 1, 2010, pp. 1-23.

[137] Totten G. E., Liang H. Mechanical tribology: materials, characterization and applications. Marcel Dekker Inc., United States of America, 2004. pp. 34-42. 
[138] Lampman S. Characterization and failure analysis on plastics. ASM International, United States of America, 2003. pp. 381-386.

[139] Silverstein R. M., Bassler C. G., Morril T. C. Identificación espectrométrica de compuestos orgánicos. Editorial Diana México, México, 1980. pp. 85-129, 243-259.

[140] Gaya U. I. Heterogeneous photocatalysis using inorganic semiconductor solids. Springer, 2013. pp. 85-86.

[141] Ramalho R. S. Tratamiento de aguas residuales. Editorial Reverté, España, 2003. pp. 47-49.

[142] Richards R. Surface and nanomolecular catalysis. CRC Press, United States of America, 2006. pp. 215.

[143] Castellan G. W. Fisicoquímica. Addison Wesley, México, 1998. pp. 659-665.

[144] Díaz Uribe C. E., Vallejo Lozada W. A., Alvaro Rueda L. J., Rendimiento cuántico de producción de radicales hidroxilo por medidas de fluorescencia en el sistema TcPPFe/ $\mathrm{H}_{2} \mathrm{O}_{2} / \mathrm{Uv}$-Vis. Revista Facultad de Ingeniería, Enero-Julio (2014) Vol.23, No.36.

[145] Lakowicz J. R. Principles of fluorescence spectroscopy. Springer, Singapore, 2006. pp. 1-8.

[146] Gómez A. Fernandez E., Lima J. L.F.C. Fluorescence probes using for detection of active oxygen species. J. Byochem. Biophys. Methods. 65 (2005), 45-80. 